\title{
๑
}

(C)2020 The Author(s)

This is an Open Access book distributed under the terms of the Creative Commons Attribution-NonCommercial-NoDerivatives Licence (CC BY-NC-ND 4.0), which permits copying and redistribution in the original format for non-commercial purposes, provided the original work is properly cited.

(http://creativecommons.org/licenses/by-nc-nd/4.0/). This does not affect the rights licensed or assigned from any third party in this book.

This title was made available Open Access through a partnership with Knowledge Unlatched.

IWA Publishing would like to thank all of the libraries for pledging to support the transition of this title to Open Access through the KU Select 2019 program.
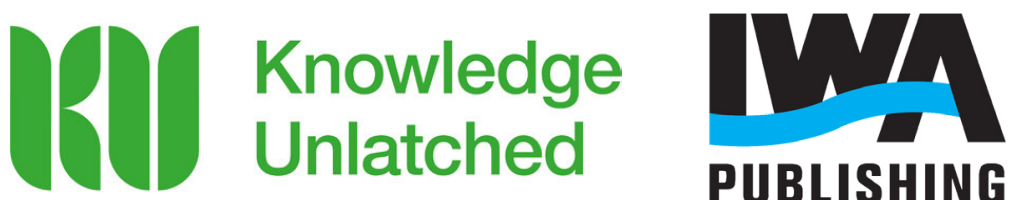

PUBLISHING 


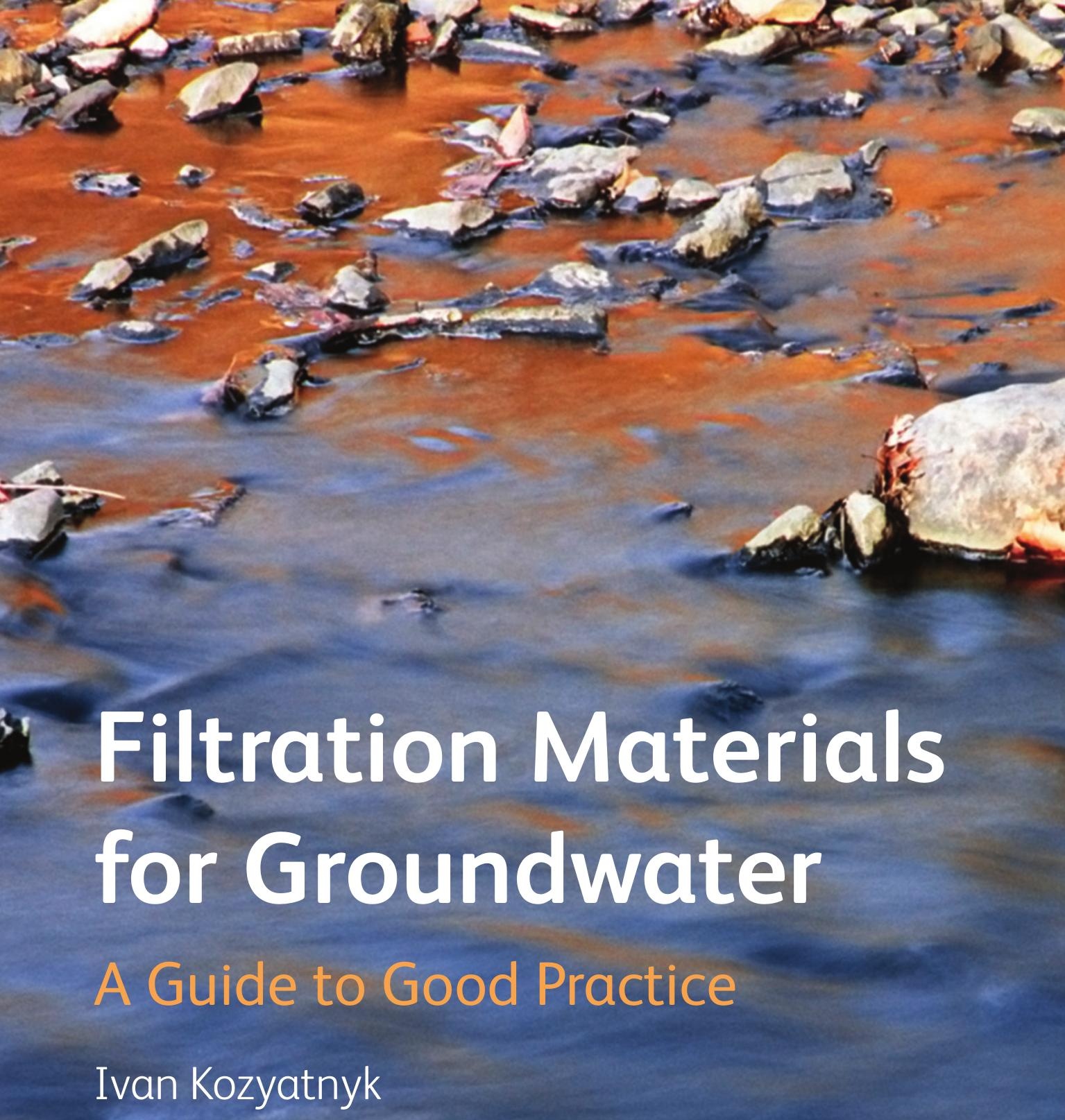

- Filtration Materials for Groundwater

A Guide to Good Practice

Ivan Kozyatnyk

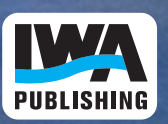

Downloaded from https://iwaponline.com/ebooks/book-pdf/651183/wio9781780407005.pdf 


\section{Filtration Materials for Groundwater}


Downloaded from https://iwaponline.com/ebooks/book-pdf/651183/wio9781780407005.pdf

by IWA Publishing publications@iwap.co.uk 


\section{Filtration Materials for Groundwater}

A Guide to Good Practice

Ivan Kozyatnyk 
Published by

First published 2016

(C) 2016 IWA Publishing
IWA Publishing

Alliance House

12 Caxton Street

London SW1H 0QS, UK

Telephone: +44 (0)20 76545500

Fax: +44 (0)207654 5555

Email: publications@iwap.co.uk

Web: www.iwapublishing.com

Apart from any fair dealing for the purposes of research or private study, or criticism or review, as permitted under the UK Copyright, Designs and Patents Act (1998), no part of this publication may be reproduced, stored or transmitted in any form or by any means, without the prior permission in writing of the publisher, or, in the case of photographic reproduction, in accordance with the terms of licenses issued by the Copyright Licensing Agency in the UK, or in accordance with the terms of licenses issued by the appropriate reproduction rights organization outside the UK. Enquiries concerning reproduction outside the terms stated here should be sent to IWA Publishing at the address printed above.

The publisher makes no representation, express or implied, with regard to the accuracy of the information contained in this book and cannot accept any legal responsibility or liability for errors or omissions that may be made.

\section{Disclaimer}

The information provided and the opinions given in this publication are not necessarily those of IWA Publishing and should not be acted upon without independent consideration and professional advice. IWA Publishing and the Authors will not accept responsibility for any loss or damage suffered by any person acting or refraining from acting upon any material contained in this publication.

ISBN: 9781780406992 (Hardback)

ISBN: 9781780407005 (eBook) 


\section{Contents}

\section{Chapter 1}

Pollutants in groundwater . . . . . . . . . . . . . 1

Sabrina Saponaro, Elena Sezenna, and Andrea Mastorgio

1.1 Introduction .......................... 1

1.2 Pollution Sources ...................... 2

1.3 Relevant Classes of Contaminants .............. 4

1.3.1 Inorganic species $\ldots \ldots \ldots \ldots \ldots \ldots \ldots \ldots \ldots$

1.3.2 Organic pollutants $\ldots \ldots \ldots \ldots \ldots \ldots \ldots \ldots$

1.3.3 Chemicals of emerging concern $\ldots \ldots \ldots \ldots \ldots 13$

1.4 References ........................... 14

\section{Chapter 2}

Filtration materials for groundwater treatment . . . . . . 19

Natalia Klymenko and Ivan Kozyatnyk

2.1 Introduction ......................... 19

2.2 Extraction of Ions of Toxic Metals from Groundwater

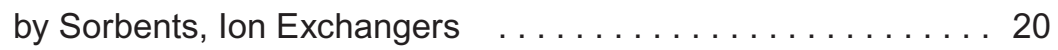

2.3 Reactive Materials ................... 21

2.4 The Use of Production Wastes in Groundwater Treatment . . . 25

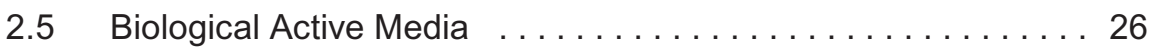

2.6 References ........................ 32

\section{Chapter 3}

Technologies for ground water treatment . . . . . . 37

3.1 Pump-and-treat technologies . . . . . . . . . . . 39

Arun Kumar Thalla, Devatha C. P. and Giuliano Crauss Daronco

3.1 .1 Introduction ......................... 39 
vi Filtration Materials for Groundwater: A Guide to Good Practice

3.1.2 Site Characterizations $\ldots \ldots \ldots \ldots \ldots \ldots \ldots \ldots \ldots \ldots 40$

3.1 .3 Treatment Methods $\ldots \ldots \ldots \ldots \ldots \ldots \ldots \ldots \ldots \ldots . \ldots \ldots 2$

3.1.3.1 Membrane filtration . . . . . . . . . . . . . . . 42

3.1.3.2 Forward osmosis . . . . . . . . . . . . . . 44

3.1.3.3 Nanotechnologies . . . . . . . . . . . . . . . 46

3.1.3.4 Electrocoagulation ... . . . . . . . . . . . . . 47

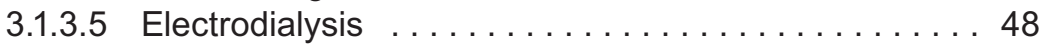

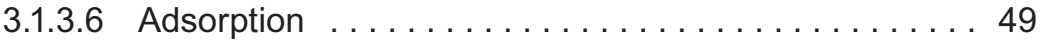

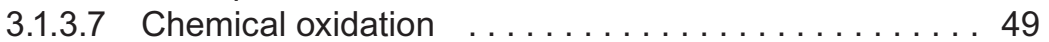

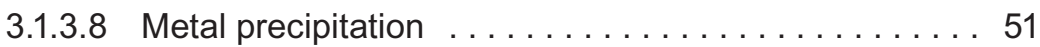

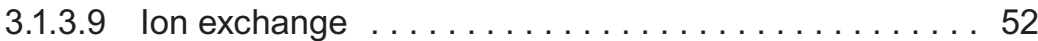

3.1.3.10 UV treatment ...................... 53

3.1.3.11 Biodegradation ................... 53

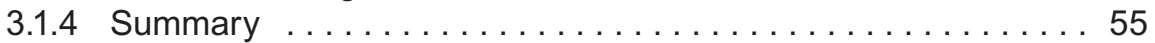

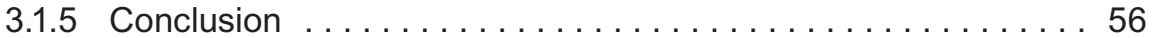

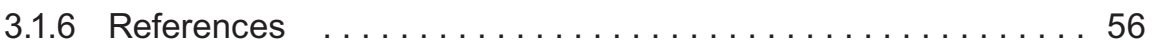

\subsection{Near-well subsurface treatment technologies} for sustainable drinking water production . . . . . . 59 Niels Hartog

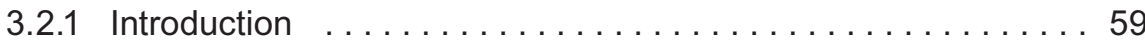

3.2.2 The Challenge and Potential for Omp Removal Using Subsurface Reactors .................... 59

3.2.3 Subsurface Reactors: Characteristics and Specifics . . . . . 60

3.2.3.1 Subsurface water treatment: the concept . . . . . . 60

3.2.3.2 The creation of a subsurface reactive zone ......61 61

3.2.3.3 Subsurface reactor volume .............6 62

3.2.3.4 Geometry of the subsurface reactive zone ......66 63

3.2.4 Subsurface Reactor Kinetics . . . . . . . . . . . . . . . 64

3.2.4.1 Contact time: travel time towards the well ......664

3.2.4.2 Removal during subsurface treatment ........66 66

3.2.5 Reactants to Create Near-Well Subsurface Reactors . . . . . . 68

3.2.6 Outlook for the Use of Near-Well Subsurface Reactors . . . . 69

3.2 .7 References ........................ 70

\section{Chapter 4}

Cost and risk assessment of treatment facilities . . . . . 71

Viktória Mikita, Tamás Madarász, Klára Szita Tóthné and

Balázs Kovács

4.1 Hydrogeological Aspects of Contaminated Site Remediation . . 71

4.1.1 Possible goals of groundwater treatment ...... 71 
4.1.2 Groundwater flow and contaminant transport modeling ....................... 72

4.2 The Risk and Performance Assessment of Treatment Facilities ........................ 74

4.2.1 Determination of acceptable risk . . . . . . . . . 74

4.2.2 Performance assessment ............. 76

4.3 Determination of Possible Technologies Based on

Risk Analysis and Modeling . . . . . . . . . . . . . . . . . 85

4.4 The Cost Estimation Procedure . . . . . . . . . . . . . . 88

4.4.1 Cost analysis by technology $\ldots \ldots \ldots \ldots \ldots \ldots 8$

4.5 The Advantages and Limitations of Pump-and-Treat

Methods and Passive Technologies . . . . . . . . . . . . . 97

4.6 References . . . . . . . . . . . . . . . . . . . . . 98

Chapter 5

Examples of modern ongoing facilities for ground

water treatment and polluted sites remediation . . . . . 103

5.1 Constructed wetlands for groundwater remediation . . 105 Oksana Coban

5.1 .1 Introduction ........................... 105

5.1 .2 A Case Study . . . . . . . . . . . . . . . . . 106

5.1 .3 Conclusions ............................ 107

5.1 .4 References ........................... 108

5.2 Constructed wetlands for the treatment of petroleum hydrocarbon contaminated groundwater a pilot scale study . . . . . . . . . . . . . . . 109 Andrea Watzinger, Paul Kinner and Thomas G. Reichenauer

5.2 .1 Introduction and Methodology ................. 109

5.2 .2 Results ................................ 110

5.2 .3 Conclusions . . . . . . . . . . . . . . . . . 113

5.2 .4 References .......................... 113

5.3 Designs of permeable reactive barriers and examples of full scale treatment . . . . . . . . . . 114 Sabrina Saponaro, Elena Sezenna, and Andrea Mastorgio

5.3 .1 Design ... . . . . . . . . . . . . . . . . . . . . . . . . 118

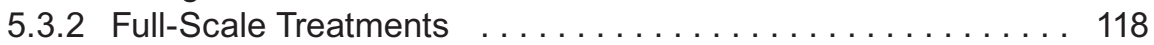

5.3 .3 References ............................ 120 
viii Filtration Materials for Groundwater: A Guide to Good Practice

\subsection{State of art of filtration for public water supply}

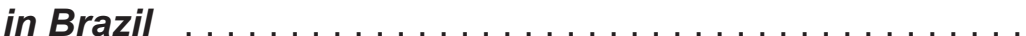

Giuliano Daronco

5.4.1 Classification According to the Filtration Rate

(Fast and Slow Filters) . . . . . . . . . . . . . . . . 122

5.4.2 Classification According to the Flow Direction

(Upflow and Downflow) ................... 123

5.4.2.1 Rating according to the type of treatment

(conventional, direct filtration and filtration line) $\ldots 123$

5.4.3 Classification According to the Filter Material

(Granular Bed Filters and Filter Type Precoat) . . . . . . . . 123

5.4.4 Classification According to the Hydraulic Arrangement

(Gravity Filters and Pressure Filters) . . . . . . . . . . . . 124

5.4.5 Classification According to the Mechanism of Action

(Action of Water Depth and Surface Action) . . . . . . . . . 124

5.4 .6 References .............................. 124

5.5 Development in groundwater treatment - Indian perspective ....................... 126

Arun Kumar Thalla and Devatha C. P.

5.5.1 Surface and Groundwater Potential in India . . . . . . . . . 127

5.5.2 Drawbacks with Surface Water . . . . . . . . . . . . 127

5.5.3 Groundwater Contamination .................. 127

5.5.4 Methods Adopted for Water Treatment in India . . . . . . . . 128

5.5.5 Government Initiatives - in Conservation of Surface \&

Ground Water Resource . . . . . . . . . . . . . . . . . . 128

5.5.6 Research Initiative by Academic and Research Institutions .. 129

5.5 .7 References ... . . . . . . . . . . . . . . . . . . . 129 


\section{Chapter 1}

\section{Pollutants in groundwater}

\section{Sabrina Saponaro, Elena Sezenna, and Andrea Mastorgio}

Politecnico di Milano, Department of Civil \& Environmental Engineering, Milan, Italy; sabrina.saponaro@polimi.it; elena.sezenna@polimi.it; and reafilippo.mastorgio@polimi.it

\subsection{INTRODUCTION}

Groundwater contamination generically refers to modifications in biological, physical or chemical characteristics (e.g., salinity, temperature, etc.), the presence of undesirable solutes at significant concentrations, or radioactivity. It may be: (i) of natural origin, (ii) the result of human activity; or (iii) a combination of the previous two. Naturally occurring processes, such as decomposition of organic material in soils or leaching of mineral deposits, can result in increased concentrations of several substances such as manganese, sulphate, chloride, organic matter, fluoride, arsenic, nitrate, selenium, uranium, and radon. Sources of groundwater contamination due to human activities are widespread and include diffuse sources as well as point-sources of pollution, such as land application of animal manure containing contaminants (e.g., veterinary pharmaceuticals) and agrochemicals in agriculture, leakages from sewers or sanitation systems, from waste disposal sites, landfills, underground storage tanks and pipelines, and accidental spills in mining, industry, traffic, health care facilities and military sites. The exploitation of petroleum products and the development of the industrial chemistry have given rise to a large number of organic chemicals, many of which are found in the environment (Kurwadkar, 2014). Various studies have shown that anthropogenic chemicals such as pesticides (Arias-Estevez et al. 2008; Postigo \& Barceló, 2015), pharmaceuticals and personal care products (Holm et al. 1995; Deo \& Halden, 
2013; Postigo \& Barceló, 2015), industrial chemicals (Diaz-Cruz \& Barceló, 2008; Meffe \& de Bustamante, 2014), and fuel additives (van Wezel et al. 2009) occur in groundwater. U.S. Geological Survey (USGS) investigations have assessed the occurrence, distribution, and benchmark exceedance of various contaminants in water from public-supply wells and domestic wells, including pesticides (Gilliom et al. 2006), volatile organic compounds (Squillace et al. 2002; Zogorski et al. 2006), pesticides and nitrate (Squillace et al. 2002; DeSimone, 2009). Chemical mixtures were frequently detected, often with concentrations of individual contaminants approaching human-health benchmarks. Chemical mixtures that most frequently occurred and had the greatest potential toxicity were composed of arsenic, strontium, uranium, radon, and nitrate (Toccalino et al. 2012).

Many organic chemicals are known to have potential human health impacts, and some of these may occur in groundwater at relevant concentrations. The list of those for which guideline values and national quality standards have been developed has been continually extended and revised. Among these: monoaromatic hydrocarbons (benzene, toluene, ethylbenzene and xylenes - BTEX), volatile chlorinated hydrocarbons (tetrachloroethene - PCE, trichloroethene TCE), and pesticides.

This chapter focuses on chemical substances that have reasonable potential to contaminate groundwater and have human health impacts. It provides information about: (i) the major sources of pollution ( $\S 1.2$ ); (ii) inorganic contaminants (§ 1.3.1 to 1.3.3), (iii) organic contaminants (§ 1.3.4); and (iv) emerging issues ( $\$ 1.3 .5$ ). Further information about the chemicals discussed in this chapter is available in the World Health Organization (WHO) Guidelines for Drinking-Water Quality, Volume 1 (WHO, 2004), as well as in the WHO's Water, Sanitation and Health website (http://www.who.int/water_sanitation_health/dwq/chemicals/en/ index.html).

\subsection{POLLUTION SOURCES}

The occurrence of natural constituents in groundwater has large variability according to the nature of the aquifer. Saltwater intrusion or leaching from natural soil can bring solutes to groundwater and affect its quality for the intended uses, especially in case of drinking purposes.

Table 1.1 summarizes the most frequent contaminants of natural origin. Arsenic and fluoride are examples of relevant naturally occurring groundwater constituents on worldwide basis. Further natural constituents of potential interest include selenium, radon and uranium. In some settings, also nitrate occur naturally at relevant concentrations, though it usually has anthropogenic origin.

Despite natural pollution sources can exist, groundwater becomes polluted primarily because of human activities. Table 1.2 summarizes pollution sources potentially affecting groundwater quality, which are roughly classifiable as industrial, municipal-residential, and agricultural sources. 
Table 1.1 Most frequent contaminants of natural origin.

\begin{tabular}{|c|c|c|}
\hline Contaminant & Origin & Possible Effects \\
\hline Iron & $\begin{array}{l}\text { Mineral dissolution in acidic and } \\
\text { reducing environment }\end{array}$ & Affects water potability \\
\hline Manganese & $\begin{array}{l}\text { Mineral dissolution in acidic and } \\
\text { reducing environment }\end{array}$ & Affects water potability \\
\hline Arsenic & $\begin{array}{l}\text { Dissolution from sediments and } \\
\text { rocks under some chemical } \\
\text { circumstances }\end{array}$ & Human health effects \\
\hline Boron & $\begin{array}{l}\text { Marine sediments and volcanic } \\
\text { rocks }\end{array}$ & $\begin{array}{l}\text { Human health effects, } \\
\text { detrimental to plants }\end{array}$ \\
\hline Fluoride & Volcanic acidic rocks and ash & $\begin{array}{l}\text { Human bone and teeth } \\
\text { damages }\end{array}$ \\
\hline Selenium & Sedimentary rocks of marine origin & Wildlife damages \\
\hline Radon & Uranium minerals & $\begin{array}{l}\text { Human health } \\
\text { effects caused by } \\
\text { radioactivity }\end{array}$ \\
\hline Uranium & $\begin{array}{l}\text { Trace elements in most rocks and } \\
\text { soils, formed by radioactive decay }\end{array}$ & $\begin{array}{l}\text { Human health effects } \\
\text { caused by radioactivity }\end{array}$ \\
\hline
\end{tabular}

Table 1.2 List of the Potential Groundwater Contamination.

\begin{tabular}{lll}
\hline $\begin{array}{l}\text { Industrial } \\
\text { Sources }\end{array}$ & $\begin{array}{l}\text { Municipal Residential } \\
\text { Sources }\end{array}$ & $\begin{array}{l}\text { Agricultural } \\
\text { Sources }\end{array}$ \\
\hline $\begin{array}{l}\text { Chemicals storage \& } \\
\text { Fuels storage \& spills }\end{array}$ & $\begin{array}{l}\text { Municipal waste } \\
\text { land-spreading } \\
\text { Salt for de-icing streets }\end{array}$ & $\begin{array}{l}\text { Chemical spills } \\
\text { Fertilizers and pesticides } \\
\text { application } \\
\text { Livestock waste storage } \\
\text { facilities \& land-spreading } \\
\text { Underground storage } \\
\text { Pipelines }\end{array}$ \\
$\begin{array}{lll}\text { Underground storage } \\
\text { tanks }\end{array}$ & Streets \& parking lots \\
& Landfills & $\begin{array}{l}\text { Wells poorly constructed or } \\
\text { abandoned }\end{array}$ \\
& $\begin{array}{l}\text { Leaky sewer lines } \\
\text { Septic systems }\end{array}$ & \\
& $\begin{array}{l}\text { Wells poorly constructed } \\
\text { or abandoned }\end{array}$ & \\
\hline
\end{tabular}

Sources: http://www.lenntech.com/groundwater/pollution-sources.htm\#ixzz3frbGDNc7. 
Many industrial facilities handle substances potentially causing groundwater contamination, such as metals, petroleum products, paints and coatings, rubber and plastics, electrical components, pharmaceuticals, pesticides, non-chlorinated and chlorinated solvents, paper, inks and dyes, fabrics, adhesives, fertilizers, wood preservatives, cleaning solvents and explosives.

Municipal wastewater systems can be a source of many categories of contaminants, such as nitrates and pollutants of emerging concern, such as ingredients of personal care products, drugs, detergents and disinfectants.

Agricultural activities have significant impact on water resources as they use herbicides, fertilizers and pesticides in direct contact with soil. Moreover land spreading of animal manures can cause nitrate pollution.

Instead of being released from industrial facilities, some substances are rather formed for natural degradation phenomena once the release of a parent chemical has occurred (Mattes et al. 2010; Chambon et al. 2013). For example, in rare instances 1,2-dichloroethene (1,2-DCE) or vinyl chloride (VC) may be released directly into groundwater but, more commonly, they are detected as breakdown products of the anaerobic biodegradation of tetrachloroethene (PCE) or trichloroethene (TCE). Similar changes can occur in the sequential reductive dehalogenation of polychlorinated biphenyls (PCBs), resulting in the formation of lower chlorinated homologues from the parent PCBs.

Pollution sources are usually classified also in term of extent, as point or diffuse pollution sources. Point-source pollution refers to contaminant inputs in relatively small areas, such as waste disposal sites and accidental spills. It results in a groundwater plume that has the highest pollutant concentrations nearest the source and diminishing concentrations farther away from the source. Diffuse pollution (or non-point pollution) refers to pollution inputs throughout a large territory. This kind of contamination may be caused by agriculture and extensive animal farming, which involve agrochemicals, nutrients, water and soil quality amendments, pesticides, and herbicides.

\subsection{RELEVANT CLASSES OF CONTAMINANTS}

\subsubsection{Inorganic species}

\subsubsection{Arsenic}

Arsenic is a metalloid, having properties of both metal and nonmetal. It can occur in several oxidation states $(-3,0,+3$ and +5$)$. It is ubiquitous in the environment and is naturally present in soil, water, air, plants, and animals (Tamaki \& Frankenberger, 1989).

Naturally occurring arsenic is commonly found in a variety of solid phases: as a component of volcanic rocks (in sulfide minerals, principally arsenopyrite), adsorbed to and co-precipitated with metal oxides (especially iron oxides), adsorbed to surfaces of clays, and associated with sulfide minerals and organic 
carbon. The average arsenic concentration in the earth's crust has been estimated to be approximately 2 parts per million (Hem, 1989; Yan-Chu, 1994).

Background concentrations of arsenic in groundwater in most countries are $<10 \mu \mathrm{g} / \mathrm{l}$. However, surveys performed in arsenic-rich areas showed a very large range of values, from $<0.5$ to $5000 \mu \mathrm{g} / 1$ (Smedley \& Kinniburgh, 2001). Investigations performed in Bangladesh indicate that 20 per cent of 25000 boreholes tested in that country have arsenic concentrations exceeding $50 \mu \mathrm{g} / \mathrm{l}$ (Alaerts et al. 2001). Arsenic concentration in German groundwater downstream of abandoned waste disposal sites was found to have an average concentration of $61 \mu \mathrm{g} / \mathrm{l}$ (253 sites), due to arsenic leaching from domestic coal ashes contained in the household waste. In contrast, the mean arsenic concentration in uncontaminated aquifers was $0.5 \mu \mathrm{g} / 1$ (472 sites) (Kerndorff et al. 1992). Naturally occurring arsenic can be mobilized and subsequently migrate into groundwater at landfills and other sites where contaminants, such as petroleum products, can cause anaerobic conditions (Welch et al. 2000).

The concentration of arsenic in natural waters is normally controlled by solidsolution interactions, particularly in groundwater where the solid/solution ratio is large. In most soils and aquifers, mineral-arsenic interactions are likely to dominate over organic matter-arsenic interactions, although organic matter can interact at some extent by reactions on mineral surface (Smedley \& Kinniburgh, 2001).

In natural waters arsenic is mostly found as inorganic oxyanion forms (trivalent arsenite or pentavalent arsenate). Redox potential (Eh) and $\mathrm{pH}$ are the most important factors controlling its speciation (Smedley \& Kinniburgh, 2001). Arsenic shows high sensitivity to mobilization at the $\mathrm{pH}$ values typically found in groundwater (6.5-8.5) and under either oxidizing or reducing conditions. Under oxidizing conditions, $\mathrm{H}_{2} \mathrm{AsO}_{4}{ }^{-}$is dominant at low $\mathrm{pH}(<6.9)$, while at higher $\mathrm{pH}$, $\mathrm{HAsO}_{4}{ }^{2-}$ becomes dominant $\left(\mathrm{H}_{3} \mathrm{AsO}_{4}\right.$ and $\mathrm{AsO}_{4}{ }^{3-}$ may be present in extremely acidic and alkaline conditions, respectively). Under reducing conditions at $\mathrm{pH}<9.2$, the uncharged $\mathrm{As}(\mathrm{III})$ species $\mathrm{H}_{3} \mathrm{AsO}_{3}$ will predominate.

Transport is largely controlled by the aquifer conditions, particularly by adsorption on ferric oxohydroxides, humic substances and clays. There is no process in the subsurface that alters arsenic species beside precipitation and adsorption. Arsenic adsorption is most likely to be non-linear, with the rate of adsorption disproportionally decreasing with increasing concentrations in groundwater. This leads to reduced retardation at high concentrations. The different arsenic species exhibit different retardation behaviors. This was demonstrated by Gulens et al. (in Smedley \& Kinniburgh, 2001) by soil column experiments with different groundwaters. They showed that: (i) As(III) moved five to six times faster than As(V) under oxidizing conditions (at $\mathrm{pH}$ 5.7); (ii) with a 'neutral' groundwater ( $\mathrm{pH}$ 6.9) under oxidizing conditions, $\mathrm{As}(\mathrm{V})$ moved faster than under the conditions (i), but it was still slower than As(III); (iii) under reducing conditions (at $\mathrm{pH} 8.3$ ), both $\mathrm{As}(\mathrm{III})$ and $\mathrm{As}(\mathrm{V})$ moved rapidly through the column; (iv) when the amount of arsenic injected was substantially reduced, the mobility of $\mathrm{As}(\mathrm{III})$ and $\mathrm{As}(\mathrm{V})$ was greatly reduced. 


\subsubsection{Fluoride}

Fluoride $\left(\mathrm{F}^{-}\right)$is an inorganic anion of fluorine.

It naturally occurs in rocks in many geological environments. High concentrations occur in some metamorphic and sedimentary rocks that contain significant amounts of fluoride-bearing minerals such as fluorite and apatite (Hem, 1989; Vithanage \& Bhattacharya, 2015).

Levels in water are normally below $1.5 \mathrm{mg} / \mathrm{l}$, but groundwater has been found to contain values $>50 \mathrm{mg} / \mathrm{l}$ in some areas rich in fluoride-containing minerals. Fluoride concentrations in groundwater are particularly high in groundwater flowing through acid volcanic rocks, e.g. in Sudan, Ethiopia, Uganda, Kenya and Tanzania. In Kenya, $61 \%$ of groundwater samples collected nationally from drinking water wells exceeded $1 \mathrm{mg} / \mathrm{l}$ (WHO, 2006).

In general high fluoride concentrations in groundwater show a strong positive correlation with dissolved solids, sodium, and alkalinity, and a strong negative correlation with hardness. The concentration of $\mathrm{F}^{-}$in groundwater is driven by calcium ions and the solubility product of fluorite $\left(\mathrm{CaF}_{2}\right)$. At equilibrium conditions, a calcium concentration of $40 \mathrm{mg} / \mathrm{l}$ equates to a fluoride concentration of $3.2 \mathrm{mg} / \mathrm{l}$. In groundwater with high concentrations of calcium ions, fluoride concentrations rarely exceed $1 \mathrm{mg} / \mathrm{l}$. High fluoride concentrations in groundwater are usually caused by a lack of calcium. During high percolation rate experiments, Flühler et al. (1985) observed increased fluoride concentration in the leachate of fluorideenriched soils due to a limited additional delivery of calcium.

In groundwater with high $\mathrm{pH}(>8)$, dominated by sodium ions and carbonate species, fluoride concentrations commonly exceed $1 \mathrm{mg} / \mathrm{l}$ (Vithanage \& Bhattacharya, 2015). Concentrations $>50 \mathrm{mg} / \mathrm{l}$ have been recorded in groundwater in South Africa and in Arizona (Hem, 1989).

Fluoride ions form strong complexes with aluminum, beryllium and iron (III).

\subsubsection{Nitrogen species}

Nitrogen is present in human and animal waste under organic forms, which may be mineralized to inorganic forms. Ammonia (ionized as $\mathrm{NH}_{4}{ }^{+}$, non-ionized as $\mathrm{NH}_{3}$ ) mainly results from animal feed lots and the use of manures in agriculture, or from on-site sanitation or leaking sewers. The nitrate ion $\left(\mathrm{NO}_{3}{ }^{-}\right)$is the stable form of combined nitrogen for oxygenated systems. Nitrate is one of the major anions in natural waters, but concentrations can be greatly elevated due to agricultural activities and sanitation practices. The nitrite ion $\left(\mathrm{NO}_{2}^{-}\right)$contains nitrogen in a relatively unstable oxidation state. Nitrite does not typically occur in natural waters at significant levels, except temporarily under reducing conditions. Chemical and biological processes can further reduce nitrite to various compounds or oxidize it to nitrate.

Natural levels of ammonia in groundwater are usually $<0.2 \mathrm{mg} / \mathrm{l}$. Nitrate concentration is normally low, and typically in the range $0-18 \mathrm{mg} / \mathrm{las} \mathrm{NO}_{3}{ }^{-}$. High 
concentrations of nitrate in groundwater are mostly caused by agricultural activity or sanitation practices. However, natural nitrate concentrations can also exceed $100 \mathrm{mg} / \mathrm{l}$ as $\mathrm{NO}_{3}{ }^{-}$in some arid parts of the world, such as Sahel and North Africa and the arid zones of Australia (WHO, 2006).

$\mathrm{NH}_{4}{ }^{+}$shows high tendency for adsorption on clay minerals, which limits its mobility in the subsurface (saturated and unsaturated zones). In contrast, interactions between minerals and nitrate or nitrite are usually negligible and both ions are typically very mobile in the subsurface. Under aerobic conditions in the subsurface, oxidation of ammonium through nitrite to nitrate by microorganisms is the only process where nitrate is formed in natural systems. When moving with water into a geologic medium that lacks oxygen, nitrate undergoes denitrification, whereby some of it can be converted into gas and released to the atmosphere (US EPA, 2007).

\subsubsection{Metals}

This paragraph focuses on metals related to human activities with physical, chemical and toxicological properties that make them potential contaminants for groundwater, i.e. cadmium $(\mathrm{Cd})$, lead $(\mathrm{Pb})$, nickel $(\mathrm{Ni})$, chromium $(\mathrm{Cr})$, and copper $(\mathrm{Cu})$.

These metals are natural constituents in groundwater, having their origin in weathering and solution of numerous minerals. However, natural concentrations in groundwater are generally low. Typical values are $<10 \mu \mathrm{g} / \mathrm{l}$ (copper, nickel), $<5 \mu \mathrm{g} / \mathrm{l}$ (lead) or $<1 \mu \mathrm{g} / \mathrm{l}$ (cadmium, chromium). The concentrations can locally increase naturally in aquifers containing high amounts of heavy metal bearing minerals, up to levels that are of toxicological relevance and exceeding drinkingwater guidelines.

Metal concentrations in groundwater may be of particular concern where it is directly affected by activities such as mining, manufacturing industries, metal finishing, wastewater and waste disposal, agriculture. As an example Table 1.3 reports ranges of typical background concentrations compared to ranges at metal mining sites or in oilfield groundwater for $\mathrm{Cd}, \mathrm{Ni}$ and $\mathrm{Pb}$. Corrosion of copper pipes can cause high copper levels in drinking-water (Araya et al. 2003). Another anthropogenic cause of elevated metal concentrations in groundwater is the acidification of rain and soils by air pollution and the mobilization of metals at lower $\mathrm{pH}$ values. This problem predominantly appears in forested areas, due to higher deposition rates of the acidifying anions sulfur and nitrate from the atmosphere in forests due to the large surface of needles and leafs and low neutralization capacity against acids of forest soils typically poor in nutrients (WHO, 2006).

Most of the metals of concern occur in groundwater mainly as cations (e.g., $\mathrm{Pb}^{2+}, \mathrm{Cu}^{2+}, \mathrm{Ni}^{2+}, \mathrm{Cd}^{2+}$, which generally become more insoluble as $\mathrm{pH}$ increases. At a nearly neutral $\mathrm{pH}$, typical for most groundwaters, the solubility of most metal 
cations is severely limited by precipitation as an oxide, hydroxide, carbonate or phosphate minerals, or more likely by strong adsorption onto hydrous metal oxides, clay or organic matter in the aquifer matrix. The adsorption decreases with decreasing $\mathrm{pH}$. As a consequence, in naturally or anthropogenically acidified groundwaters, metals are mobile and can travel long distances. Furthermore, as simple cations, there is no microbial or chemical degradation.

Table 1.3 A few element concentrations ( $\mu \mathrm{g} / \mathrm{l})$ from oilfield and metal mining sites compared to groundwater background values (adapted from WHO 2006).

\begin{tabular}{llll}
\hline Element & $\begin{array}{l}\text { Oilfield } \\
\text { Groundwater }\end{array}$ & $\begin{array}{l}\text { Metal Mining } \\
\text { Groundwater }\end{array}$ & $\begin{array}{l}\text { Background } \\
\text { Values }\end{array}$ \\
\hline $\mathrm{Cd}$ & $1-100$ & $1-400$ & $1-5$ \\
$\mathrm{Ni}$ & $1-500$ & $1-100,000$ & $1-170$ \\
$\mathrm{~Pb}$ & $1-30$ & $10-1500$ & $<1-10$ \\
\hline
\end{tabular}

In addition, most oxyanions tend to become less strongly sorbed as the $\mathrm{pH}$ increases (Sposito, 1989). Therefore, the oxyanion-forming metals such as chromium are some of the more common trace contaminants in groundwater. Chromium can be found in the environment in two valence states, $\mathrm{Cr}$ (III) and $\mathrm{Cr}(\mathrm{VI})$. The former predominates in soils, whereas the latter occurs exclusively as chromate $\left(\mathrm{CrO}_{4}{ }^{2-}\right)$ from anthropogenic sources. Chromium is mobile as stable $\mathrm{Cr}(\mathrm{VI})$ oxyanion species under oxidizing conditions, but forms cationic $\mathrm{Cr}$ (III) species in reducing environments and hence behaves relatively immobile under these conditions. For example, in contaminated groundwater at industrial and waste disposal sites Chromium occurs as $\mathrm{Cr}^{3+}$ and $\mathrm{CrO}_{4}{ }^{2-}$ species. In most aquifers chromium is not very mobile because of precipitation of hydrous $\mathrm{Cr}$ (III) oxide. (Smedley \& Kinniburgh, 2001).

In a soil solution containing a variety of heavy metal cations that tend to adsorb to particle surfaces, there is competition between metals for the available sites. Of several factors that determine this selectivity, ionic potential, which is equal to the charge of an ion over its ionic radius, has a significant effect. Cations with a lower ionic potential tend to release their solvating water molecules more readily so that inner sphere surface complexes can be formed. Selectivity sequences are arranged in order of decreasing ionic radius, which results in increasing ionic potential and decreasing affinity or selectivity for adsorption. Metals within the transition group differ in that electron configuration becomes more important than ionic radius in determining selectivity. The relative affinity of some metals belonging to different transition groups is given by: $\mathrm{Cu}^{2+}>\mathrm{Ni}^{2+}>\mathrm{Co}^{2+}>\mathrm{Fe}^{2+}>\mathrm{Mn}^{2+}$. However, this sequence can be changed in groundwater by naturally occurring complexing agents like fulvic acids, which is especially true for copper (Schnitzer \& Khan, 1972). 


\subsubsection{Organic pollutants}

Human activity has released and release to the environment a vast range of anthropogenic organic chemicals, commonly termed 'micro-pollutants', that may detrimentally impact groundwater quality. Here the focus is on commercially and industrially derived class of chemicals which have been observed to occur frequently as groundwater contaminants, due to widespread use and associated release potential and physical and chemical properties facilitating their occurrence in groundwater. Of the many organic chemicals that potentially contaminate groundwater, the major chemical groups include:

- aromatic hydrocarbons: benzene, toluene, ethylbenzene and xylenes (BTEX);

- chlorinated hydrocarbons (aliphatic and aromatic): dichloromethane, trichloromethane (also known as chloroform), tetrachloromethane (also known as carbon tetrachloride), vinyl chloride, 1,1-dichloroethene, 1,2-dichloroethene cis-and trans-isomers, trichloroethene, tetrachloroethene (also known as perchloroethene), 1,2-dichloroethane, 1,2-dichlorobenzene, and 1,4-dichlorobenzene.

Other chemical groups may have received widespread industrial use, but are thought to pose a much lower risk to groundwater. Examples of the latter may include Polycyclic Aromatic Hydrocarbons (PAHs) and Polychlorinated Biphenyls (PCBs).

\subsubsection{Aromatic hydrocarbons (BTEX)}

Mononuclear (single-ring) aromatic hydrocarbons, such as BTEX, are amongst the most common groundwater contaminants and the major aromatic fraction of many fuels. Thus this class of compounds is typically associated with fuel and fuel-related contamination point-sources, originating from petroleum production, refining and wholesale and retail distribution (service stations) of petroleum products. They are also used as solvents and raw materials in chemical production (Newell et al. 1995).

A German-USA groundwater survey performed in the past (Kerndorff et al. 1992) showed that BTEX were quite diffused, benzene being the most frequently detected.

Natural attenuation processes (volatilization, dispersion and biodegradation) of BTEX are very significant mechanisms reducing the pollutant concentrations and plume extension in groundwater. Usually the BTEX plume is limited to distances of a few hundred meters from source zones. In Newell and Connor (1998) and Wiedemeier et al. (1999), 86\% of the 604 plumes evaluated in the USA were less than $100 \mathrm{~m}$ long, with only $2 \%$ of plumes longer than about $300 \mathrm{~m}$. One of the studies indicated $8 \%$ of 271 plumes as still growing, 59\% of plumes as approximately stable, and $33 \%$ of plumes as shrinking. Thus although hydrocarbon sources can be numerous, BTEX impacts are likely to remain local to the sources zones. 
Among the natural attenuation processes, biodegradation is usually the most affecting mechanism BTEX removal, due to their high biodegradability under a wide range of conditions. BTEX are readily degraded when dissolved oxygen is present in groundwater while, in general, their degradation rate is lower under anaerobic conditions. Rates may vary significantly for individual compounds (Barker et al. 1987; Wiedemeier et al. 1999; Noble \& Morgan, 2002).

\subsubsection{Chlorinated hydrocarbons}

Chlorinated hydrocarbons are used in a variety of industrial activities (e.g., metal stripping, chemical manufacturing, pesticide production, etc.), including almost any facility where solvents, cleaners or paint removers are used on metals, textiles and leathers. Complex mixtures of chlorinated hydrocarbons may arise from leakages at hazardous waste disposal sites, where many solvent types may have been disposed. In contrast, spills at industrial manufacturing/processing sites may well comprise liquid chlorinated hydrocarbons with a high proportion of a single component. A multitude of point sources exist in many urban areas, due to the diversity and frequency of chlorinated hydrocarbon users.

In many industrialized countries, chlorinated hydrocarbons are the most frequently detected groundwater contaminants at hazardous waste sites (Kerndorff et al. 1992; Plumb, 1992; NRC, 1994). Trichloroethene (TCE) and tetrachloroethene (PCE), 1,2-dichloroethene cis (1,2-DCE cis) and vinyl chloride (VC) have been the most frequently detected chlorinated hydrocarbons. Many groundwater supplies or monitoring wells were contaminated particularly by TCE and to a lesser extent by PCE (Cavallero et al. 1985; Fusillo, 1985; Rivett et al. 1990).

Many chlorinated hydrocarbons enter the subsurface in the Dense Non Aqueous Phase Liquid (DNAPL) form and may travel down to significant depths within the aquifers (Pankow \& Cherry, 1996). Dissolution of DNAPL sources is expected to be slow, taking years to decades, particularly from residual DNAPL pools that have diffused into low-permeability strata.

On average chlorinated hydrocarbon plumes are significantly longer than BTEX plumes. Newell et al. (1990) reported a median length of about $300 \mathrm{~m}$ for chlorinated ethenes (PCE, TCE, DCE, VC) plumes (88 sites), while Mackay and Cherry (1989) and Jackson (1998) mentioned dissolved-phase plumes in the 1-10 km-scale. This is partially due to limited sorption, particularly for the less hydrophobic compounds (Rivett et al. 2001; Rivett \& Allen-King, 2003).

Under aerobic conditions, biodegradation of solvents such as TCE and PCE can be limited to non-existent. Under reducing conditions biodegradation pathways exist, the most known being those involving the sequential reductive dechlorination of chlorinated hydrocarbons where lesser chlorinated organics (TCE, 1,2-DCE cis, VC) and ultimately hydrocarbons, such as ethane or ethene, are formed (Vogel et al. 1987). Biodegradation of chlorinated hydrocarbons has proven to be relatively complicated with five possible degradation processes 
(Wiedemeier et al. 1999). Under anaerobic or low oxygen conditions, degradation processes include: (i) dehalorespiration, where chlorinated hydrocarbons are used as the electron acceptor and effectively respired, (ii) direct anaerobic oxidation, and (iii) anaerobic co-metabolism. Under aerobic conditions, further processes are: (iv) direct aerobic oxidation, and (v) aerobic co-metabolism. Direct processes involve the chlorinated hydrocarbon being used as the primary growth substrate. Dehalorespiration and co-metabolism both require an alternative primary growth substrate to be present. That primary substrate is normally a relatively biodegradable substrate and may include anthropogenic carbon, such as BTEX contamination. Alternatively, anaerobic conditions may be driven by high levels of naturally occurring carbon acting as the substrate (Lorah \& Olsen, 1999). Due to the complexity of biodegradation processes, there is a wide divergence in reported biodegradation rates of chlorinated hydrocarbons (Wiedemeier et al. 1999; Noble \& Morgan, 2002). Much longer half-life values may occur for chlorinated hydrocarbons compared to BTEX.

\subsubsection{Pesticides}

Pesticides represent a wide range of compounds used mostly as insecticides, herbicides, and fungicides. Pesticides are intentionally applied to protect crops in agriculture as well as to control pests and unwanted vegetation in gardens, buildings, railway tracks, forests and roadsides. They may be accidentally released from production sites or, more often, transported away from their site of application in water, air or dust. Pesticides can reach groundwater after accidental spills or excessive application in geologically sensitive settings, from contamination of poorly sealed wells by surface runoff after intensive rains following field application and from storage or production sites.

A major study, the National Pesticide Survey, conducted by the US EPA in the late 1980s detected 46 pesticides in groundwater in 26 states originating from normal agricultural practice (Williams et al. 1988). Pesticides detected in more than five states were alachlor, aldicarb, atrazine, cyanazine, metolachlor and simazine. More recently, extensive sampling within the USGS National Water Quality Assessment program has confirmed the widespread occurrence of pesticides (Kolpin et al. 2000). The newer work has shown that pesticides, especially insecticides, are also reaching water resources in urban and suburban areas, including residential sources. This work has also demonstrated widespread detection of pesticide metabolites. This picture is largely confirmed by monitoring efforts in Europe. Herbicides, which are widely used in cereal cultivation, such as methylchlorophenoxypropionic acid and isoproturon are detected in the countries of northern Europe (Spliid \& Køppen, 1998). Most detected groundwater pesticide concentrations were in the range 0.1 to $10 \mu \mathrm{g} / \mathrm{l}$. Concentrations significantly above this range can probably be attributed to local point-source contamination from poor disposal practices or from nonagricultural usage such as on railways. Because 
of high analysis costs, much less monitoring has been undertaken in low income countries and data from tropical regions are scarce. However, atrazine residues from its use in sugar cane cultivation were widely observed in groundwater in Barbados and carbofuran was detected in shallow groundwater beneath irrigated vegetable cultivation in Sri Lanka (Chilton et al. 1998).

The mobility and persistence of pesticides in the environment are well understood because admission of a new pesticide for the market requires a series of standardized laboratory and field experiments. The overall likelihood of a pesticide to be a groundwater pollutant is dependent both on its persistence and its soil sorption. In general, soils with moderate-to-high organic matter and clay content will absorb pesticides onto soil particles, making them less available for leaching, and moderate or low permeability soils allow less water infiltration.

There are several processes by which pesticide may be degraded. Organic phosphorus pesticides tend to hydrolyze rather quickly at $\mathrm{pH}$ values above neutral (Graham-Bryce, 1981). The biodegradability of pesticides depends on their molecular structure and soil half-lives can vary between a couple of days to years (Lavy et al. 1996; Chilton et al. 2000). Carbamates are noted for their high susceptibility to degradation (Williams et al. 1988). Chlorinated pesticides and triazine herbicides are the most resistant to biodegradation and may persist for years following application. For all pesticides there is potential for incomplete transformation of the parent compound into metabolites, which may also be more or less toxic (Sawyer et al. 1994) and may themselves be persistent enough to be detected in groundwater.

\subsubsection{Polycyclic aromatic hydrocarbons}

PAHs are a diverse class of compounds of natural and anthropogenic origin. They are a component of creosotes and coal tars frequently associated with former gasworks and coal carbonization (coking) works (Johansen et al. 1997).

PAHs are generally not found in water in notable concentrations. Most of them, in fact, have extremely low solubility in water and have a high tendency to adsorb to the organic matrix of soils, particularly the higher molecular mass (higher-ring PAHs, such as the 5-ring benzo(a)pyrene). However: (i) creosote and coal tars may occur as a DNAPL and slowly migrate deep into the subsurface, and (ii) higher ring member PAHs are much more resistant to biodegradation and hence dissolved plumes, although slow to develop, may persist and grow over decades (King \& Barker, 1999).

\subsubsection{Polychlorinated biphenyls}

PCBs are a class of stable compounds, each containing a biphenyl nucleus (two linked benzene rings) with two or more substituent chlorine atoms. PCBs were produced industrially as complex mixtures that often contained between 40 and 60 different chlorinated biphenyls. PCB oils, historically used in electrical transformer facilities, were DNAPLs. 
Most PCBs are of low solubility in water and sorptive and hence dissolvedphase plumes in groundwater tend not to be large. Dissolved PCBs are generally slow to biodegrade and hence may serve as long-term sources of groundwater contamination.

\subsubsection{Chemicals of emerging concern}

Recently an increasing concern is posed by: (i) micropollutants originating from pharmaceuticals, and (ii) endocrine disrupting compounds, i.e. various environmental contaminants which mimic estrogens and other sex-hormones and hence interfere with endogenous endocrine systems, with potential adverse effects on human health.

\subsubsection{Pharmaceuticals}

There are a number of routes through which pharmaceuticals can impact groundwater, but primarily the sources are both untreated and treated sewage. There is also evidence that substances of pharmaceutical origin are not completely eliminated during wastewater treatment or biodegraded in the environment (Daughton \& Ternes, 1999; Drewes \& Shore, 2001).

A lack of knowledge still persists regarding the fate of pharmaceuticals during travel through the subsurface. However, pharmaceutically active compounds such as clofibric acid (blood-lipid regulating agent), carbamazepine and primidone (antiepileptic drugs) and iodinated $\mathrm{X}$ ray contrast agent have been detected in groundwater samples in Germany and the USA (Heberer et al. 1998; Kuehn \& Mueller, 2000; Drewes et al. 2001).

\subsubsection{Endocrine disrupting compounds (EDCs)}

More than 70000 chemicals are discussed with respect to endocrine disruptive potential (Bradley \& Zacharewski, 1998). These compounds represent both synthetic chemicals produced industrially (such as cleaners, pesticides, food additives, birth control pills, cosmetics) and naturally occurring compounds (such as steroidal hormones, plant produced estrogens, herbal supplements and metals). The steroidal sex hormones estradiol, estrone and testosterone are a class of hormonally active agents of particular interest because they are naturally excreted into the environment from human and animal sources as well as extensively used as pharmaceuticals (e.g., birth control pills). Other hormonally active compounds, such as various phenolics and phthalates, are used in a variety of industrial applications worldwide (NRC, 1999). Alkylphenol is a biological metabolite of alkylphenol polyethoxylates commonly used in a variety of industrial, agricultural and household applications as nonionic surfactants. Alkylphenol and compounds are both believed to be endocrine disrupters (Lye et al. 1999). Another synthetic chemical that has measurable hormonal activity is Bisphenol A, used as a chemical 
intermediate for numerous industrial products including polymers, resins, dyes and flame retardants. Of the numerous synthetic chemicals that have been implicated as endocrine disrupters, many are no longer used in commerce in many countries, such as some organochlorine pesticides (e.g., DDT, endosulphan, dieldrin, and toxaphene), and PCBs. Whilst endocrine disrupting compounds are largely organic compounds, it should be noted that some inorganic substances such as metals are also suspected of endocrine disrupting effects.

The occurrence of ECDs in groundwater is linked to the release of sewage, manure, or spill of specific synthetic chemicals into the environment. The specific processes used in wastewater treatment facilities play a key role in the introduction of EDCs into surface water and groundwater (Drewes \& Shore, 2001).

The transport of EDCs to groundwater depends on their hydrophobicity and degradability. The majority of highly potent compounds, such as steroids, are hydrophobic and degradable. Degradation rates of EDC compounds depend on temperature, soil characteristics and their molecular weights (IUPAC, 2003).

\subsection{REFERENCES}

Alaerts G. J., Khouri N. and Kabir B. (2001). Strategies to mitigate arsenic contamination in water supply, Report WHO 04.2005, United Nations Synthesis Report on Arsenic in Drinking Water.

Araya M., Chen B., Klevay L. M., Strain J. J., Johnson L., Robson P., Shi W., Nielsen F., Zhu H., Olivares M., Pizarro F. and Haber L. T. (2003). Confirmation of an acute no-observed adverse-effect and low-observed-adverse-effect level for copper in bottled drinking water in a multi-site international study. Regulatory Toxicology and Pharmacology, 38, 389-399.

Arias-Estevez M., Lopez-Periago E., Martınez-Carballo E., Simal-Gandara J., Mejuto J. and Garcia-Rio L. (2008). The mobility and degradation of pesticides in soils and the pollution of groundwater resources. Agriculture, Ecosystems and Environment, 123, 247-260.

Barker J. F., Patrick G. C. and Major D. (1987). Natural attenuation of aromatic hydrocarbons in a shallow sand aquifer. Ground Water Monitoring Review, 7(4), 64-71.

Bradley E. G. and Zacharewski T. R. (1998). Exoestrogens: mechanisms of action and strategies for identification and assessment. Environmental Contamination and Toxicology, 17, 49-57.

Cavallero A., Corradi C., De Felice G. and Grassi P. (1985). Underground water pollution in Milan by industrial chlorinated organic compounds. In: Effects of Landuse Upon Freshwaters, J. F. de L. G. Solbe (ed.), Ellis Harwood, Chichester, pp. 68-84.

Chambon J. C., Bjerg P. L., Scheutz C., Bælum J., Jakobsen R. and Binning P. J. (2013). Review of reactive kinetic models describing reductive dechlorination of chlorinated ethenes in soil and groundwater. Biotechnology and Bioengineering, 110, 1-23.

Chilton P. J., Lawrence A. R. and Stuart M. E. (1998). Pesticides in groundwater: some preliminary results from recent research in temperate and tropical environments. In: Groundwater Contaminants and Their Migration, J. Mather (ed.), Special Publication 128, Geological Society, London, pp. 333-345. 
Chilton P. J., Stuart M. E., Lawrence A. R., Gooddy D. C., Williams R. J. and Johnson A. C. (2000). Assessing pesticide pollution of groundwater: current knowledge and remaining gaps. In: Groundwater: Past Achievements and Future Challenges, O. T. N. Sililo (ed.), Balkema, Rotterdam, pp. 17-26.

Daughton C. and Ternes T. (1999). Pharmaceuticals and personal care products in the environment: agents of subtle change? Environ Health Perspective, 107(suppl. 6), 907-938.

Deo R. P. and Halden R. U. (2013). Pharmaceuticals in the built and natural water environment of the United States. Water, 5, 1346-1365.

DeSimone L. A., Hamilton P. A. and Gilliom R. J. (2009). Quality of water from domestic wells in principal aquifers of the United States, 1991-2004 - Overview of major findings, Report US Geological Survey, Circular, 1332.

Díaz-Cruz M. S. and Barceló D. (2008). Trace organic chemicals contamination in ground water recharge. Chemosphere, 72, 333-342.

Drewes J. E. and Shore L. S. (2001). Concerns about pharmaceuticals in water reuse, groundwater recharge, and animal waste. In: Pharmaceuticals and Personal Care Products in the Environment, Ch. Daughton and T. L. Jones-Lepp (ed.), American Chemical Society Symposium Series No. 791, Washington, DC, pp. 206-228.

Flühler H. P., Ferlin P., Selim H. M. and Schulin R. (1985). Transport von Fluorid, Bromid und Chlorid in Bodensäulen und in einem natürlich gelagertem Boden. Z. Dtsch. Geol. Gesellschaft, 136, 375-383.

Fusillo T. V., Hochreiter J. J. and Lord D. G. (1985). Distribution of volatile organic compounds in a New Jersey coastal plain aquifer. Ground Water, 23(3), 354-360.

Gilliom R. J., Barbash J. E., Crawford C. G., Hamilton P. A., Martin J. D., Nakagaki N., Nowell L. H., Scott J. C., Stackelberg P. E., Thelin G. P. and Wolock D. M. (2006). Pesticides in the nation's streams and ground water, 1992-2001, Report U.S. Geological Survey, Ciruclar 1291.

Graham-Bryce I. J. (1981). The behaviour of pesticides in soil. In: The Chemistry of Soil Processes, D. J. Greenland and M. H. B. Hayes (ed.), John Wiley \& Sons Ltd., Sussex, pp. 621-671.

Heberer T., Schmidt-Bäumler K. and Stan H.-J. (1998). Occurrence and distribution of organic contaminants in the aquatic system in Berlin. Part I: Drug residues and other polar contaminants in Berlin surface and groundwater. Acta Hydrochimica et Hydrobiologica, 26, 272-278.

Hem J. D. (1989). Study and interpretation of the chemical characteristics of natural water, 3rd (ed), USGS, Water Supply Paper, 2254.

Holm J. V., Rugge, K., Bjerg, P. L. and Christensen T. H. (1995). Occurrence and distribution of pharmaceutical organic compounds in the groundwater downgradient of a landfill (Grindsted, Denmark). Environmental Science and Technology, 29(5), 1415-1420.

IUPAC (2003). Endocrine disrupters in the environment. Pure and Applied Chemistry, 75(5), 631-681.

Jackson R. E. (1998). The migration, dissolution and fate of chlorinated solvents in the urbanized alluvial valleys of the southwestern USA. Hydrogeology Journal, 6(1), $144-155$.

Johansen S. S., Hansen A. B., Mosbaek H. and Arvin E. (1997). Characterization of heteroaromatic and other organic compounds in groundwater at creosote-contaminated sites in Denmark. Groundwater Monitoring and Remediation, 17(2), 106-115. 
Kerndorff H., Schleyer R., Milde G. and Plumb R. H. (1992). Geochemistry of groundwater pollutants at German waste disposal sites. In: Groundwater Contamination and Analysis at Hazardous Waste Sites, S. Lesage and R. E. Jackson (ed.), Marcel Dekker, Inc. New York, Basel, Hong Kong, pp. 245-272.

King M. W. G. and Barker J. F. (1999). Migration and natural fate of a coal tar creosote plume 1. Overview and plume development. Journal of Contaminant Hydrology, 39, 249-279.

Kolpin D. W., Barbash J. E. and Gilliom R. J. (2000). Pesticides in groundwater of the United States, 1992-96. Ground Water, 38(6), 858-863.

Kuehn W. and Mueller U. (2000). Riverbank filtration - an overview. Journal of American Water Works, 92(12), 60-69.

Kurwadkar S. (2014). Emerging trends in groundwater pollution and quality. Water Environment Research, 86(10), 1677-1691.

Lavy T. L., Mattice J. D., Massey J. H., Skulman B. W. and Senseman S. A. (1996). Longterm in situ leaching and degradation of six herbicides aged in subsoils. Journal of Environmental Quality, 25, 1268-1279.

Lorah M. M. and Olsen L. D. (1999). Natural attenuation of chlorinated volatile organic compounds in a freshwater tidal wetland: field evidence of anaerobic biodegradation. Water Resources Research, 35, 3811-3827.

Lye C. M., Frid C. L. J., Gill M. E., Cooper D. W. and Jones D. M. (1999). Estrogenic alkylphenols in fish tissues, sediments, and waters from the UK Tyne and Tees Estuaries. Environmental Science and Technology, 33(7), 1009-1014.

Mackay D. M. and Cherry J. A. (1989). Groundwater contamination: Pump-and-treat remediation. Environmental Science and Technology, 23(6), 630-636.

Mattes T. E., Alexander A. K. and Coleman N. V. (2010). Aerobic biodegradation of the chloroethenes: pathways, enzymes, ecology, and evolution. FEMS Microbiological Reviews, 34, 445-475.

Meffe R. and de Bustamante I. (2014). Emerging organic contaminants in surface water and groundwater: A first overview of the situation in Italy. Science of the Total Environment, 481, 280-295.

Newell C. J. and Connor J. A. (1998). Characteristics of Dissolved Hydrocarbon Plumes: Results from four studies, Report API technical transfer bulletin 12.98, American Petroleum Institute, Washington DC.

Newell C. J., Acree S. D., Ross R. R. and Huling S. G. (1995). Light Non Aqueous Phase Liquids, Report US EPA, Ground Water Issue, Oklahoma.

Newell C. J., Hopkins L. P. and Bedient P. B. (1990). A hydrogeologic database for groundwater modelling. Ground Water, 28(5), 703-714.

Noble P. and Morgan P. (2002). The Effects of Contaminant Concentration on the Potential For Natural Attenuation, Report EA (for England \& Wales) R\&D, TR. Bristol, pp. 2-228.

NRC (1994). Alternatives of Ground Water Cleanup, National Academy Press, National Research Council, Washington, DC.

NRC (1999). Hormonally Active Agents in the Environment, National Academy Press, National Research Council, Washington, DC.

Pankow J. F. and Cherry J. A. (1996). Dense Chlorinated Solvents and Other DNAPLs in Groundwater, Waterloo Press, Portland, Oregon.

Plumb R. H. (1992). The importance of volatile organic compounds as a disposal site monitoring parameter. In: Groundwater Contamination and Analysis at Hazardous 
Waste Sites, S. Lesage and R. E. Jackson (ed.), Marcel Dekker, Inc. New York, Basel, Hong Kong, pp. 173-197.

Postigo C. and Barceló D. (2015). Synthetic organic compounds and their transformation products in groundwater: Occurrence, fate and mitigation. Science of the Total Environment, 503-504, 32-47.

Rivett M. O. and Allen-King R. M. (2003). A controlled field experiment on groundwater contamination by a multicomponent DNAPL: dissolved-plume retardation. Journal of Contaminant Hydrology, 66, 117-146.

Rivett M. O., Feenstra S. and Cherry J. A. (2001). A controlled field experiment on groundwater contamination by a multicomponent DNAPL: creation of the emplacedsource and overview of dissolved plume development. Journal of Contaminant Hydrology, 49, 111-149.

Rivett M. O., Lerner D. N., Lloyd J. W. and Clark L. (1990). Organic contamination of the Birmingham aquifer. UK Journal of Hydrology, 113, 307-323.

Sawyer C. N., McCarty P. L. and Parkin G. F. (1994). Chemistry for Environmental Engineering, 4th edn, McGraw-Hill, New York.

Schnitzer M. and Khan S. U. (1972). Humic Substances in the Environment, Marcel Dekker, Inc., New York.

Smedley P. L. and Kinniburgh D. G. (2001). Source and behaviour of arsenic in natural waters, Report United Nations Synthesis on Arsenic in Drinking Water.

Spliid N. H. and Køppen B. (1998). Occurrence of pesticides in Danish shallow groundwater. Chemosphere, 37(7), 1307-1316.

Sposito G. (1989). The Chemistry of Soils, OUP, New York.

Squillace P. J., Scott J. C., Moran M. J., Nolan B. T. and Kolpin D. W. (2002). VOCs, pesticides, nitrate, and their mixtures in ground-water used for drinking water in the United States. Environmental Science and Technology, 36, 1923-1930.

Tamaki S. and Frankenberger W. T. (1989). Environmental biochemistry of arsenic, Report San Joaquin Valley drainage program under U.S. Bureau of Reclamation, San Joaquin Valley Drainage Program, Sacramento-CA.

Toccalino P. L., Normal J. E. and Scott J. C. (2012). Chemical mixtures in untreated water from public-supply wells in the U.S. - occurrence, composition, and potential toxicity. Science of the Total Environment, 431, 262-270.

US EPA (2007). Monitored Natural Attenuation of Inorganic Contaminants in Ground Water Volume 2 Assessment for Non-Radionuclides Including Arsenic, Cadmium, Chromium, Copper, Lead, Nickel, Nitrate, Perchlorate, and Selenium, EPA/600/R-07/140.

Van Wezel A., Puijker L., Vink C., Versteegh A. and de Voogt P. (2009). Odour and flavour thresholds of gasoline additives (MTBE, ETBE and TAME) and their occurrence in Dutch drinking water collection areas. Chemosphere, 76, 672-676.

Vithanage M. and Bhattacharya P. (2015). Fluoride in the environment: sources, distribution and defluoridation. Environmental Chemistry Letters, 13, 131-147.

Vogel T. M., Criddle C. S. and McCarty P. L. (1987). Transformations of halogenated aliphatic compounds. Environmental Science and Technology, 21, 722-736.

Welch A. H., Watkins S. A., Helsel D. R. and Focazio M. F. (2000). Arsenic in groundwater resources of the United States, Report U.S. Geological Survey Fact Sheet.

WHO (2004). Guidelines for Drinking-water Quality: Recommendations, Report WHO, 3rd edn, vol. 1, Geneva. 
18 Filtration Materials for Groundwater: A Guide to Good Practice

WHO (2006). Protecting groundwater for health: managing the quality of drinking-water sources. Report WHO Drinking-water Quality Series.

Wiedemeier T. H., Rifai H. S., Newell C. J. and Wilson J. T. (1999). Natural Attenuation of Fuels and Chlorinated Solvents in the Subsurface, John Wiley \& Sons, New York.

Williams W. M., Holden P. W., Parsons D. W. and Lorber M. W. (1988). Pesticides in Ground Water Data Base, Interim Report, US EPA, Office of Pesticide Programs, Washington, DC.

Yan-Chu H. (1994). Arsenic distribution in soils. In: Arsenic in The Environment. Part I: Cycling and Characterization, J. O. Nriagu (ed.). John Wiley \& Sons, New York, pp. 17-51. 


\section{Chapter 2}

\section{Filtration materials for groundwater treatment}

\section{Natalia Klymenko}

Professor, A.V. Dumansky Institute of Colloid and Water Chemistry National Academy of Science of Ukraine, Department of sorption and biology of water treatment, Kyiv, Ukraine; nklymenko00@gmail.com

Ivan Kozyatnyk

Post-Doc, Umeå University, Department of Chemistry, Umeå, Sweden; koziatnik@gmail.com

\subsection{INTRODUCTION}

On the composition and type of groundwater pollution are divided into chemical (organic and inorganic), biological, radioactive and thermal. Chemical contamination of groundwater is the most common and difficult to remove. We will focus in this section on the removal from groundwater of chemical (organic and inorganic) and radioactive contamination.

Depending on the type of activity and composition of the waste number and type of polluting chemicals can be extremely wide. Industrial wastes can contaminate aquifers with inorganic (iron, zinc, chromium, cooper, heavy metals, sulphates, chlorides, cyanides, thiocyanates) and organic (phenols, aldehydes, chlorine, arsenic, fluorine, nitrogen substituted compounds, oil products) pollutants. Iron, manganese, arsenic, boron, fluoride are main natural sources of interstratal artesian water contamination.

In this section, we will estimate the characteristic, barrier capabilities, conditions, limitation and the prospects of this materials application based on the principles of their work. 


\subsection{EXTRACTION OF IONS OF TOXIC METALS FROM GROUNDWATER BY SORBENTS, ION EXCHANGERS}

Improvement of methods for sorptive extraction of toxic metal ions by functionalizing the synthetic and natural sorbents guarantees a high efficiency treatment of polluted water. The specified functionalization is achieved by using different organic and inorganic reagents that form stable complex compounds with metals (Pavlovic et al. 2009; Goncharuk et al. 2011).

In recent time, the extraction of toxic metal ions from water has involved the use of synthetic organic-inorganic layered double hydroxides (LDH) or hydrotalcites built of brucite-like layers. The use of synthetic magnesiumaluminium hydrotalcites functionalized by anions of nitrilitriacetic (NTA) and diethylenetriaminepentaacetic (DTPA) acids was proposed in paper (Liang et al. 2010). A sorbent based on zinc-aluminum LDH intercalated by anions of ethylene diamine tetracidic acid (EDTA) was proposed for effective extraction of $\mathrm{Cu}$ (II), $\mathrm{Ni}$ (II) and $\mathrm{Co}$ (II) from aqueous solutions, while the same sorbent intercalated by DTPA was proposed for extraction of $\mathrm{Pb}$ (II) (Puzyrnaya et al. 2014).

Zeolites are a common type of sorbents for extraction of ions of heavy metals from polluted water. Zeolites are referred to the group of aluminosilicates having the crystalline lattice formed by tetrahedrons $\left[\mathrm{SiO}_{4}\right]^{4-}$ and $\left[\mathrm{AlO}_{4}\right]^{5-}$ united by their common vertexes into a three-dimensional frame.

The filter charged with zeolite material consisting of calcium heulandite $\mathrm{Ca}\left[\mathrm{Al}_{2} \mathrm{Si}_{7} \mathrm{O}_{18}\right] \cdot 6 \mathrm{H}_{2} \mathrm{O}$ and rock impurities in the form of potassium feldspar $\mathrm{AlSi}_{3} \mathrm{O}_{8}$ ensures the efficiency of polluted water treatment from $\mathrm{Ni}^{2+}, \mathrm{Cu}^{2+}$, and $\mathrm{Zn}^{2+}$ ions equal to 89,86 , and $85 \%$, respectively, at the linear filtering velocity of $1.5 \mathrm{~m} \mathrm{~h}^{-1}$ and the average zeolite size range equal to 1-3 $\mathrm{mm}$ (Filatova et al. 2014).

The removal of iron from water involves the use of filtering media of a wide spectrum of different materials. They include the crushed anthracite or Purolite grade of size $0.6-1.2,0.8-2$ and $1.5-3 \mathrm{~mm}$ and quartz sands, hydroanthracites of grades A, N and P; albitophyre; ceramic, glass and porcelain crumbles; sodiumpotassium aluminosilicates; polymer and mineral fibers based on basaltic rock formations; blast-furnace granulated slag; wastes of mining and concentration enterprises; different combinations of quartz sand, anthracite, pyrolusite and zeolite for charging of multilayer filters. The activated aluminosilicate sorbent Glint with alkaline properties is known for its high retention (Mamchenko et al. 2009).

For effective water treatment from iron and manganese it is proposed to use for media Ca-Mg carbonate rocks: dolomite $\mathrm{CaMg}\left(\mathrm{SiO}_{3}\right)_{2}$ and diopside $\mathrm{CaMg}\left(\mathrm{SiO}_{2}\right)$. The chemical activation of dolomite and diopside by a $2 \% \mathrm{HCl}$ solution and their thermal treatment in air at temperatures $500-900^{\circ} \mathrm{C}$ lead to significant improvement of sorption properties of sorbent. The dolomite modified in two stages by consecutive treatment with solutions of salts of divalent manganese and potassium permanganate demonstrated a high sorption activity (Mamchenko et al. 2008). 


\subsection{REACTIVE MATERIALS}

The combining of chemical and physical methods of water treatment, i.e. the use of granular media with catalytic properties can be a promising approach for the methods of water treatment from iron and manganese compounds. Higher manganese oxides $\left(\mathrm{Mn}_{3} \mathrm{O}_{4}\right.$ and $\left.\mathrm{MnO}_{2}\right)$ and iron oxides are catalysts of $\mathrm{Mn}(\mathrm{II})$ and $\mathrm{Fe}$ (II) oxidation. Ions of divalent manganese and iron are oxidized by atmospheric oxygen forming insoluble compounds and are removed by a medium layer. Such compounds - catalysts are called modified media (Birm, Greensand, Filox, Pyrolox and others) (Kaleta et al. 2007; Michel et al. 2008; Tarasevich et al. 2008; Jeż-Walkowiak et al. 2011; Mamchenko \& Chernova, 2012).

Birm is an aluminosilicate covered with manganese and iron oxides; it is not depleted in the process of impurity removal and is more cost-effective that other media. Deironing by using Birm is possible in the $\mathrm{pH}$ interval from 6.8 to 8.5. For effective demanganization the value of $\mathrm{pH}$ should be no less than 8 . If the water contains iron compounds, besides manganese, the value of $\mathrm{pH}$ should not exceed 8.5.

The working conditions in case of using Birm should be as follows:

- water $\mathrm{pH} 6.8-9.0$;

- content of free oxygen exceeds the content of iron by $15 \%$;

- content of $\mathrm{HCO}_{3}^{-}$anions is twice as large as the sum $\left(\left(\mathrm{SiO}_{4}\right)^{2-}+\mathrm{Cl}^{-}\right)$;

- oxidizability (chemical oxygen demand) is $<4 \mathrm{mg} \mathrm{L}^{-1}$;

- absence of hydrogen sulphide and petrochemicals;

- filtering rate in the service mode: $8.6-12 \mathrm{~m} \mathrm{~h}^{-1}$ and more at specific conditions; in the back-wash mode: $24-29 \mathrm{~m} \mathrm{~h}^{-1}$;

- content of iron is up to $10 \mathrm{mg} \mathrm{L}^{-1}$; organic matter is no more than 4-5 $\mathrm{mg} \mathrm{L}^{-1}$;

- alkalinity should be twice as large as the sum of sulphate and chloride concentrations;

- absence of hydrogen sulphide, polyphosphates and petrochemicals;

- chemical oxygen demand with permanganate is no more than 4-5 $\mathrm{mg} \mathrm{L}^{-1}$;

- Birm is not recommended for use in the presence of hydrogen sulfide and sulfides;

- concentration of free chlorine is no less than $0.5 \mathrm{mg} \mathrm{L}^{-1}$ (higher concentrations substantially reduce the Birm activity and can deplete the catalytic coating of pellets;

- height of the filtering layer is $75-90 \mathrm{~cm}$;

- extension of the layer is $35-50 \%$;

- maximum water temperature is $38^{\circ} \mathrm{C}$.

Physical properties of sorbent Birm ensure high quality filtering, while the filter can be easily cleaned from retained particles by using back-wash. Birm can be used in both the pressurized and non-pressurized water treatment systems. Unlike other filtering media, Birm does not require any chemical reagents for its regeneration 


\section{Filtration Materials for Groundwater: A Guide to Good Practice}

and needs only periodic washing. It is a solid material with long service life in a wide temperature range.

Alyans-Neva Company (Russia) developed a catalytically active filtering material $(\mathrm{MZhF})$ that ensures an effective operation at the iron and manganese concentrations in water of up to 50 and $2 \mathrm{mg} \mathrm{L}^{-1}$, respectively. The raw material for production of $\mathrm{MZhF}$ is the rock of sedimentary formation, the composition of which includes a mixture of $\mathrm{Al}, \mathrm{Ca}, \mathrm{Fe}, \mathrm{Mn}$, and $\mathrm{Si}$ minerals. Table 2.1 presents comparative characteristics of different sorbents-catalysts for water treatment from iron and manganese ions.

The groundwater treatment from manganese compounds required of developing a technology for producing the sorbent-catalyst based on the manganese carbonateand-oxide ore burned and modified by manganese salts. The test of efficiency of the manganese ion removal from groundwater using the specified sorbent revealed that at the linear filtering velocity of $2.83 \mathrm{~m} \mathrm{~h}^{-1}$ and the height of the sorbentcatalyst layer equal to $0.56 \mathrm{~m}$ the volume of treated water during each filter cycle (having duration $65 \pm 3$ hours) amounted to $7000 \mathrm{~L}$. The manganese concentration in treated water amounted to $0.078 \mathrm{mg} \mathrm{L}^{-1}$ at the time of breakthrough. The regeneration of filtering medium was performed by the back-wash with initial water at the flow rate of $300 \mathrm{~L} \mathrm{~h}^{-1}$ during $30 \mathrm{~min}$ (Mamchenko et al. 2012).

Modification of the sorbent - catalyst greensand made it possible to obtain a novel sorbent LIGS suitable for the removal of fluoride from water. LIGS (lanthanumimpregnated greensand) was prepared by thermally impregnating lanthanum onto greensand at $950^{\circ} \mathrm{C}$. It exhibited higher fluoride removal capacity than most other conventionally used sorbents.

LIGS could efficiently remove fluoride from water with various initial fluoride concentrations to permissible limits. More than $90 \%$ of fluoride was found to be removed within 240 min with respect to normally occurring initial fluoride values of $10 \mathrm{mg} \cdot \mathrm{L}^{-1}$. Though most ions did not cause strong interference, the competition for fluoride sorption onto LIGS was evident on the part of anions, nitrates, and bicarbonates (Vivek Vardhan \& Srimurali, 2015).

For effective use of natural sorbents it is expedient to modify them using the organic and inorganic complexing substances for ensuring their high selectivity with regard to ions of heavy metals (Ghoul et al. 2003; Gao et al. 2006; Liu, 2007; de Paiva et al. 2008; Jung et al. 2008).

The high efficiency of using montmorillonite with sorbed-on-its-surface polyethyleneimine (Mt-PEI) for the removal of ions of uranium, $\mathrm{Cu}(\mathrm{II}), \mathrm{Cd}(\mathrm{II})$, $\mathrm{Pb}(\mathrm{II}), \mathrm{Zn}(\mathrm{II}), \mathrm{Co}(\mathrm{II})$, and $\mathrm{Ni}(\mathrm{II})$ was shown in papers (Goncharuk et al. 2010, 2011). The adsorption capacity of modified montmorillonite rises according to the following sequence: $\mathrm{Cu}$ (II) $>\mathrm{Pb}$ (II) $>\mathrm{Ni}$ (II) $\geq \mathrm{Zn}$ (II) $>\mathrm{Co}$ (II) $\geq \mathrm{Cd}$ (II). Such composite sorbent is reasonably promising for the treatment of water with $\mathrm{pH}$ in the interval 3-7.

The maximum sorption of metals on the composite sorbent observed from $263.16 \mu \mathrm{mol} \mathrm{g}^{-1}$ for $\mathrm{Cu}(\mathrm{II})$ to 53.36 for $\mathrm{Cd}(\mathrm{II})$. These results exceed the sorption on unmodified montmorillonite by a factor of 6 and 2, respectively. 
Filtration materials for groundwater treatment

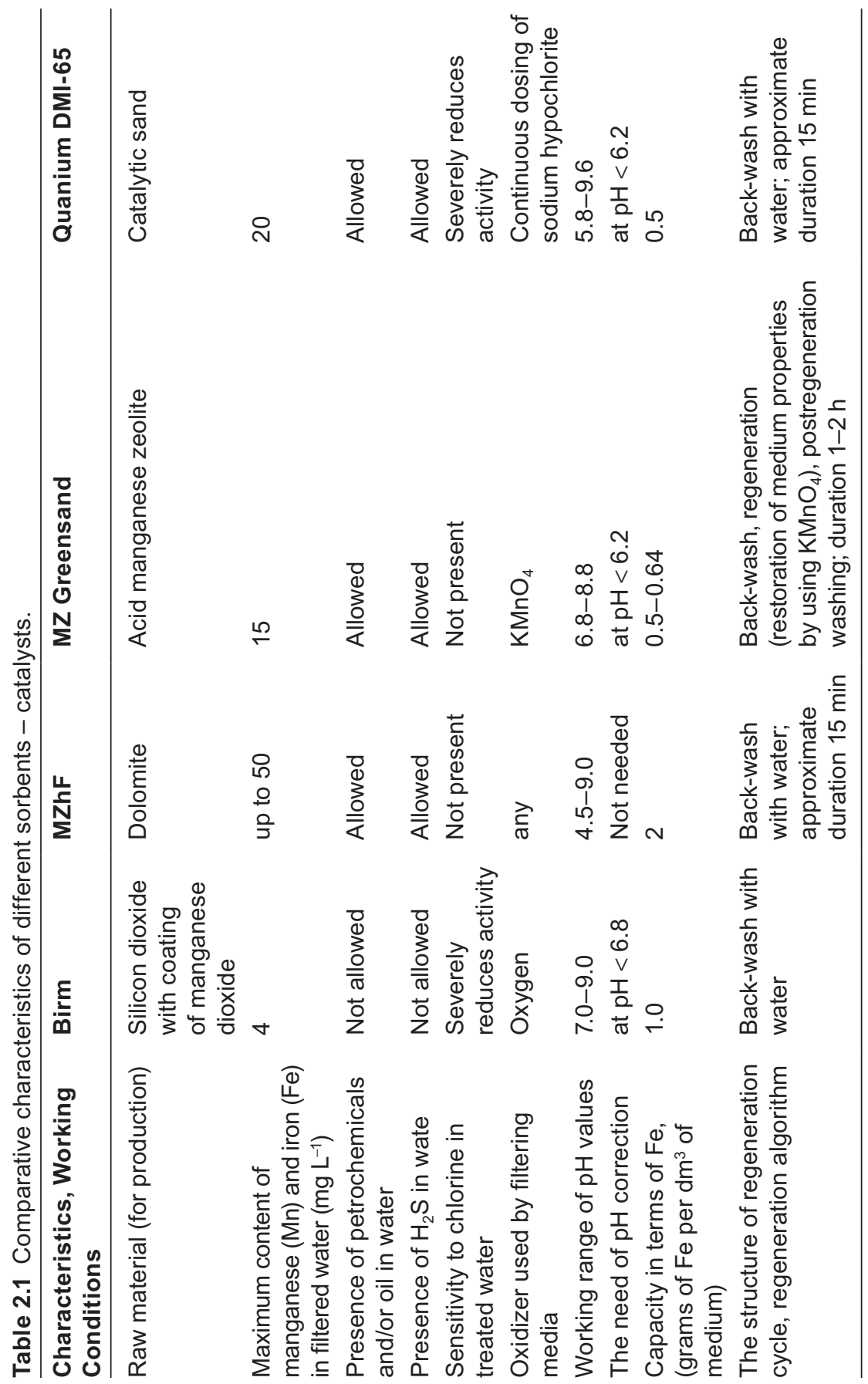




\section{Filtration Materials for Groundwater: A Guide to Good Practice}

Nanotechnology has been identified as a technology that could play an important role in resolving or reducing many of the problems involving water purification and quality (Bottero et al. 2006). Nanotechnology includes the development and use of materials, devices, and systems at the level of atoms and molecules, cutting across disciplines such as chemistry, physics, biology, engineering, and materials science (Masciangioli \& Zhang, 2003). Nanomaterials range from 1 to $100 \mathrm{~nm}$, and often exhibit novel and significantly changed physical, chemical, and biological properties. Such changes result from their structure, larger surface area per unit of volume, and quantum effects that occur at the nanoscale. Furthermore, nanotechnology has been identified as a technology that will play an important role in resolving or reducing many of the problems involving water purification and quality (Bottero et al. 2006). Many promising nanotechnologies already exist that can be applied to water treatment technology. For example, carbon nanotubes can effectively remove humic substances (Hyung \& Kim, 2008). However, the current cost of carbon nanotubes prevents their use for large-scale water treatment applications. The discharge of nanotubes into the environment and their exposure to people are another major concern (Upadhyayula et al. 2009). Furthermore, (Elliott et al. 2009) the pesticide lindane can be effectively degraded with zerovalent iron nanoparticles. There is still a need to develop a low-cost technology that effectively removes pollutants from water without releasing nanoparticles into the environment. One promising technology impregnates nanoparticles into sorbents. Impregnated sorbents are cheaper than free nanoparticles, but special attention needs to be paid to leaching of nanoparticles from the sorbents by monitoring the toxicity of the treated water.

Iron is the fourth most abundant element in the earth's crust. Over the last decade, a great deal of research has been focused on the removal of contaminants using zero-valent iron (ZVI) because ZVI is non-toxic, abundant, cheap, easy to produce, and its reduction process requires little maintenance. Because ZVI is a reactive metal with standard redox potential $\left(E_{0}=-0.44 \mathrm{~V}\right)$, it is an effective reductant when reacting with oxidized contaminants such as $\mathrm{Cr}(\mathrm{VI})$. The removal mechanism of contaminants by ZVI concerns the directional transfer of electrons from ZVI to the contaminants, transforming the contaminants into non-toxic or less toxic species. On the other hand, ZVI can degrade and oxidize a series of organic compounds in the presence of dissolved oxygen. In the last ten years, the adaptation of nano ZVI (nZVI) to remove many kinds of contaminants has received increasing attention due to its higher surface area and higher reactivity than ZVI (Fu et al. 2014). nZVI in remediation of contaminated groundwater or wastewater is limited due to its lack of stability, easy aggregation, and difficulty in separating nZVI from the treated solution. To address these issues, nZVI supported on solid porous materials (e.g., carbon, resin, bentonite, kaolinite, and zeolite) have been used to remove different contaminants. Immobilizing nZVI particles on supporting materials for contaminant removal not only provides an easy operation but also maintains the excellent reduction capabilities of nZVI. For 
example, nZVI supported on ordered mesoporous carbon has been synthesized to reduce nitrobenzene, a method that has increased removal efficiency compared with carbon and nZVI alone (Ling et al. 2012). At least one study (Zhu et al. 2009) has demonstrated the removal of arsenic from water using nano zero-valent iron on activated carbon.

\subsection{THE USE OF PRODUCTION WASTES IN GROUNDWATER TREATMENT}

The production wastes can be used as sorbents for the removal of organic and inorganic pollutants from groundwater.

It was established in paper (Khobotova et al. 2011) that the use of ferronickel production sludge as a sorbent involved the need and expediency of its chemical activation by acid or alkali. The sorption capacity of slag is determined by its high content of dioxide $\mathrm{CaMgSi}_{2} \mathrm{O}_{6}$ in amorphous state (53\%). Given the acidic and alkaline activations, the highest values of exchange capacity are reached at temperature $20^{\circ} \mathrm{C}$ and $70-80^{\circ} \mathrm{C}$, respectively. The acidic activation is more efficient.

Perspective sorbent for ground water purification from different types of pollutants is special reprocessed red mud which is a by-product of bauxite processing via the Bayer process. Red mud presents a promising application in water treatment for removal of toxic heavy metal and metalloid ions, inorganic anions such as nitrate, fluoride and phosphate, as well as organics including dyes, phenolic, compounds and bacteria (Wang et al. 2008) Sorbent from red mud after treatment with $0.05 \mathrm{M} \mathrm{L}^{-1} \mathrm{HCl}$ exhibited advanced application potential due to lower alkalinity and content of water soluble ions. However, chemical and mineral composition of red mud samples from various locations differ significantly, thus acid treatment should be optimized for each samples (Smičiklas et al. 2014).

It was established that moistened mixtures of red mud and $8 \%(\mathrm{~W} / \mathrm{W}) \mathrm{CaSO}_{4}$ form aggregates which are stable in aqueous media. The red mud mixtures aggregates had maximum capacities for $\mathrm{Cu}^{2+}, \mathrm{Zn}^{2+}, \mathrm{Ni}^{2+}$ and $\mathrm{Cd}^{2+}$ of 19,$72 ; 12,59$; 10,95 and $10,57 \mathrm{mg} \mathrm{g}^{-1}$ respectively.

When effluent from an urban sewage treatment plant was percolated through red mud aggregates packed into columns, purification efficiencies to $\mathrm{P}, \mathrm{Ni}^{2+}, \mathrm{Cu}^{2+}$ and $\mathrm{Zn}^{2+}$ were 100, 100, 68 and 56\% respectively.

Aggregated red mud is suitable for treatment of ground water and wastewater, in particular those principal contaminants are $\mathrm{P}$ or heavy metals (López et al. 1998; Liu et al. 2011). Activated red mud can be used as an effective and low cost adsorbent for the treatment of waters contaminated with $\mathrm{Pb}$ (II) ions (Sahu et al. 2013). The sample of sorbent prepared by heating red mud at $700^{\circ} \mathrm{C}$ for $2 \mathrm{~h}$, exhibited of the maximum removal of phosphate (99\%). This occurred at $\mathrm{pH} 7,0$ and $25^{\circ} \mathrm{C}$ with initial phosphate concentration of $155 \mathrm{mg} \mathrm{P} \cdot \mathrm{L}^{-1}$ (Li et al. 2006).

A possibilities of fluoride removal from aqueous solution using original and $\mathrm{HCl}$-activated red mud forms were investigated. The maximum removal of fluoride 
adsorption capacity was obtained at $\mathrm{pH} 5.5$. At a $\mathrm{pH}$ above 5.5 fluoride removal decreases sharply because of stronger competition with hydroxide ions on the adsorbent surface. The maximum adsorption capacity obtained was $0.33 \mathrm{mmol} \mathrm{g}^{-1}$ (Çengeloğlu et al. 2002).

It is shown investigation of nitrate removal using red mud and $\mathrm{HCl}$-activated red mud (ARM) that adsorption capacity of the original and ARM was found to be 1.86 and $5.86 \mathrm{mmol} \mathrm{NO}_{3}{ }^{-} \mathrm{g}^{-1}$; red mud, respectively (Cengeloglu et al. 2006).

Table 2.2 summarizes the adsorption capacity of various metal ions on differently acidified red muds, where RM is red mud which is activated by $\mathrm{HCl}$, was treated by $\mathrm{H}_{2} \mathrm{O}_{2}$ and then treated at $500^{\circ} \mathrm{C}$ or is mixed with $\mathrm{CaSO}_{4}$.

Efforts have also been made to convert red mud into a low-cost adsorbent for phenol and its derivates from water. The experiments demonstrated that phenol removal was constant in a wide $\mathrm{pH}$ range of $1-9$ and it took $10 \mathrm{~h}$ to reach equilibrium (Tor et al. 2006). The red mud was employed for the removal of several chlorophenol compounds from wastewater. The results showed that 2,4-dichlorophenol and 4-chlorophenol were sorbed by the red mud up to 94-97\%, while the removal of 2-chlorophenol and phenol was up to $50-81 \%$.

\subsection{BIOLOGICAL ACTIVE MEDIA}

The removal of iron from water on filtering media is associated with the development of biological activity on sorbent grains (Mamchenko et al. 2009). This is determined by the ability of iron bacteria to maintain the progress of complex chemical reactions without any energy consumption and without any use of reagents. The profuse growth of iron bacteria is observed in water with iron concentration in the range from 10 to $30 \mathrm{mg} \mathrm{L}^{-1}$. However, the experience has shown that their growth is possible even at the iron concentration as small as onehundredth of the above specified values. The biological method of iron removal from water makes use of three groups of ferrobacteria: thread (Leptothrix ochracea, Crentotrix polyspora), stalked (Jallionella ferruginea) and true (Eubacteriajes) bacteria. The conditions of their existence differ in terms of temperature (from $10-15$ to $\left.20-25^{\circ} \mathrm{C}\right), \mathrm{pH}(6-8$, sometimes $2-4)$, the presence of oxygen dissolved in water, oxidation-reduction potential $(100-400 \mathrm{mV}), \mathrm{Fe}^{2+}$ concentration $(0.1-$ $30 \mathrm{mg} \mathrm{L}^{-1}$ ), organic substances, and salinity (up to $1 \mathrm{~g} \mathrm{~L}^{-1}$ ). Ferrobacteria play a catalytic role speeding up the iron oxidation by dissolved oxygen. In case of using the biomass of ferrobacteria, oxidation products are characterized by higher density as compared to iron (III) hydroxide. For the treatment of groundwater with enhanced iron content, carbonate hardness and specific microbial contamination, a process flow diagram was proposed that included: three-stage water aeration, twostage filtering in Aquazur-type plants with sand medium where the microorganism immobilization occurs; secondary two-stage aeration; post-treatment of water with lime milk, and sodium hypochlorite. The specified plants ensure obtaining of water with iron concentration $\leq 0.03 \mathrm{mg} \mathrm{L}^{-1}$ (Sanchez \& Burbano, 2006). 


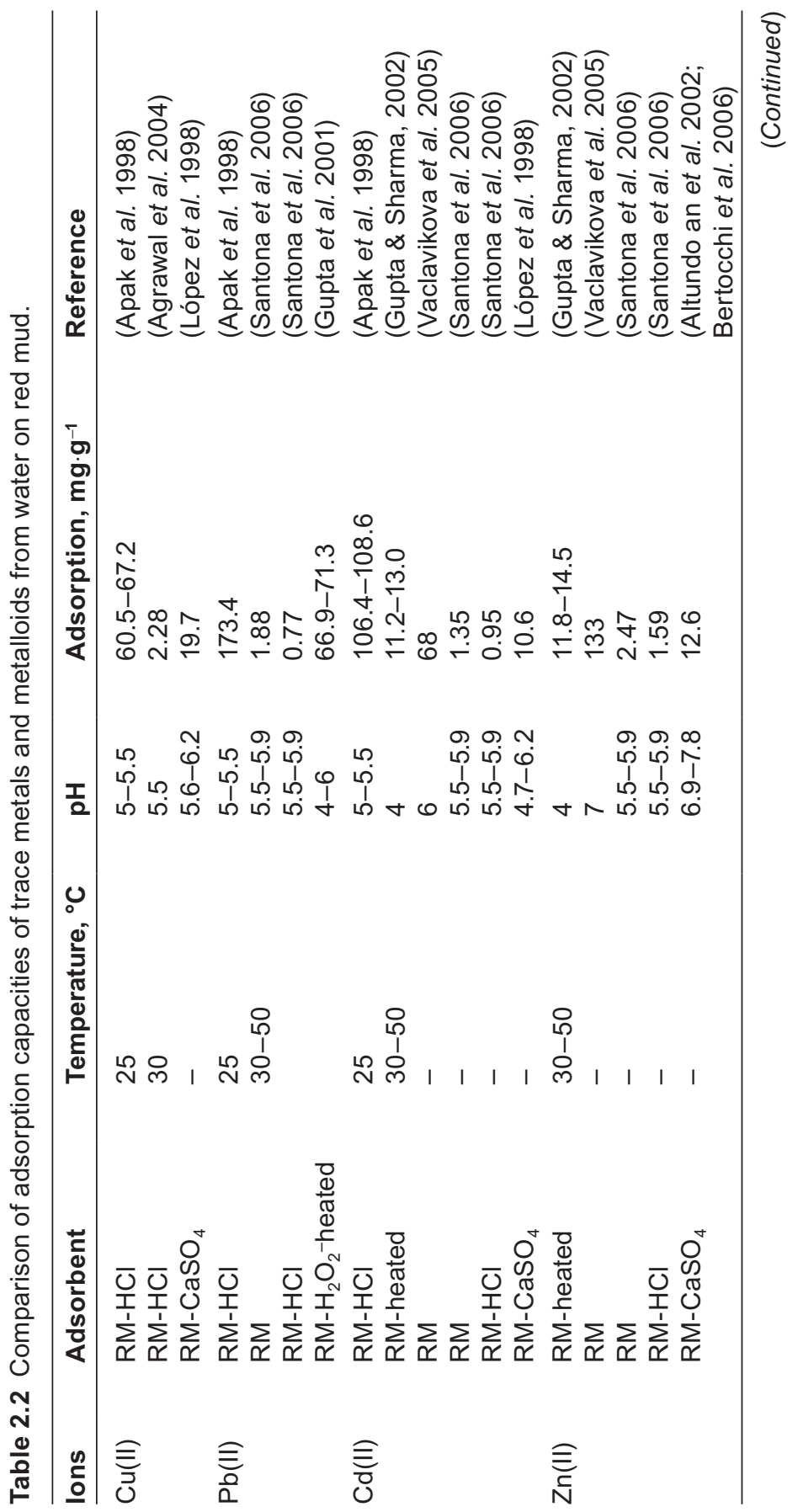




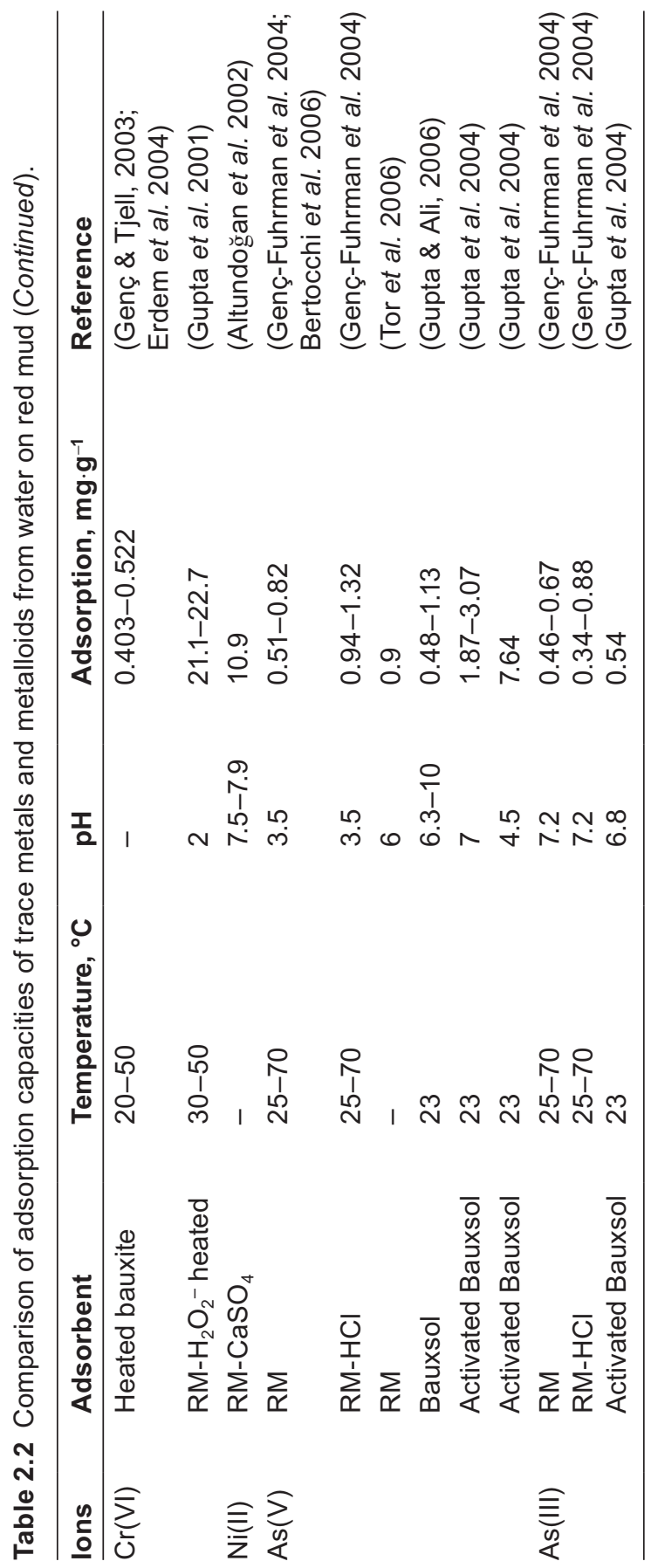


The full-scale implementation of the aeration and multistage filtration (MSF) technology using two filters (up flow roughing filter (URF) and slow sand filter (SSF)) revealed that in the effluent the values of total removal of manganese and iron were $89 \%$ and $92 \%$, respectively. Turbidity, colour and faecal coliforms were also removed by $97 \%, 58 \%$ and $100 \%$, respectively. In case of oxidation with aeration and MSF the literature review indicates the predominance of filtration mechanisms and biological activity. Bacteria are capable of contributing to oxidation of the iron and manganese present in the water and facilitating their removal by filtration units. Good results were obtained at the filtration rate of 0.48-0.55 $\mathrm{m} \mathrm{h}^{-1}$ for URF filter and $0.15 \mathrm{~m} \mathrm{~h}^{-1}$ for the flow filter (Sanchez \& Burbano, 2006).

Biosorbent from the sea plant wrack possessing a high adsorption capacity in its initial state (after drying and cleaning) or after chemical modification (phosphorating, borating, and others) is proposed for the heavy metal removal from water. During the removal of heavy metals the $\mathrm{pH}$ value of treated water should be maintained at the level of 5-7 (Hofmann et al. 2005).

The application of biosorption using the phytopathogenic bacteria Xanthomonas campestris immobilized on fibrous carriers or activated sludge is a promising technique for the treatment of uranium-containing water. Sorption of uranium (VI) on bacteria X. Campestris is characterized by a complex nature with clearly pronounced maximum in the region of $\mathrm{pH} 4-6$. The maximum attained values of uranium sorption amount to $50 \mathrm{mg} \mathrm{g}^{-1}$ of dry biomass. In the case of uranium sorption by the biomass of bacteria Pseudomonas aeruginosa, the sorption value can reach $100 \mathrm{mg} \mathrm{g}^{-1}$ of dry biomass (Puzyrnaya et al. 2014). The use of immobilized activated sludge as a biosorbent in bioreactor with fibrous carrier of the circulation type makes it possible to achieve the degree of treatment from uranium (VI) $>95 \%$ at the initial uranium concentration of $20 \mathrm{mg} \mathrm{L}^{-1}$ (Kornilovich et al. 2001).

Depending on the metal and microorganism the binding of metal by biomass can proceed in two ways. The first way is biosorption; this mechanism is determined by the ability of specific biomolecules (living or dead biomass) to bind and concentrate individual ions or molecules from water (Volesky, 2007). A more complex phenomenon is bioaccumulation; it is based on metabolic activity of cells and occurs in accordance with the mechanism of active transport that is a function of only living cells (Davis et al. 2003).

Certain biosorbents are capable of concentrating a large spectrum of metals, while other sorbents are strictly specific in regard to only one metal. Ionic exchange plays the main part in the process of sorption. The main ion-exchange centres are as follows: acetamide, phosphate, sulfhydryl, carboxyl, amino and amido groups. The amount of metal bound by the surface of cells in a number of cases exceeds the stoichiometric ratios (Fein et al. 1997; Zouboulis et al. 2004). Similar groups interact with metals in cytoplasmic membrane. One of the manifestations of protection from toxic metals by microorganisms is the formation of substances that bind metals forming low-toxic compounds. Different high- and low-molecular 
compounds, including peptides and hydrogen sulfide released by certain bacteria and algae, and also polysaccharides of capsules bind large amounts of metals (Anand et al. 1996; Prado Acosta et al. 2005).

The selection of microorganism, the biomass of which could be used as a biosorbent of metal ions should be performed with due regard for the safety of microorganism for the environment. Gram-positive bacteria that are referred to GRAS-organisms are good biosorbents from the viewpoint of their environmental compatibility and human safety since the majority of them are nonpathogenic and nontoxic (Prado Acosta et al. 2005). Owing to the thickness of their cell wall the gram-positive bacteria are stable and relatively insensitive to the environmental effects.

With due regard for the above mentioned, cells of Bacillus polymyxa with their high capability to intensive synthesis of polysaccharides have a good potential for biosorption of metals. The removal of metals $\mathrm{Ca}, \mathrm{Fe}, \mathrm{Cu}, \mathrm{U}(\mathrm{VI}), \mathrm{Sr}, \mathrm{Cr}(\mathrm{VI})$ and $\mathrm{Cr}$ (III) is possible by using cells of B. Polymyxa (Anand et al. 1996; Philip \& Venkobachar, 2001; Prado Acosta et al. 2005; Shevchuk \& Klimenko, 2009; Shevchuk et al. 2010). The living cells not only accumulate $\mathrm{Cr}(\mathrm{VI})$, but also reduce it to $\mathrm{Cr}(\mathrm{III})$; while the dead biomass of $B$. Polymyxa is only capable of $\mathrm{Cr}(\mathrm{VI})$ biosorption. From the viewpoint of using the microbial mass as a sorbent for water treatment from metals and radionuclides, it is more promising to use such microorganisms that interact with metals via biosorption rather than bioaccumulation.

It is known that SSF filters reduce the bacteria content, cloudiness and organic level in water. It was shown (Rao et al. 2013) that small additions of bentonite clay to SSF filter enhanced its ability of contaminant removal from groundwater at the bentonite content of $10 \%$.

In the absence of bentonite additions the filter was unable to retain nitrate ions during filtration. Table 2.3 demonstrates the effects of bentonite addition to SSF.

Table 2.3 shows that additions of bentonite to SSF cause it to retain cationic and anionic contaminants in addition to bacterial contaminants. Interestingly, the BASSF specimen was able to reduce the nitrate concentration of the groundwater sample from the initial value of $288 \mathrm{mg} \mathrm{L}^{-1}$ to the average value of $92 \mathrm{mg} \mathrm{L}^{-1}$ and of the nitrate spiked solution from $298 \mathrm{mg} \mathrm{L}^{-1}$ to the average value of $145 \mathrm{mg} \mathrm{L}^{-1}$. In comparison, the SSF specimen was unable to remove nitrate even after the passage of 10 litters of nitrate spiked solution.

Granular active carbon (GAC) is granular media was amenable to microbial colonization that could grow into significant biomass or biofilm. This naturally occurring active biofilm is capable of processing and biodegrading a significant fraction of entrapped waterborne nutrients in the GAC pores, dissolved organic matter (DOM) adsorbed to the GAC surfaces and other contaminants, minerals and microorganisms contained is source water (Klimenko et al. 2002b; Simpson, 2008). Biofilm provide a habitat for microbiota that graze on associated organics. Biodegradation of pollutants occurs at specifies rates which are a function 
of prevailing environmental factors such as availability of nutrients, oxygen concentration, $\mathrm{pH}$ value, concentration and bioavailability of contaminants (Rattier et al. 2014). As consistent with (Klimenko et al. 2002a) the BAC process is considering as a subsequent combination of the following stages:

Table 2.3 Ion retention by BASSF* and SSF specimens.

\begin{tabular}{|c|c|c|c|}
\hline \multirow[t]{3}{*}{ Species } & Mass Permeated & Mass Retained & \multirow[b]{2}{*}{$\%$ Retained } \\
\hline & $\mathbf{m g}$ & & \\
\hline & \multicolumn{3}{|c|}{$\begin{array}{l}\text { BASSF Specimen Permeated with } \\
\text { Contaminated Groundwater }\end{array}$} \\
\hline Sodium & 2100 & 895 & 43 \\
\hline Calcium & 1192 & 738 & 62 \\
\hline Magnesium & 510 & 275 & 54 \\
\hline Potassium & 954 & 567 & 59 \\
\hline Bicarbonate & 5588 & 3151 & 56 \\
\hline Nitrate & 2838 & 1912 & 67 \\
\hline Chloride & 3824 & 2525 & 66 \\
\hline Sulphate & 951 & 532 & 56 \\
\hline \multirow[t]{3}{*}{ Nitrate } & \multicolumn{3}{|c|}{ SSF Specimen permeated with nitrate spiked solution } \\
\hline & 3206 & 0 & 0 \\
\hline & \multicolumn{3}{|c|}{ BASSF Specimen permeated with nitrate spiked solution } \\
\hline Nitrate & 819 & 384 & 47 \\
\hline
\end{tabular}

${ }^{*}$ Bentonite amended slow sand filter

- The primary physical adsorption of molecules in the porous structure of the AC.

- A certain part of the adsorbed molecules is modified and then desorbed from the porous structure of the $\mathrm{AC}$ due to the effect of the concentration gradient.

- The desorbed molecules of the substrate pass though the biofilm, where they undergo complete or partial mineralization.

- A new portion of the adsorbate molecules (substrate) passes through the biofilm towards the AC from aqueous solution.

- Some portions of the adsorbate molecules passing through the biofilm from aqueous solution are degraded (modified) by it.

- An additional amount of the adsorbate molecules can adsorb on the AC surface. This amount is equivalent to the bioregenerated AC surface.

The amount of the adsorbed molecules under the adsorption equilibrium $\left(N_{\text {mol ads }}\right)$ per time unit is equal to the desorbed one $\left(N_{\text {mol des }}\right)$ :

$\Sigma N_{\text {molads }}=\Sigma N_{\text {moldes }}$ 


\section{Filtration Materials for Groundwater: A Guide to Good Practice}

On the contrary, one can assume that the amount of the desorbed molecules with biosorption is lower than that of the adsorbed ones. It results in their complete or partial biodegradation when these pass through the biofilm. Thus, the following diffusion of the adsorbate molecules from aqueous solution through the biofilm into the porous structure of the $\mathrm{AC}$ is feasible:

$$
\Sigma N_{\text {mol ads }}>\Sigma N_{\text {moldes }}
$$

According to the hypothesis we offer, the driving forces of the process are the concentration gradient and the differences in the Gibbs free energy between the adsorbate molecules in solution $\left(-\Delta G_{a d s}^{0}\right)$ and the modified adsorbate molecules $\left(-\Delta G_{\text {mod }}^{0}\right)$ inside the porous structure.

A criterion in estimating the contribution of biodegradation into the biosorption process consists of comparing the equilibrium and dynamic adsorptive capacities of the AC. The equilibrium adsorptive capacity (EAC) is determined under the static conditions in the absence of an effect of the kinetic factors. Under the dynamic conditions, there is an essential effect of the kinetic and dynamic factors of the process on the dynamic adsorptive capacity (DAC). DAC is almost always lower therefore than equilibrium adsorption if there are no accompanying processes of biodegradation.

Thus the comparisons between the equilibrium and dynamic adsorptive capacities can be used for evaluation a contribution of the biodegrading compononent in cumulative effect.

The dependence of the biological component contribution into a general efficiency of a biosorption process as is follows the higher the change in the Gibbs free energy $\left(-\Delta G_{a d s}^{0}\right)$, the lower the contribution of the biological oxidation into a biosorption process (Smolin et al. 2009a; Smolin et al. 2009b; Klymenko et al. 2010).

\subsection{REFERENCES}

Agrawal A., Sahu K. K. and Pandey B. D. (2004). A comparative adsorption study of copper on various industrial solid wastes. AIChE Journal, 50(10), 2430-2438.

Altundoğan H. S., Altundoğan S., Tümen F. and Bildik M. (2002). Arsenic adsorption from aqueous solutions by activated red mud. Waste Management, 22(3), 357-363.

Anand P., Modak J. M. and Natarajan K. A. (1996). Biobeneficiation of bauxite using Bacillus polymyxa: Calcium and iron removal. International Journal of Mineral Processing, 48(1-2), 51-60.

Apak R., Güçlï K. and Turgut M. H. (1998). Modeling of Copper(II), Cadmium(II), and Lead(II) adsorption on red mud. Journal of Colloid and Interface Science, 203(1), 122-130.

Bertocchi A. F., Ghiani M., Peretti R. and Zucca A. (2006). Red mud and fly ash for remediation of mine sites contaminated with $\mathrm{As}, \mathrm{Cd}, \mathrm{Cu}, \mathrm{Pb}$ and $\mathrm{Zn}$. Journal of Hazardous Materials, 134(1-3), 112-119. 
Bottero J. Y., Rose J. and Wiesner M. R. (2006). Nanotechnologies: Tools for sustainability in a new wave of water treatment processes. Integrated Environmental Assessment and Management, 2(4), 391-395.

Çengeloğlu Y., Kır E. and Ersöz M. (2002). Removal of fluoride from aqueous solution by using red mud. Separation and Purification Technology, 28(1), 81-86.

Cengeloglu Y., Tor A., Ersoz M. and Arslan G. (2006). Removal of nitrate from aqueous solution by using red mud. Separation and Purification Technology, 51(3), 374-378.

Davis T. A., Volesky B. and Mucci A. (2003). A review of the biochemistry of heavy metal biosorption by brown algae. Water Research, 37(18), 4311-4330.

de Paiva L. B., Morales A. R. and Valenzuela Díaz F. R. (2008). Organoclays: Properties, preparation and applications. Applied Clay Science, 42(1-2), 8-24.

Elliott D. W., Lien H. L. and Zhang W. X. (2009). Degradation of lindane by zero-valent iron nanoparticles. Journal of Environmental Engineering, 135(5), 317-324.

Erdem M., Altundoğan H. S. and Tümen F. (2004). Removal of hexavalent chromium by using heat-activated bauxite. Minerals Engineering, 17(9-10), 1045-1052.

Fein J. B., Daughney C. J., Yee N. and Davis T. A. (1997). A chemical equilibrium model for metal adsorption onto bacterial surfaces. Geochimica et Cosmochimica Acta, 61(16), 3319-3328.

Filatova E. G., Pomazkina O. I. and Pozhidaev Y. N. (2014). Development of the zeolitesorption process for electroplating wastewater treatment. Journal of Water Chemistry and Technology, 36(6), 303-308.

Fu F., Dionysiou D. D. and Liu H. (2014). The use of zero-valent iron for groundwater remediation and wastewater treatment: A review. Journal of Hazardous Materials, 267, 194-205.

Gao B., An F. and Liu K. (2006). Studies on chelating adsorption properties of novel composite material polyethyleneimine/silica gel for heavy-metal ions. Applied Surface Science, 253(4), 1946-1952.

Genç-Fuhrman H., Tjell J. C. and McConchie D. (2004). Adsorption of arsenic from water using activated neutralized red mud. Environmental Science \& Technology, 38(8), 2428-2434.

Genç H. and Tjell J. C. (2003). Effects of phosphate, silicate, sulphate, and bicarbonate on arsenate removal using activated seawater neutralised red mud (bauxsol). In: XII International Conference on Heavy Metals in the Environment, C. Boutron and C. Ferrari (eds), 1st edn. Grenoble, pp. 537-540.

Ghoul M., Bacquet M. and Morcellet M. (2003). Uptake of heavy metals from synthetic aqueous solutions using modified PEI - silica gels. Water Research, 37(4), 729-734.

Goncharuk V. V., Puzyrnaya L. N., Pshinko G. N., Bogolepov A. A. and Demchenko V. Y. (2010). The removal of heavy metals from aqueous solutions by montmorillonite modified with polyethylenimine. Journal of Water Chemistry and Technology, 32(2), 67-72.

Goncharuk V. V., Puzyrnaya L. N., Pshinko G. N., Bogolepov A. A. and Demchenko V. Y. (2011). Comparative research of removing ions of heavy metals from aqueous solutions with montmorillonite modified by polyethylenimine. Journal of Water Chemistry and Technology, 33(3), 147-152.

Gupta V. K. and Ali I. (2006). Removal of 2,4-dinitrophenol from wastewater by adsorption technology: A batch and column study. International Journal of Environment and Pollution, 27(1-3), 104-120. 


\section{Filtration Materials for Groundwater: A Guide to Good Practice}

Gupta V. K., Ali I. and Saini V. K. (2004). Removal of chlorophenols from wastewater using red mud: An aluminum industry waste. Environmental Science \& Technology, 38(14), 4012-4018.

Gupta V. K., Gupta M. and Sharma S. (2001). Process development for the removal of lead and chromium from aqueous solutions using red mud - an aluminium industry waste. Water Research, 35(5), 1125-1134.

Gupta V. K. and Sharma S. (2002). Removal of Cadmium and Zinc from aqueous solutions using red mud. Environmental Science \& Technology, 36(16), 3612-3617.

Hofmann J., Wecks M., Freier U., Pausch N. and Gemende B. (2005). Eelgrass is used as bioadsorbent for removing heavy metals from aqueous solutions, e.g. aqueous extract of soil, sediment, sludge or industrial residue, ground, waste or waste tip percolation water or process liquor. In: Google Patents.

Hyung H. and Kim J. H. (2008). Natural organic matter (NOM) adsorption to multi-walled carbon nanotubes: Effect of NOM characteristics and water quality parameters. Environmental Science and Technology, 42(12), 4416-4421.

Jeż-Walkowiak J., Dymaczewski Z. and Sozański M. M. (2011). Parametry technologiczne procesu filtracji pospiesznej wód podziemnych przez złoża oksydacyjne i chemicznie nieaktywne. Inżynieria Ekologiczna, 112-121.

Jung Y., Kim S., Park S.-J. and Kim J. M. (2008). Preparation of functionalized nanoporous carbons for uranium loading. Colloids and Surfaces A: Physicochemical and Engineering Aspects, 313-314, 292-295.

Kaleta J., Papciak D. and Puszkarewicz A. (2007). Klinoptylolity i diatomity w aspekcie przydatnoœci w uzdatnianiu wody i oczyszczaniu œcieków. Gospodarka Surowcami Mineralnymi, 23(3), 21-34.

Khobotova E. B., Graivoronskaya I. V., Datsenko V. V. and Baumer V. N. (2011). The assessment of the possibility of using slag in producing ferronickel for purification of wastewaters. Journal of Water Chemistry and Technology, 33(4), 261-265.

Klimenko N., Winther-Nielsen M., Smolin S., Nevynna L. and Sydorenko J. (2002a). Role of the physico-chemical factors in the purification process of water from surfaceactive matter by biosorption. Water Research, 36(20), 5132-5140.

Klimenko N. A., Marutovsky R. M., Pidlisnyuk V. V., Nevinnaya L. V., Smolin S. K., Kohlmann J. and Radeke K. H. (2002b). Biosorption processes for natural and wastewater treatment - part 1: Literature review. Engineering in Life Sciences, 2(10), 317-324.

Klymenko N. A., Kozyatnyk I. P. and Savchyna L. A. (2010). Removing of fulvic acids by ozonation and biological active carbon filtration. Water Research, 44(18), 5316-5322.

Kornilovich B. Y., Gvozdyak P. I., Pshinko G. N., Spasenova L. N., Koval'chuk I. A. and Safronova V. G. (2001). Treatment of uranium containing waters by immobilized microorganisms. Khimiya i Tekhnologiya Vody, 23(5), 545-551.

Li Y., Liu C., Luan Z., Peng X., Zhu C., Chen Z., Zhang Z., Fan J. and Jia Z. (2006). Phosphate removal from aqueous solutions using raw and activated red mud and fly ash. Journal of Hazardous Materials, 137(1), 374-383.

Liang X., Hou W., Xu Y., Sun G., Wang L., Sun Y. and Qin X. (2010). Sorption of lead ion by layered double hydroxide intercalated with diethylenetriaminepentaacetic acid. Colloids and Surfaces A: Physicochemical and Engineering Aspects, 366(1-3), 50-57.

Ling X., Li J., Zhu W., Zhu Y., Sun X., Shen J., Han W. and Wang L. (2012). Synthesis of nanoscale zero-valent iron/ordered mesoporous carbon for adsorption and synergistic reduction of nitrobenzene. Chemosphere, 87(6), 655-660. 
Liu P. (2007). Polymer modified clay minerals: A review. Applied Clay Science, 38(1-2), 64-76.

Liu Y., Naidu R. and Ming H. (2011). Red mud as an amendment for pollutants in solid and liquid phases. Geoderma, 163(1-2), 1-12.

López E., Soto B., Arias M., Núñez A., Rubinos D. and Barral M. T. (1998). Adsorbent properties of red mud and its use for wastewater treatment. Water Research, 32(4), 1314-1322.

Mamchenko A. V. and Chernova N. N. (2012). Determination of basic parameters affecting the water treatment from manganese compounds on the sorbent-catalyst. Journal of Water Chemistry and Technology, 34(5), 234-239.

Mamchenko A. V., Kiy N. N., Chernova L. G. and Misochka I. V. (2008). The investigation of the impact of the modification methods of natural dolomite on water demanganesation. Journal of Water Chemistry and Technology, 30(4), 191-196.

Mamchenko A. V., Misochka I. V., Deshko I. I., Kiy N. N. and Gerasimenko N. G. (2009). Priority areas in the technology of purifying underground waters of iron. Journal of Water Chemistry and Technology, 31(1), 34-45.

Mamchenko A. V., Savchenko O. A., Chernova N. N. and Yakupova I. V. (2012). Purification of undergound waters of manganese compounds using a natural sorbent-catalyst. Journal of Water Chemistry and Technology, 34(4), 169-174.

Masciangioli T. and Zhang W. X. (2003). Environmental technologies at the nanoscale. Environmental Science and Technology, 37(5), 102A-108A.

Michel M., Kiedryńska L. and Tyszko E. (2008). Badania skuteczności odmanganiania wody podziemnej na modyfikowanym chalcedonicie i masie katalitycznej Purolite MZ-10. Ochrona Środowiska, 30(3), 15-20.

Pavlovic I., Pérez M. R., Barriga C. and Ulibarri M. A. (2009). Adsorption of $\mathrm{Cu}^{2+}, \mathrm{Cd}^{2+}$ and $\mathrm{Pb}^{2+}$ ions by layered double hydroxides intercalated with the chelating agents diethylenetriaminepentaacetate and meso-2,3-dimercaptosuccinate. Applied Clay Science, 43(1), 125-129.

Philip L. and Venkobachar C. (2001). An insight into the mechanism of biosorption of copper by Bacillus polymyxa. International Journal of Environment and Pollution, 15(4), 448-460.

Prado Acosta M., Valdman E., Leite S. G. F., Battaglini F. and Ruzal S. M. (2005). Biosorption of copper by paenibacillus polymyxa cells and their exopolysaccharide. World Journal of Microbiology and Biotechnology, 21(6-7), 1157-1163.

Puzyrnaya L. N., Kosorukov A. A., Pshinko G. N. and Demchenko V. Y. (2014). Removal of toxic metals from aqueous solutions by layered double hydroxides. Journal of Water Chemistry and Technology, 36(2), 62-69.

Rao S. M., Malini R., Lydia A. and Lee Y. (2013). Contaminants removal by bentonite amended slow sand filter. Journal of Water Chemistry and Technology, 35(1), 23-29.

Rattier M., Reungoat J., Keller J. and Gernjak W. (2014). Removal of micropollutants during tertiary wastewater treatment by biofiltration: Role of nitrifiers and removal mechanisms. Water Research, 54, 89-99.

Sahu M. K., Mandal S., Dash S. S., Badhai P. and Patel R. K. (2013). Removal of Pb(II) from aqueous solution by acid activated red mud. Journal of Environmental Chemical Engineering, 1(4), 1315-1324.

Sanchez L. D. and Burbano L. M. (2006). Iron and manganese removal by multi-stage filtration (MSF). In: Recent Progress in Slow Sand and Alternative Biofiltration Processes, R. Gimbel, N. Graham and R. Collins (eds), IWA Publishing, London, pp. 389-393.

Santona L., Castaldi P. and Melis P. (2006). Evaluation of the interaction mechanisms between red muds and heavy metals. Journal of Hazardous Materials, 136(2), 324-329. 
Shevchuk I. A. and Klimenko N. A. (2009). Biological features of sorption of U(VI) and strontium ions by Bacillus polymyxa IMV 8910 cells. Journal of Water Chemistry and Technology, 31(5), 324-328.

Shevchuk I. A., Klimenko N. A. and Stavskaya S. S. (2010). Sorption of ions of U(VI) and strontium by biosorption based on Bacillus polymyxa IMV 8910 in aqueous systems. Journal of Water Chemistry and Technology, 32(3), 176-181.

Simpson D. R. (2008). Biofilm processes in biologically active carbon water purification. Water Research, 42(12), 2839-2848.

Smičiklas I., Smiljanić S., Perić-Grujić A., Šljivić-Ivanović M., Mitrić M. and Antonović D. (2014). Effect of acid treatment on red mud properties with implications on $\mathrm{Ni}(\mathrm{II})$ sorption and stability. Chemical Engineering Journal, 242, 27-35.

Smolin S. K., Nevinnaya L. V., Sinel'nikova A. V., Titarenko N. Z. and Klimenko N. A. (2009a). Features of biosorption filtration of aromatic compounds in water treatment. Journal of Water Chemistry and Technology, 31(4), 256-263.

Smolin S. K., Shvidenko O. G., Zabneva O. V., Sinel'nikova A. V., Nevinnaya L. V. and Klimenko N. A. (2009b). Removal of aromatic compounds from water on biologically activated carbon. Journal of Water Chemistry and Technology, 31(6), 367-372.

Tarasevich Y. I., Polyakov V. E., Ivanova Z. G. and Krysenko D. A. (2008). Obtaining and properties of clinoptilolite modified by manganese dioxide. Journal of Water Chemistry and Technology, 30(2), 85-91.

Tor A., Cengeloglu Y., Aydin M. E. and Ersoz M. (2006). Removal of phenol from aqueous phase by using neutralized red mud. Journal of Colloid and Interface Science, 300(2), 498-503.

Upadhyayula V. K. K., Deng S., Mitchell M. C. and Smith G. B. (2009). Application of carbon nanotube technology for removal of contaminants in drinking water: A review. Science of The Total Environment, 408(1), 1-13.

Vaclavikova M., Misaelides P., Gallios G., Jakabsky S. and Hredzak S. (2005). Removal of cadmium, zinc, copper and lead by red mud, an iron oxides containing hydrometallurgical waste. In: Studies in Surface Science and Catalysis, C. C. Aldo Gamba and C. Salvatore (eds), Elsevier, pp. 517-525.

Vivek Vardhan C. M. and Srimurali M. (2015). Defluoridation of drinking water using a novel sorbent: Lanthanum-impregnated green sand. Desalination and Water Treatment, 57(1), 1-11.

Volesky B. (2007). Biosorption and me. Water Research, 41(18), 4017-4029.

Wang S., Ang H. M. and Tadé M. O. (2008). Novel applications of red mud as coagulant, adsorbent and catalyst for environmentally benign processes. Chemosphere, 72(11), $1621-1635$.

Zhu H., Jia Y., Wu X. and Wang H. (2009). Removal of arsenic from water by supported nano zero-valent iron on activated carbon. Journal of Hazardous Materials, 172(2-3), $1591-1596$.

Zouboulis A. I., Loukidou M. X. and Matis K. A. (2004). Biosorption of toxic metals from aqueous solutions by bacteria strains isolated from metal-polluted soils. Process Biochemistry, 39(8), 909-916. 


\section{Chapter 3}

\section{Technologies for ground water treatment}


Downloaded from https://iwaponline.com/ebooks/book-pdf/651183/wio9781780407005.pdf

by IWA Publishing publications@iwap.co.uk 


\subsection{Pump-and-treat technologies}

\section{Arun Kumar Thalla*1, Devatha C. P.1 and Giuliano Crauss Daronco ${ }^{2}$}

${ }^{1}$ Department of Civil Engineering, NITK Surathkal, Mangalore - 575025, INDIA; revacp@gmail.com

2 Department of Physical Sciences and Engineering, Regional University of Northwestern Rio Grande do Sul (UNIJUI), BRAZIL; giuliano.daronco@ unijui.edu.br

${ }^{*}$ Corresponding author: thallpce@gmail.com

\subsubsection{INTRODUCTION}

In present scenario, the quality of ground water has drawn interest among people due to the awareness gained by them in the areas of surface water contamination and its adverse effects. About three decades ago, it was considered that groundwater was covered by natural filters and presumed to be safe. But groundwater as we are aware can be polluted by many ways viz. waste spills, dumps, penetration of landfill Leachate, leakages in sewer lines, mining works etc. Thus, the groundwater with dissolved chemicals need to be treated which is usually done by pumping the water to the surface and treating them appropriately based on the type and level of contamination this technique is popularly known as pump and treat technique. The pollutants can also be controlled by providing containment barriers that helps in arresting the movement of the polluted water from spreading to the nearby bore well, wetlands, aquifer or any other resources and then pumping out these pollutants from there.

Pump and treat technology involves the installation of wells, so that the water can be pumped out for treatment. The treatment technology can vary according to the type of contaminants present in the water. Suppose, if there is one particular contaminant then it may require simpler technique. But if groundwater is either 
highly polluted with single substance or contains heterogeneous substances then multiple techniques might be required to treat it.

The groundwater after treatment is checked against the regulatory standards and if the treated water satisfies the conditions/criteria, it can either be used to recharge ground water bodies, surface water streams or sent for further treatment. Also the filter media used for the treatment, any sludge or waste products obtained during the treatment process need to be managed carefully otherwise it will end up contaminating the site and ground water successively. Further, observation of extraction unit and treatment system has to be done periodically in order to make sure that the concentration of the plume decreases and it is not scattering. Figure 3.1.1 represents the pump and treatment system of an extraction well (US-EPA, 2012).

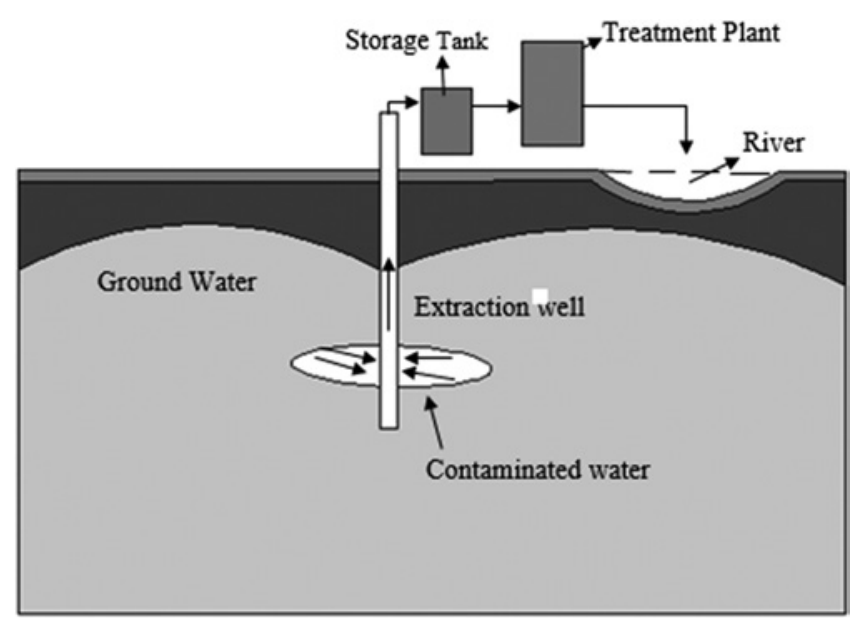

Figure 3.1.1 Simple pump and treat system.

The technology will survive for decades and the definite time required for the treatment will be subjected to the various factors such as

(1) Type and Concentration of pollutant.

(2) Extent of contamination or areal extent of the plumes.

(3) Flow path of contaminant.

(4) Type of soil/aquifer media

\subsubsection{SITE CHARACTERIZATIONS}

Pump and treat technique is suitable for treating waters which dissolve the impurities or contaminants in it. It strongly depends on hydrogeology and contaminant characteristics. Comprehensive characterization of the contaminated site plays 
a critical role in the effectiveness of the pump-and-treat technique (US-EPA, 1990; Changlin Huang \& Mayer, 1997). Steps involved in characterizations may include preliminary observation using geophysical instrument for borehole, cone penetration and sampling of both soils and groundwater. Recent advancement in sampling of soil using hollow stem auger, continuous core and ground water samples by direct push equipment without installing wells. Innovative method like vibratory drilling used to collect both soil cores and ground water may fasten the process of sampling and characterization. Sensitive bore hole flow meters that measure the vertical change in hydraulic conductivity is a recent development. Further, all these techniques will allow subsurface mapping with a detail which otherwise will be expensive if done using conventional drilling methods.

Site characterization helps in:

(1) Hydrogeological settings/data includes homogeneity of aquifer material, porosity, storage coefficient and hydraulic conductivity, data on recharge/ discharge area. Storage coefficient is less significant compared to hydraulic conductivity for long term pumping. If the aquifer encountered is heterogeneous, it hinders the process of plume movement. This information is required to examine the limit up to which the problem of tailing and rebound may occur.

(2) (a) Proper assessment of the type, extent and form of contaminant which in turn helps in understanding the containment in its physical phase (i.e., sorbed and aqueous phase for inorganic contaminants and gaseous phase for organic liquids) and capacity of spread between the plates. which are the essential parameters in deciding the effective treatment goals. Degree of uncertainty is high in estimating the pollutant characteristics because it depends on the source of pollution, data associated with the development of plume, reactive/non-reactive pollutant, dispersion/ diffusion characteristics and velocity of flow encountered.

(b) Contaminant chemistry may also complicate the remediation process because it may be organic or inorganic. If the pollutant involved is non-aqueous phase liquid (NAPL) like gasoline, it becomes complex for contaminant characterization. The nature of non-aqueous phase pollutant is immiscible and moves separately in water. So it moves along with the pressure gradients and gravity of ground water movement and in case of dense non-aqueous phase liquid (DNAPL) like chlorinated solvents, it move below the water table.

(3) Overall put together will have great influence on development of plume which is controlled by hydrogeology, flow dynamics and entrapment morphology.

But research studies revealed that for homogenous aquifer material and dissolved contaminants, this technique is highly preferred. So, ideal site for efficient use of pump and treat system is homogeneous, single layer with hydraulic conductivity 
more than $10^{-5} \mathrm{~cm} / \mathrm{s}$ (Mercer et al. 1990) from hydrogeology perspective. It is suitable for chemical/pollutants which have retardation coefficient less than 10 which means $10 \%$ of the contaminant plume should get dissolved in ground water at any given time from contaminant perspective.

Further the regular meeting with officials would be helpful to assure that investigation actions and outcome comply with the regulatory standards. This positive approach may inhibit delay in gaining the essential regulatory approvals. Site characterization could be done in an innovative way to obtain data in proficient and low cost manner.

The polluted sites could be characterized promptly with the help of push probes that are mounted on a vehicle and this method is a recent development in cone penetrometer and sensor technology. Pollutant concentration could be collected in situ and measurement of stratigraphic data and real time analysis could be done by the probe. Rearrangement could be done in the probe to collect groundwater, soil and gases for corresponding laboratory investigation. Computer simulated images about subsurface geologic characteristics can be obtained with the help of electrical resistance tomography, cross well and ground penetrating radar, high resolution seismic reflection, vertical induced profiling. Chemical tracers are also helpful in finding and quantifying the polluted area depending on their attraction to particular pollutant.

\subsubsection{TREATMENT METHODS}

Commonly adopted methods for treating ground water extracted through the method of pump and treat are

- Membrane filtration

- Forward Osmosis

- Nanotechnologies

- Electrocoagulation

- Electrodialysis

- Adsorption

- Chemical oxidation

- Metal precipitation

- Ion exchange

- UV treatment

- Biodegradation

\subsubsection{Membrane filtration}

Filtration process helps to remove the suspended and precipitated particles that have escaped the process of sedimentation or precipitation respectively, or the solids in order to safe guard the injection well from fouling. The filter media usually consists of anthracite, sand and any other media. Backwashing of the media should be done 
periodically in order to maintain the flow rate and efficiency of the filter media. The backwashed water could be directed for clarification process which then will remove the sludge. Figure 3.1.2 shows the membrane filtration of groundwater (GE Healthcare).

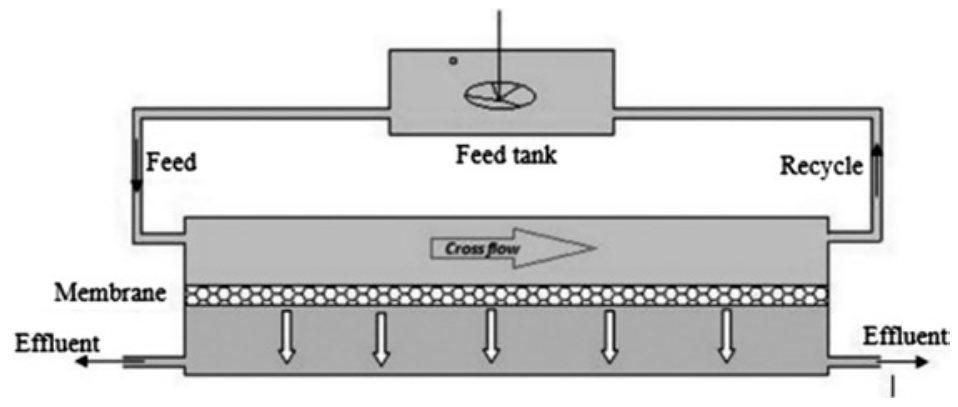

Figure 3.1.2 Membrane treatment.

Membrane treatment is the method of driving water through the membrane and the membrane behaves as a sieve which eliminates the pollutants present in the influent stream. The pores present in that membrane will usually fluctuate according to the type of pollutant that is present in the incoming water. Technologies like nano-filtration, ultra-filtration, micro-filtration, Forward Osmosis, hyper filtration or reverse osmosis have been used in the recent times to improve the effectiveness of the treatment technology. Table 3.1.1 shows the various technologies available in membrane treatment method (Suthan, 1999).

Table 3.1.1 Membrane technologies.

\begin{tabular}{ll}
\hline $\begin{array}{l}\text { Filtration } \\
\text { Technology }\end{array}$ & $\begin{array}{l}\text { Size Limit of } \\
\text { Contaminants, Solids }\end{array}$ \\
\hline Reverse osmosis & $<0.001 \mu \mathrm{m}$ \\
Nano filtration & $0.001-0.01 \mu \mathrm{m}$ \\
Ultrafiltration & $0.01-0.1 \mu \mathrm{m}$ \\
Microfiltration & $0.8-2.0 \mu \mathrm{m}$ \\
Conventional filtration & $1.0-2000 \mu \mathrm{m}$ \\
\hline
\end{tabular}

This technology works well individually also it can be processed as pretreatment in combination with other treatment methods. The different filtration technologies differ based on the size of the pores present in the filter media, weight of pollutants and solids that percolate through the medium. Different materials used, their type and resistance to fouling have been listed in Table 3.1.2 (Dietrich, 1995). 
Table 3.1.2 Materials used in membrane filtration.

\begin{tabular}{llll}
\hline Type & $\begin{array}{l}\text { Membrane Area/ } \\
\text { Unit Volume }\end{array}$ & $\begin{array}{l}\text { Fouling } \\
\text { Resistance }\end{array}$ & $\begin{array}{l}\text { Typical } \\
\text { Material }\end{array}$ \\
\hline Spiral-wound & Large & Good & Composite polyamide \\
Capillary & Medium to large & Poor & Polysulfone \\
Fine hollow fiber & Large & Poor & Polyanide \\
Tabular & Small & Excellent & Polysulfone \\
Flat sheet & Medium & Good & Polyolefin \\
\hline
\end{tabular}

One of the major disadvantages of this technique is that the materials which produce fouling condition should be removed periodically leading to stoppage of the treatment process temporarily. Failure of removal or improper monitoring may lead to damage of the media and it will reach a point where the entire media has to be replaced. The presence of fouling material in the system may hinder the treatment process.

\subsubsection{Forward osmosis}

Forward osmosis or osmosis is the transport of water from a low concentration solution to a higher one through a semipermeable membrane as shown in Figure 3.1.3. It can also be explained as the movement of water from a region of its higher concentration to a region of its lower concentration. This movement is also exhibited by the solutes in a direction opposite to that of water flow. However, their movement is restricted by the semipermeable membrane. Currently, the term "Forward osmosis" is being used to denote the osmosis process especially while referring to its engineering applications. This terminology also serves to distinguish it from the reverse osmosis process which is also related to the phenomenon of osmosis.

Osmotic pressure is not to be confused with a pressure within the system. It's rather the pressure required to stop the flow of water from feed side to draw side. If we apply a pressure equal to the osmotic pressure difference - to the draw side, the flow of water can be stopped. On further increasing the pressure, water starts flowing from draw side to feed side, which is termed as reverse osmosis process.

The first application of forward osmosis, as a physical phenomenon should have been for the pickling of foods. It was known that saline conditions were not favorable for microbes. The high salt concentration resulted in the dehydration or temporary inactivation of most pathogens. The engineering applications of the same were investigated as early as the mid-1970s (Achilli et al. 2010). Forward osmosis has been investigated for several engineering applications already. Major applications include separation processes such as desalination, wastewater 
treatment, concentrating landfill leachate and liquid food processing. In the separation applications mentioned above, the defective water is taken as the feed and a higher concentration solution is taken on the draw side. The draw solution draws pure water from the feed side which is then separated from the draw solution using suitable methods. In this context, forward osmosis can be considered simply as a pretreatment process before the actual separation process.

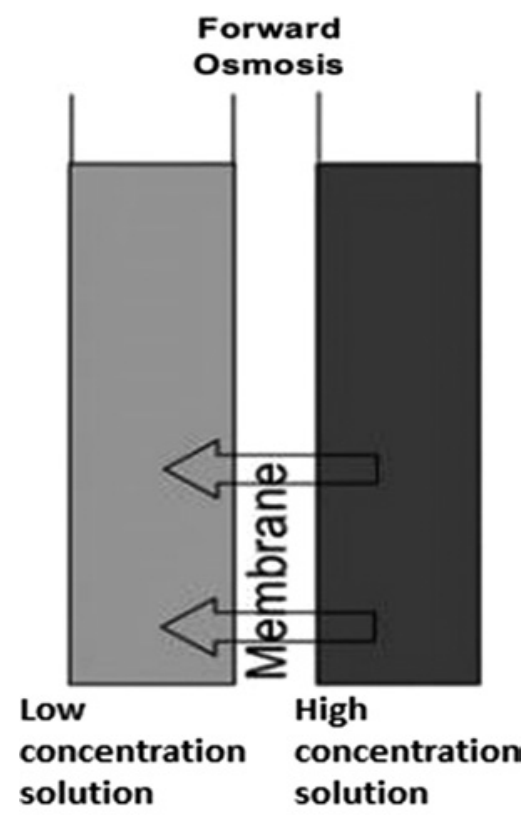

Figure 3.1.3 Diagrammatic representation of forward osmosis process.

As far as desalination or removal of dissolved salts from water are concerned, reverse osmosis is the most accepted method adopted. However this process is very costly since it involves the application of pressure on the draw side. Feed waters with higher salinity will require larger pressure application. Forward osmosis has several advantages over reverse osmosis process. It doesn't require application of pressure, rejects a wide range of solutes and the fouling tendency is also low in comparison. Although the forward osmosis process does not require any energy input, the extraction of pure water demands energy. In such applications, the main purpose of the process is to separate water from the impurities relying on the semipermeable nature of the membrane. Certain applications using forward osmosis has been creatively modified such that further extraction of water is not required. Emergency forward osmosis kits using sucrose as draw solute and fertilizer draw solutes for irrigation water (Phuntsho et al. 2011) are some examples. 
Though the forward osmosis defines a greener technology, its scalability needs to grow beyond the laboratory research levels before it can take the place of reverse osmosis. A number of researches have been conducted and is still being conducted revolving around various aspects of the technology including flux characterization, draw solutes and membranes. However, the key researches which would result in a breakthrough for the technology is the development of a suitable draw solute and membrane resulting in an appreciable flux and low reverse salt diffusion.

\subsubsection{Nanotechnologies}

In the field of Environmental engineering, nanotechnology provides potential materials, processes and devices with unique properties which could be incorporated in various environmental related applications towards removing contaminants, enhanced mobility in environmental media and desired application flexibility (Madhavi et al. 2013). The important property of nano materials i.e., large surface-to-volume ratio of nanomaterials can bring about surprising surface and quantum size effects. Nanoscale materials can either directly or indirectly improve the environment i.e., by direct use of nanomaterials to detect or reduce or stabilise the pollutant/contaminant or by indirect application of nanotechnological instruments to reduce the environmental pollution or to design cleaner industrial processes so as to produce environmental friendly products. Among all the environmental application of nanotechnology, remediation of contaminated groundwater using nanoscale zero valent iron (nZVI) is the most prominent example of rapidly emerging technology with considerable potential benefits. In addition to the environmental applications, nanotechnology has diverse application in water resource division.

Water resources planning aim mainly on the critical issue of protecting the water systems against hazardous chemical and biological contamination. Research is underway to use advance nanotechnology in water purification for safe drinking. Also nanofilters could be good option for remediation of groundwater as well as surface water contaminated with hazardous chemicals. Further for the identification of water borne contaminants, nanosensors can be developed. Desalination, method for removing salt, is an expensive method hence carbon nanotube membranes can be used as alternative so as to reduce desalination cost. Overall, nanotechnology has promising environmental and water resource applications and researches are carried to develop these fields of application.

Advances in nanoscale science and engineering suggest that many of the current problems involving water quality could be resolved or greatly diminished by using nano-absorbent, nanocatalysts, bioactive nanoparticles, nanostructured catalytic membranes, submicron, nanopowder, nanotubes, magnetic nanoparticles, granules, flake, high surface area metal particle supramolecular assemblies with characteristic length scales of 9-10 nm including clusters, micromolecules, 
nanoparticles and colloids have a significant impact on water quality in natural environment.

Although UV irradiation, aerosol technologies, lithography, laser ablation, ultrasonic fields, and photochemical reduction techniques have been used successfully to produce nanoparticles that can be used for the treatment of ground water contamination, they are remain expensive and involve the use of hazardous chemicals. Therefore, there is a significant interest in the development of environmentally friendly and sustainable methods that avoid the use of any toxic substance in the synthesis protocol. Kharissova et al. (2013) stated that the synthesis of such materials using environmentally friendly and biocompatible reagents could lower the toxicity of the resulting materials and the environmental impact of the by products.

Greener synthesis of nanoparticles is one such area where researchers are using biological systems mostly plants for nanoparticle synthesis as it is cost effective and environmnental friendly. Further, this technique does not require high pressure, energy, temperature or toxic chemicals as the conventional ways.

\subsubsection{Electrocoagulation}

Electrolysis is a process in which oxidation and reduction reactions take place when electric current is applied to an electrolytic solution. Electrocoagulation is based on dissolution of the electrode material used as an anode. This so-called "sacrificial anode" produces metal ions which act as coagulant agents in the aqueous solution in situ. At its simplest, an electrocoagulation system consists of an anode and a cathode made of metal plates, both submerged in the aqueous solution being treated as shown in Figure 3.1.4. The electrodes are usually made of aluminum, iron, or stainless steel (SS), because these metals are cheap, readily available, proven effective, and non-toxic. Thus they have been adopted as the main electrode materials used in EC systems. The electrodes produce metal hydroxides which destabilize pollutants present in the solution, allowing agglomeration and further separation from the solution by settling or floatation. Destabilization is achieved mainly by two important mechanisms i.e., charge neutralization of negatively charged colloids by cationic hydrolysis products and sweep flocculation where impurities are trapped and removed by the amorphous hydroxide precipitate produced. Recent application of Electrocoagulation is found in disinfection and eradication of biological species like algae, e-coli and also found effective in treating humic acids, natural organic matter, pesticide, micro-pollutants, boron, arsenic, chromium, cadmium, iron, cyanide, phosphate and mercury present in ground water. Electrocoagulation has been found fast, feasible, economic and ecological alternative in the treatment of ground water. As a by-product of this process, hydrogen gas can be produced which could be utilized to reduce energy demand. The disadvantage of the treatment would be disposal of the sludge generated as it contains the metal hydroxides (Kuokkanen et al. 2013). 


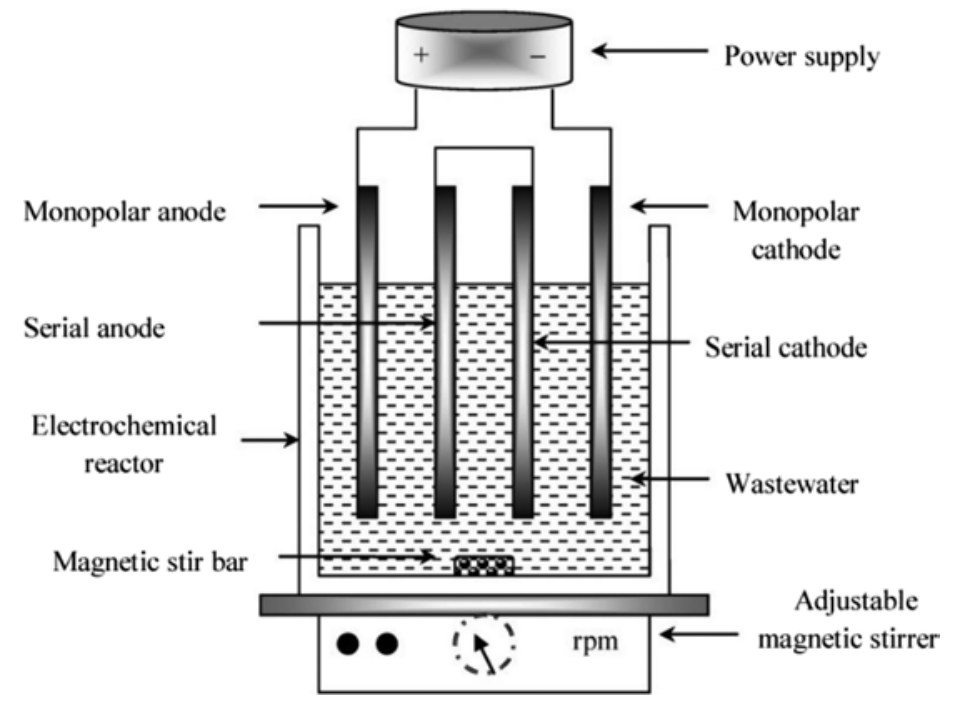

Figure 3.1.4 Electrocoagulation setup.

\subsubsection{Electrodialysis}

Electro dialysis reversal (EDR) is an advanced water treatment process based on electro-dialysis (ED). ED/EDR is based on the principles governing the behavior of an ionic solution when it is subject to direct current (DC) potential. In ED, alternating anion and Cation permeable membranes (called anion transfer and Cation transfer membranes) are placed in layers with an anode on one side of the assembly and a cathode on the other (Figure 3.1.5). When a current is applied to the system, water within one group of channels is "de-ionized". Cations migrate through the Cation transfer membrane towards the cathode, and the anions migrate through the anion transfer membrane towards the anode. In the adjacent channels, the membranes do not allow migration in the direction the ions are drawn (cations cannot migrate through the anion membrane and anions cannot migrate through the Cation membrane). Thus, alternating channels are formed of deionized product water and ion-rich concentrate stream. A conductivity monitor is installed in the outlet stream to open a product diversion valve arrangement that will send the product water to final storage if it meets the specified conductivity requirements. It is sent to waste via the Off Specification Product (OSP) line if the product water conductivity exceeds the maximum allowable conductivity determined by the system product water requirements. The EDR treatment concept is applied to the remediation of groundwater containing elevated chlorides and TDS to meet drinking water standards and reclamation of $80 \%$ of the produced water. Disadvantages of EDR treatment includes maintenance of membrane accrual, water sampling and monitoring costs, cleanup time (Roquebert et al. 2000). 


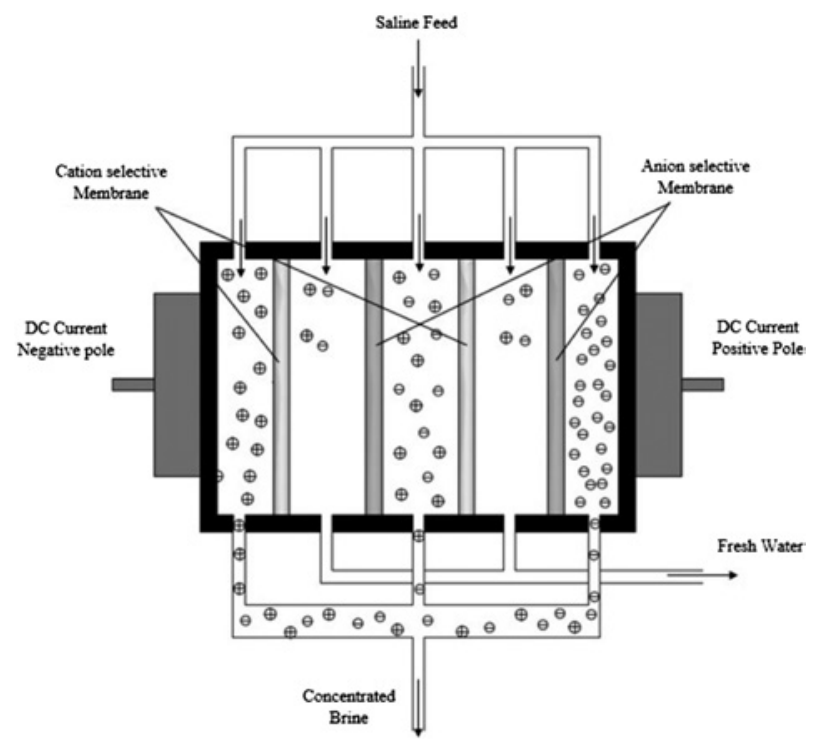

Figure 3.1.5 Electro-dialysis setup.

\subsubsection{Adsorption}

The pollutant can acquire positive, negative or neutral charge on its surface. Adsorbent should be chosen in such a way that it should get attached to adsorbate effectively. Dissolved substances can be removed by the process of adsorption and they act as adsorbate. Various adsorbents are being used these days to remove different kinds of pollutants. For example, fluoride could be removed by activated carbon, activated coconut shell, red mud, clay, and various low cost adsorbents (Mohapatra et al. 2009). Similarly, arsenic could also be removed by $\mathrm{Al}_{2} \mathrm{O}_{3}$, $\mathrm{Al}(\mathrm{OH})_{3}$, carbon, FeO, etc. (Yadanaparthi et al. 2009) could be used. Further adsorbents prepared from activated sludge, heat and acid activated Laterite soil grains etc. are also being extensively used as adsorbents for the removal of phosphorous and chromium (Shyama et al. 2015).

\subsubsection{Chemical oxidation}

When an oxidation of organic compound takes place, then the compound will be degraded into products with maximum oxygen or minimum hydrogen content. Oxidizing agents which are strong in nature can be used to synthesize the organic materials which are present in groundwater during pump and treat technology (Zeff et al. 1989). The most commonly used oxidizing agents are hydrogen peroxide and ozone. These agents can be used in combination with ultra-violet light to handle organic pollutants. Free radicals are formed during advanced oxidation process 
which uses ultraviolet light to boost ozone and hydrogen peroxide consumption. This advanced oxidation process is non-selective and non-specific. Chain reaction involves the formation of free radicals and stable species as shown in Figure 3.1.6 (Report On Technical Evaluations of Ozonation Technology, 2015).

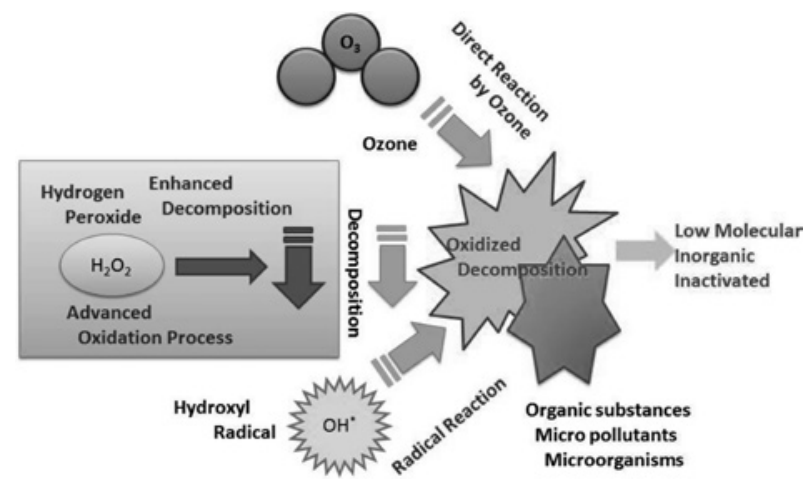

Figure 3.1.6 Advanced oxidation process with hydrogen peroxide.

\subsection{Ozone chemistry}

Ozonation is the process of oxidizing the contaminant into ionic form with the help of ozone. Hydrogen peroxide and permanganate are the two chemicals which plays a major role in the process of ozonation. Generally, ozone will be mixed with peroxide and permanganate and will be used for the oxidation process. For example, it helps to convert phenol into their ionic form (Qui et al. 1999). There are two ways by which the compound can get oxidized:

(1) Formation of intermediate ozonide compound by the interaction of $\mathrm{O}_{3}$ with unsaturated carbon bonds.

(2) Whereas, the compound other than carbon could be oxidized by hydroxyl radicals whichare formed as a result of the reaction ofozone with hydroxide ion or hydrogen peroxide (Hoigne \& Bader, 1976).

The following equations will explain the oxidation process (Beltran, 2003).

$$
\begin{aligned}
& \mathrm{O}_{3}+\mathrm{OH}^{-} \rightarrow \mathrm{O}_{2}^{--}+\mathrm{HO}_{2}^{-} \\
& \mathrm{H}_{2} \mathrm{O}_{2} \leftrightarrow \mathrm{HO}_{2}^{-}+\mathrm{H}^{+} \\
& \mathrm{O}_{3}+\mathrm{HO}_{2}^{-} \rightarrow \mathrm{OH}^{\bullet}+\mathrm{O}_{2}^{--}+\mathrm{O}_{2}
\end{aligned}
$$

The metals present in the soil also helps for the initiation of ozonation process. The production of hydroxyl radical during this process might be stimulated by constituents present in the soil such as organic matter, acids and alcohols. Also 
there are chances that process could be hindered by other common constituents such as carbonates and tertiary alcohols.

Carbonate and bicarbonate ions suppress the oxidation process by consuming hydrogen peroxide and ozone and hinder the effect caused by ultraviolet radiation thus water containing these ions demand high dosage of ultraviolet fluxes and oxidizers. Efficacy of Ultraviolet light also depends on colloids or suspended particles present in the water. More the colloidal/suspended particles, lesser is the efficiency as it scatters the UV light.

\subsubsection{Metal precipitation}

Precipitation involves usage of chemicals to dissolve the metals so that it could be easily removed in the form of sludge. This method is unlikely to precipitate organic metals and sometimes it could be obtained in the form of hydrous metal oxides. $\mathrm{pH}$ is to be adjusted for the effectiveness of the this method by adding acids or bases based on the requirement.

Metals in the groundwater could be precipitated as follows:

\subsection{Hydroxide precipitation}

In this process, the heavy metals can be eliminated by the addition of lime, caustic soda (Roh et al. 2000). The basic reaction relating precipitation of sulfide is as follows:

$$
\mathrm{Me}^{++}+2 \mathrm{OH}^{-} \leftrightarrow \mathrm{Me}(\mathrm{OH})_{2} \downarrow
$$

Advantages

(1) Ease of operation and $\mathrm{pH}$ control.

(2) This method incur low cost for operation.

Limitations

(1) Low metal precipitation will occur at $\mathrm{pH} 6$ and the sludge resolubilize if the $\mathrm{pH}$ reduces beyond 6 .

(2) Presence of cyanide or complex substances causes interference to the process.

(3) Hydroxide precipitates are difficult to dewater.

(4) This process is tedious if two or more metals are present and they have to be removed simultaneously which is not possible as hydroxides have different solubility for different metals.

\subsection{Sulfide precipitation}

Heavy metals could be separated from groundwater by means of sulfide precipitation (Miao et al. 2012). It can be done by adding sodium hydrosulfide and 
sodium sulfide in a soluble form. It can be examined using feedback control loop with the help of ion-specific electrodes. Excess sulfide reagent should not be added as it may leads to foul odor or the formation of $\mathrm{H}_{2} \mathrm{~S}$. The basic reaction relating precipitation of sulfide is as follows:

$$
\mathrm{Me}^{++}+\mathrm{S}^{--} \leftrightarrow \mathrm{MeS} \downarrow
$$

Advantages

(1) Metal of high degree contamination could be removed selectively and time consuming process.

(2) The sludge formed is denser than the sludge obtained from hydroxide process and leaching problem is avoided greatly.

(3) Presence of chelating agents and complex substances don't hinder the process.

Limitations

(1) Emission of $\mathrm{H}_{2} \mathrm{~S}$ gas which may lead to toxic environment.

(2) This method is complex and cost consuming when compared with hydroxide precipitation.

\subsection{Carbonate precipitation}

Sodium carbonate, which is commonly known as soda ash, is used for heavy metals precipitation (Patricia et al. 1999). It has following advantages over the conventional methods:

(1) This treatment doesn't require any change of $\mathrm{pH}$.

(2) Dense precipitate will be obtained.

(3) The sludge which was obtained through this process has good dewatering characteristics.

The general equation for carbonate precipitation could be written as follows

$$
\mathrm{Me}^{++}+\mathrm{CO}_{3}^{--} \leftrightarrow \mathrm{MeCO}_{3} \downarrow
$$

The metal precipitated in any of the above precipitation methods should be removed immediately. The efficiency of this technology depends on the density and size of the metal precipitates. The precipitates can be removed by means of coagulation with the help of commonly used coagulants like aluminium sulfate, ferric chloride, magnesium chloride, etc. it also leads to a disadvantage that adding coagulants will increase the sludge disposal costs.

\subsubsection{9 lon exchange}

Ion exchange is a method of replacing ions of one insoluble substance by ions of another resin in a solution (AFCEE/ERT, 2002). For instance, if $\mathrm{M}^{-} \mathrm{A}^{+}$substance 
is present in a solution, then that cation could be replaced with another cationic resin $\mathrm{B}^{+}$.

$$
\mathrm{M}^{-} \mathrm{A}^{+}+\mathrm{B}^{+} \leftrightarrow \mathrm{M}^{-} \mathrm{B}^{+}+\mathrm{A}^{+}
$$

Similarly, if $\mathrm{M}^{+} \mathrm{A}^{-}$substance is present in the solution, then that anion could be replaced with another anionic resin $\mathrm{B}^{-}$.

$$
\mathrm{M}^{+} \mathrm{A}^{-}+\mathrm{B}^{-} \leftrightarrow \mathrm{M}^{+} \mathrm{B}^{-}+\mathrm{A}^{-}
$$

The resin which was used as an exchanger could be prepared from organic, polymeric, inorganic materials. This exchange system contains small resin beads which makes resin bed. The bed diameter usually will be two to six feet and contains enormous amount of beads. Brine solution and exchanged resins will be the waste generated out of this technology and it requires proper treatment methods. This technology consists of three steps viz. adsorption, regeneration and rinse.

This technology can be used to remove acids, alkaline, organic and inorganic substances, charged particles and polar and bipolar substances.

\subsubsection{UV treatment}

The process of UV treatment depends on the factors such as design of equipment, type and concentration of contaminant type and dosage of oxidant and water quality parameters.

Total suspended solids, total dissolved solids, iron, hardness, COD, etc. could be removed by any pretreatment before undergoing UV treatment. Proper designing of equipment is required to achieve satisfactory performance of UV treatment (Robert, 1996).

The treatment could be either bench scale or pilot studies to understand the size and requirement of the system. The following features are necessary to make the UV treatment system work efficiently.

- Proper utilization of UV light energy and turbulent mixing should be there even at low flux rates.

- Feasibility for multipoint oxidant dosing system and continuous oxidant dosage adjustment.

- Availability of effective low maintenance quartz tube and reactor chamber wall cleaner.

- Afford space for serviceability and future expansion.

- Manufacturing and safety requirements should be met.

- UV lamp/power turn-down capability while maintaining constant UV density.

\subsubsection{Biodegradation}

Biological treatment of groundwater is not needed for all the cases. However, when leachate which originates from any waste dump/landfill leaks or wastewater 


\section{Filtration Materials for Groundwater: A Guide to Good Practice}

from in sewer line leaks to the subsurface then it might reach the aquifer and pollute the groundwater source. Such waters will require biological treatment in order to remove the organic constituents present in the aquifer (Taylor, 2015). Biological treatments include the use of bioaugmentation, bioventing, biosparging, bioslurping, and phytoremediation.

Biological processes like trickling filter, activated sludge process, rotating biological contactor (RBC), anaerobic digesters, fluidized bed reactors, and aeration lagoons are used for treatment of ground water when it has a considerable amount of organic matter. Suspended growth process like activated sludge process, requires operation attention to regulate the biomass. Therefore attached growth system has gained demand for ground water pump and treats technology. Activated sludge process that is designed for pump and treats technology is ineffective as organic constituent's concentrations are low for maintaining microbial population.

The frequently used bio-systems for treating groundwater these days are Movable media, submerged media bioreactor and fluidized bed bioreactor. Submerged fixed film reactor composes of plastic media immersed in water (Thalla et al. 2012). In order to provide oxygen, bubbled air is forced at the base of reactor. On continuous basis, the contaminated water is allowed to flow through the reactor (Figure 3.1.7). Proper selection of media, supply of nutrients and oxygen, Control of $\mathrm{pH}$ within the range is leads to increase in the efficacy of the system for biodegradation of carbon, nitrogen and phosphorous (Thalla et al. 2010).

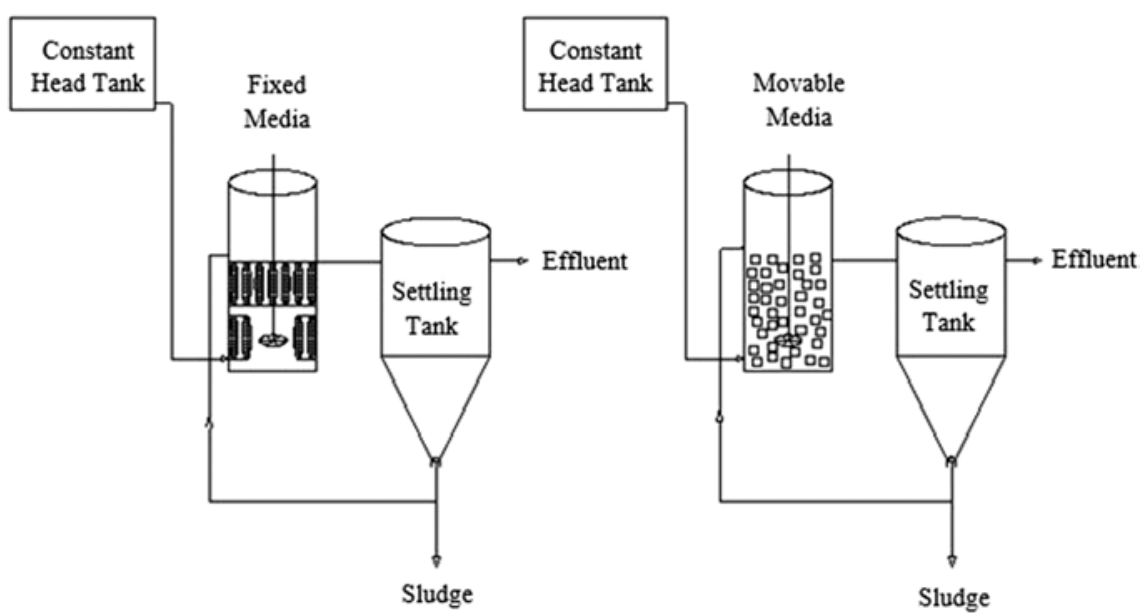

Figure 3.1.7 Fixed and Movable media bioreactor.

In fluidised bed reactor, the biomass available per unit reactor volume is more compared to any other suspended growth system. Microbes grow on the support media which is held in suspension by the flow. Drag forces caused by the 
fluid flow against the support media provide bed expansion. Increase in biomass thickness on the fluidized bed media, results in difference effective particle diameter and settling velocity. Design of reactor must be efficient to distribute and control the influent flow so that these density changes in bed media can be accounted for. Careful monitoring of flow velocity and by using expanded cross sectional areas at the top of the bed; the biomass is retained in the reactor. For the treatment of hazardous organic compounds Granular activated carbon (GAC) has gained popularity for the fluidized bed media. Biophysical-chemical reactor environment is created where the contaminants are first adsorbed to the GAC particles and then degraded by the growth of biofilm surrounding the GAC particle. The schematic of a fluidized bed bioreactor is shown in Figure 3.1.8. Researchers have reported that apart from dissolved organic carbon, colour, arsenic, turbidity, manganese, iron could also be removed by these processes (Peterson et al. 1997).

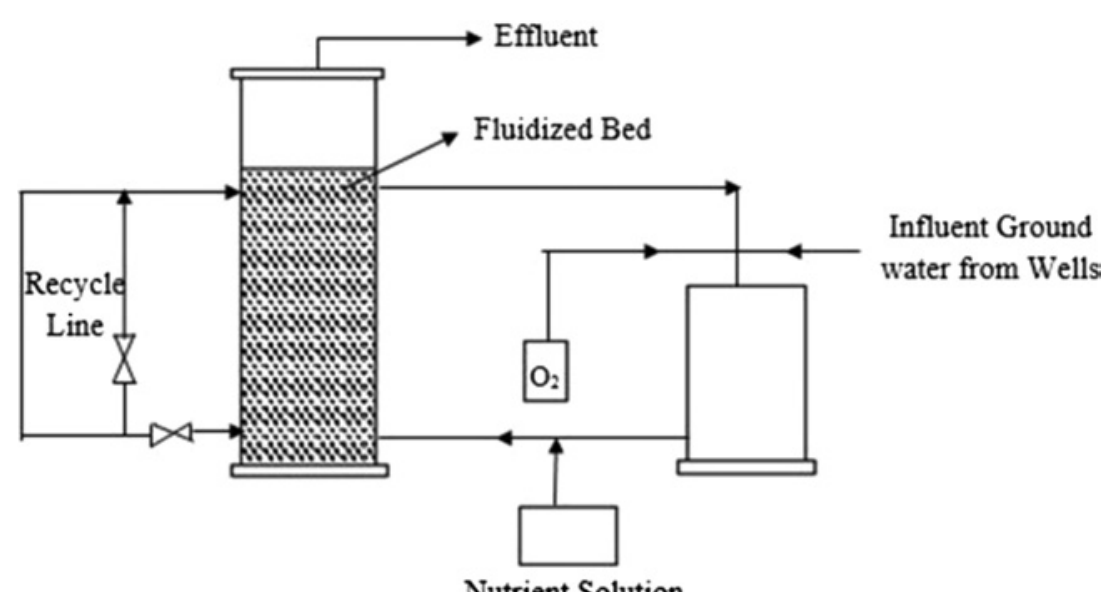

Figure 3.1.8 Fluidized bed bioreactor.

\subsubsection{SUMMARY}

Groundwater serves as one of the predominant source for domestic, agricultural and industrial applications in the present scenario. Quality of the ground water is important and to be assessed with carefully so as to decide proper treatment or remedial measures that will help in protecting the health of humans and environment. Proper management of ground water resource involves characterization of site in terms of its geological formation, hydrology, and type of contaminant, its strength and extent of contamination; selecting suitable treatment or remedial measure to mitigate the problem. A thorough knowledge of the surround conditions within the subsurface, advantages and drawbacks of the available treatment options are 
essential for the proper implementation of the techniques. Several technologies have been discussed in this chapter, however based on the conditions (contaminant) any one or a combination of techniques may be adopted for treatment.

The summary of the suitable treatment technology based on the type of contaminant is given below in Table 3.1.3.

Table 3.1.3 Type of pollutants and treatment technologies.

\begin{tabular}{ll}
\hline Pollutant & Treatment \\
\hline Heavy metals & Metal precipitation \\
Metal contaminants & Chemical treatment \\
Leachate & Biological treatment \\
Organic compounds & Chemical oxidation \\
Dissolved substances & Adsorption \\
Soil particles & Sedimentation \\
\hline
\end{tabular}

\subsubsection{CONCLUSION}

(1) The efficacy of pump-and-treat technology depends upon proper understanding of the hydro-geologic conditions and pollutant properties. As the complexity of pollutant and geological conditions of the site increases, the success of pump-and-treat system in meeting the targeted goals decreases.

(2) Various remedial or treatment technologies available for pump and treat are discussed in the chapter. However, a combination or sequence of remedial technologies is likely to be more effective and necessary at most sites.

\subsubsection{REFERENCES}

Achilli A., Cath T. Y. and Childress A. E. (2010). Selection of inorganic based draw solutions for forward osmosis applications. Journal of Membrane Science, 364, 233-241.

AFCEE/ERT. (2002). Perchlorate Treatment Technology Fact Sheet Ion Exchange. https:// clu-in.org/download/contaminantfocus/perchlorate/Ion-Exchange.pdf (assessed 10 October 2015).

Arun Kumar T., Devatha C. and Michel T. (2012). Experimental evaluation of activated sludge-biofilm reactor: Influence of composite media. Journal of Hazardous, Toxic, and Radioactive Waste Management (ASCE), 15(2), 134-141.

Arun Kumar T., Renu B. and Pramod K. (2010). Nitrification kinetics of activated sludge-biofilm reactors: A mathematical model. Bioresource Technology (Elsevier), 101, 5827-5835.

Changlin H. and Alex S. M. (1997). Pump-and-treat optimization using well locations and pumping rates as decision variables. Water Resources Research, 33(5), 1001-1012.

Dietrich J. A. (1995). Membrane technology comes of age. Pollution Engineering, 27(7), $20-25$. 
GE Healthcare Bio-Sciences AB, Sweden (2015). Cross Flow Filtration Method Handbook. www.gelifesciences.com/AKTA (assesed 10 October 2015).

Kharissova O. V., Dias H. V. R., Kharisov B. I., Pérez B. O. and Pérez V. M. J. (2013). The greener synthesis of nanoparticles. Trends in Biotechnology, 31, 240-248.

Kuokkanen V., Kuokkanen T., Rämö J. and Lassi U. (2013). Recent applications of electrocoagulation in treatment of water and wastewater - A review. Green Sustain. Chem., 3, 89-121.

Madhavia V., Prasadb T. N. V. K. V. and Madhavi G. (2013). Synthesis and spectral characterization of iron based micro and nanoparticles. International Journal of Nanomaterials and Biostructures, 3(2), 31-34.

Mercer J. W. and Cohen R. M. (1990). A review of immiscible fluids in the subsurface: Properties, models, characterization and remediation. Journal of Contaminant Hydrology, 6, 107-163.

Miao Z., Brusseau M. L., Carroll K. C., Carreón-Diazconti C. and Johnson B. (2012). Sulfate reduction in groundwater: Characterization and applications for remediation. Environmental Geochemistry and Health, 34(4), 539-550.

Mohapatra M., Anand S., Mishra B. K., Giles D. E. and Singh, P. (2009). Review of fluoride removal from drinking water. Journal of Environmental Management, 91(1), 67-77.

Mulligan C. N., Yong R. N. and Gibbs B. F. (2001). Remediation technologies for metal contaminated soils and groundwater: An evaluation. Engineering Geology, 60, 193-207.

Patricia D., Mackenzie David P., Horney and Timothy M. Sivavec (1999). Mineral precipitation and porosity losses in granular iron columns. Journal of Hazardous Materials, 68, 1-17.

Phuntsho S., Shon H.Y., Hong S, Lee S. and Vigneswaran S. (2006). A novel low energy fertilizer driven forward osmosis desalination for direct fertigation: Evaluating the performance of fertilizer draw solutions. Journal of Membrane Science, 375, $172-181$.

Report on Technical Evaluations of Ozonation Technology (Outline) 2015. www.sbmc. or.jp/english/ozonation_technology.html (assessed 10 October 2015).

Roh Y., Lee S. Y. and Elless M. P. (2000). Characterization of corrosion products in the permeable reactive barriers. Environmental Geology, 40(1), 184-194.

Roquebert V., Booth S., Cushing R. S., Crozes G. and Hansen E. (2000). Electrodialysis reversal (EDR) and ion exchange as polishing treatment for perchlorate treatment. Desalination, 131, 285-291.

Suthan S. Suthersan. (1999). Pump and treat systems, remediation engineering: Design concepts. Boca Raton: CRC Press LLC.

Syama I. J., Thalla A. K. and Manu, D. S. (2015). Performance of laterite soil grains as adsorbent in the removal of chromium. Current World Environ, 10(1), 270-280.

Taylor P. A. (2015). Physical, chemical, and biological treatment of groundwater at contaminated nuclear and NORM sites. Environmental Remediation and Restoration of Contaminated Nuclear and Norm Sites, 237, 237-256.

US-EPA. (1990). Basics of pump-and-treat ground-water remediation technology. Report no. EPA/600/8-90/003.

US-EPA. (2001). Cost analyses for selected groundwater cleanup projects: Pump and treat systems and permeable reactive barriers. Report No. EPA 542-R-00-013.

US-EPA. (2012). A citizen's guide to pump and treat. Report no. EPA-542-F-12-017. 


\section{Filtration Materials for Groundwater: A Guide to Good Practice}

Yadanaparthi S. K. R., Graybill D. and von Wandruszka R. (2009). Adsorbents for the removal of arsenic, cadmium, and lead from contaminated waters. Journal of Hazardous Materials, 171(1), 1-15.

Zeff J. D. and Barich J. T. (1989). A review of ULTROX ${ }^{\mathrm{TM}}$ Ultraviolet Oxidation Technology as Applied to Industrial, Groundwater, Wastewater and Superfund Sites, presented at the Summer Natl. Mtg., Am. Inst. Chem. Eng., Philadelphia, PA. 


\subsection{Near-well subsurface treatment technologies for sustainable drinking water production}

\section{Niels Hartog}

KWR Watercycle Research Institute, Groningenhaven 7, 3433 PE, Nieuwegein, The Netherlands; niels.hartog@kwrwater.nl

\subsubsection{INTRODUCTION}

With a rapidly expanding world population with more and more inhabitants concentrated in highly urbanized and industrialized society, technologies for costeffective sustainable drinking water production are required now more than ever. With the combined impacts of climatic change on the variability of the hydrologic system and the ageing demographics makes this an enormous challenge for both developing and developed countries alike. Due to the rather polar nature of many of the emerging organic micro pollutants (OMP) conventional treatment technologies as activated coal reactors are increasingly unable to provide sufficient pollutant removal and innovative water treatment technologies are therefore required. One of the promising technological possibilities for the treatment of extracted groundwater is the use of near-well subsurface treatment technologies. These provide the opportunity for sustainable water treatment by enhancing the sediments surrounding a groundwater extraction well with a reactive material. The reactive material with which the sediment reactivity is enhanced is selected based on the nature of the targeted pollutants. In this way the volume around the extraction wells is effectively turned into a subsurface reactor through which the groundwater flows as it travels towards the extraction well.

\subsubsection{THE CHALLENGE AND POTENTIAL FOR OMP REMOVAL USING SUBSURFACE REACTORS}

Organic micropollutants (OMPs) pose a threat to many vulnerable groundwater, artificial recharge and riverbank extraction sites, increasing the purification 
challenge. Many of the OMPS which are found in the extracted groundwater water have a relatively high molecular polarity. As a result, these compounds interact little with non-polar components in the subsurface, such as coal particles and sedimentary organic matter, and hence they are relatively mobile. By taking advantage of the large volume and the slower flow velocities in the subsurface, preceding any above-ground treatment, subsurface water treatment can contribute to higher overall removal efficiencies for polar OMPs in groundwater.

The reactivity of sediments can be enhanced in various ways, but recent studies have shown that various OMPS interact strongly with hydrophilic mineral phases. For example, adsorption of glyphosate, AMPA, and metolachlor to iron and manganese (hydr)oxides and their subsequent degradation has been observed (e.g., Lee \& Benson, 2004; Barrett \& McBride, 2005). The natural content of iron and manganese (hydr) oxides in aquifer sediments is typically low $(<1 \%)$, so increasing the content of these minerals locally around a groundwater extraction might therefore enhance the removal of certain OMPS before extraction. Also, it has been suggested by operators that the application of subsurface iron removal reduces the levels of OMPs observed in the extracted groundwater. An obvious hypothesis is that this is due to the underground enrichment with iron hydroxides, but this has not yet been investigated further.

\subsubsection{SUBSURFACE REACTORS: CHARACTERISTICS AND SPECIFICS}

\subsubsection{Subsurface water treatment: the concept}

Central to this concept of subsurface water treatment is the creation a subterranean reactive zone (Figure 3.2.1) in the aquifer at some distance from an extraction well. In this zone, the reactivity of the sediment has been artificially increased, such that the concentrations of one or more contaminants decrease with a certain desired degree. The purification of the groundwater therefore takes place underground, before it reaches the ground water extraction well.

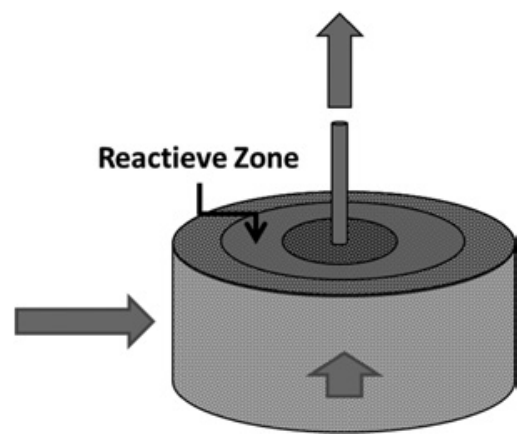

Figure 3.2.1 Schematic representation of the concept for subsurface water treatment. 


\subsubsection{The creation of a subsurface reactive zone}

For subsurface water treatment a reactive subterranean zone is created, such that the ground water flowing toward the extraction well is being treated. If the target contaminants flow from all sides with the groundwater toward the well, or when the direction from which the contaminants flow is unknown, this requires a reactive zone completely surrounding the extraction well (Figure 3.2.1). For very shallow phreatic abstractions these reactive zone could still possibly be created through excavation to the required depth of the extraction filters. More effectively and efficiently however, such zone can be created by temporarily using the extraction well for the injection of an aqueous solution containing reactive media. Although, the nature and volume of the reactive solution used depends on, amongst other aspects, the removal effects desired and type of pollutant(s), a number of general basic steps can be distinguished (Figure 3.2.2). Thus, after the injection of a given volume of reactive solution, a further volume of water (i.e., raw or pure) is injected to push the reactive agent further away from the well into the aquifer. This aims to ensure that all potential reactivity in the solution (i.e., precipitates or particles) can be immobilized in the aquifer. After this, at least the total volume injected is extracted back again and purged, if necessary, in order to ensure that, when shifting the produced water from the well to distribution, no residue of the reactive solution is distributed. With this the steps for underground purification are realized and the groundwater extracted is treated by subsurface water treatment, and possibly followed by additional (existing) purification steps, before distribution.
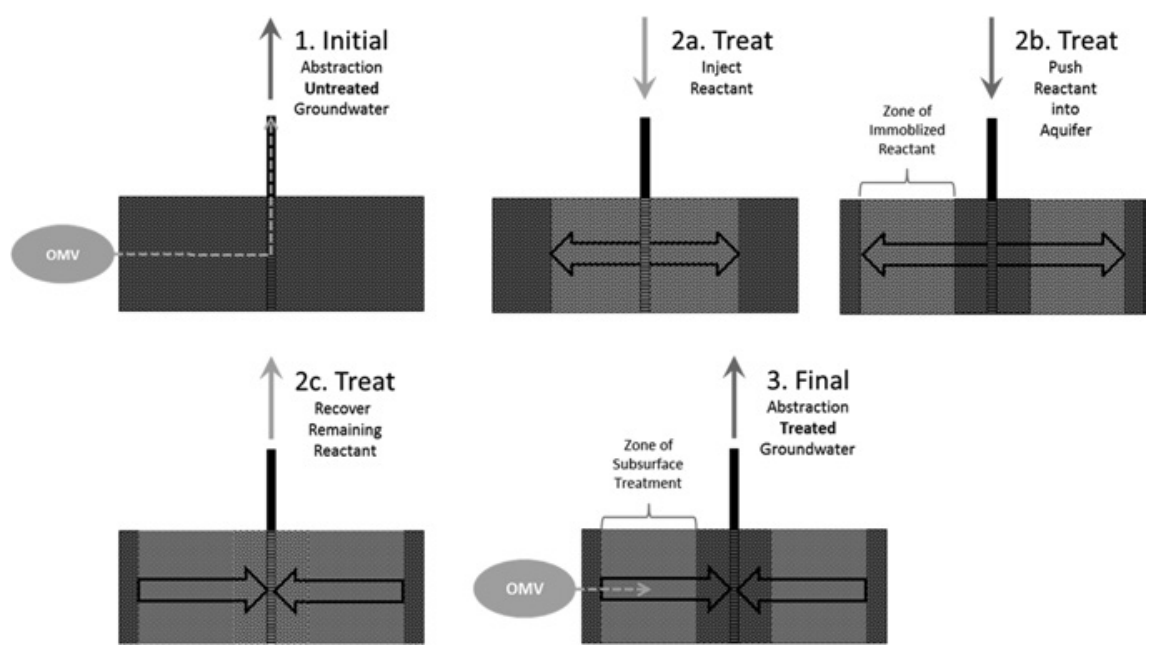

Figure 3.2.2 Schematized general steps in the creation of a subsurface reactive zone for subsurface treatment of contaminants. 


\subsubsection{Subsurface Reactor volume}

The pore volume available for the enhancement of sediment around a well (Figure 3.2.3) is basically controlled by the porosity of the sediment, the thickness of treated aquifer, and the radius of treatment around the well, following:

$$
V(R)=n \pi\left(R^{2}-r^{2}\right) D
$$

where:

$V(R)$ is the available pore volume

$R$ is the radial distance from the well for treated sediments (m)

$r$ is the radius of the well $(\mathrm{m})$

$D$ is the length of the well screen across the aquifer (m)

$n$ is the average effective porosity of the aquifer (dimensionless)

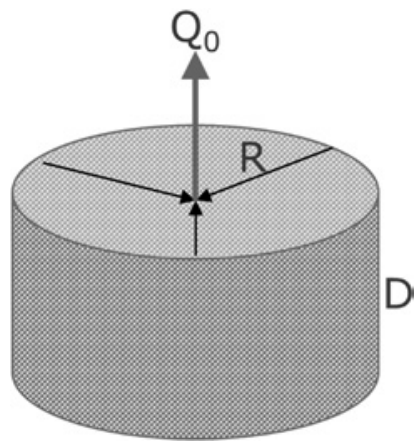

Figure 3.2.3 Schematic representation of a well, extracting with rate $Q_{0}\left(\mathrm{~m}^{3} / \mathrm{hr}\right)$ across a screen with length $d(\mathrm{~m})$.

Of these variables, the screen length and particularly the radius for the zone around a well to be treated can be varied to control the available pore volume for precipitates or introduced particles. Due to its quadratic dependence on distance from the well, bulk available pore space equals the volume of an Olympic size swimming pool $\left(2500 \mathrm{~m}^{3}\right)$ within relatively short distances from the well (Figure 3.2.4). For example, for a screen length of 10 meter this volume is reached with 20 meters away from the well, while for screen lengths of 50 meters this volume is reached within 8 meters. These volumes represent a considerable "empty-bed reactor volume", even if only a fraction thereof, say less than 1 to $10 \%$, can be used for sediment enhancement to prevent significant permeability reductions. If needed, increasing the radial distance away from the well for the treatment of the surrounding sediment will lead to larger available pore volumes, although this obviously will also increase the injection volumes required for sediment 
treatment. If the targeted OMPs enter the well at specific depths, than depth specific treatment using well packers could provide a more efficient alternative for sediment enhancement.

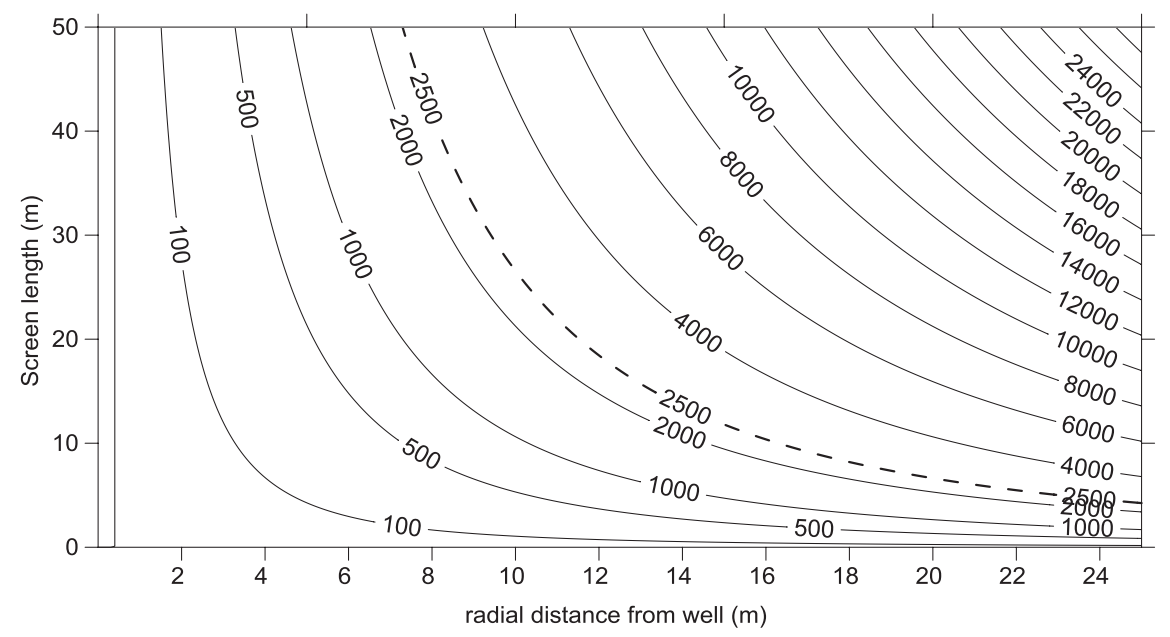

Figure 3.2.4 The pore volume surrounding a well as a function of screen length and distance from a well. Assumed well radius: $0.4 \mathrm{~m}$, porosity: 0.3 dashed line represents the volume of an Olympic size swimming pool $\left(2500 \mathrm{~m}^{3}\right)$.

\subsubsection{Geometry of the subsurface reactive zone}

For simplicity, the consideration of the creation of a reactive zone for subsurface water treatment has assumed a homogenous aquifer with a certain permeability. As a result, the volume that is injected over the length of the filter is evenly distributed and there is a uniform cylindrical reactive zone over the entire height of the aquifer (Figures 3.2.1 and 3.2.2). However, aquifers are known to always contain a certain degree of heterogeneity, so that the permeability in the aquifer varies with different depths.

Because of this heterogeneity (Figure 3.2.5), the majority of the reactive solution will flow into the most permeable portion of the aquifer upon injection. This distribution of the injected solution into permeable and less permeable layers of the aquifer is based on the relative differences in permeability. Since of the total injected volume a smaller part infiltrates into the less permeable layers, the created reactive zone in these layers, extends less far into the aquifer, and has a smaller pore volume. Since during extraction the lower permeability in these layers also causes a correspondingly lower groundwater flow rate, the contact times in the reactive zone in these layers with different permeabilities are equal. 

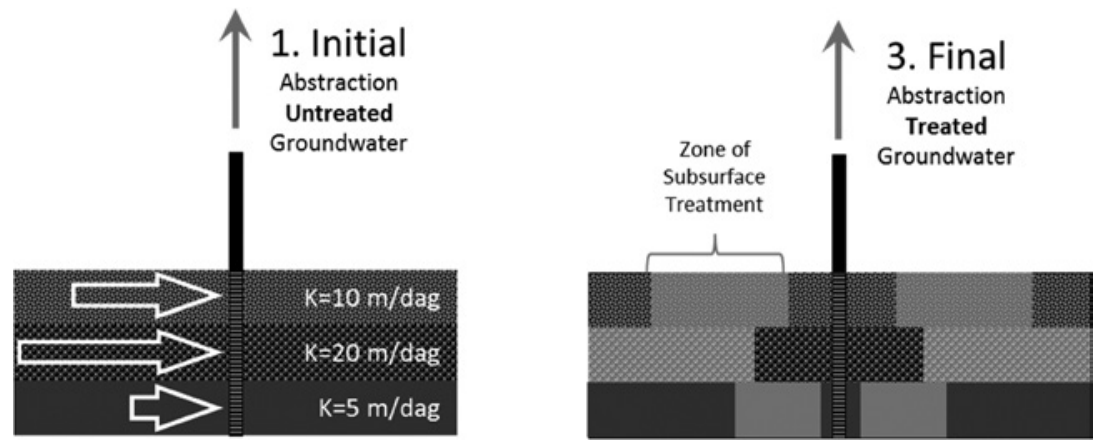

Figure 3.2.5 Influence of heterogeneity in the permeability field on the geometry of the subsurface reactive zone.

\subsubsection{SUBSURFACE REACTOR KINETICS}

\subsubsection{Contact time: travel time towards the well}

In addition to the available pore volume (reactor volume) in enhanced sediments around a well, the contact time would be an important factor in the overall removal of OMPs. For subsurface water treatment around a well (Figure 3.2.3), this contact time is the time required for a water particle to flow from the outer perimeter of the treated zone towards the extracting well. Using a simple approximation, following e.g., De Vries (1975), the travel time during radial flow towards a well can be expressed as:

$$
t(r)=\pi n \frac{D}{Q_{0}}\left(R^{2}-r^{2}\right)
$$

where:

$t(r)$ is the travel time of a water particle from distance $R$ to the well (hr)

$R$ is the distance from the well (m)

$r$ is the radius of the well $(\mathrm{m})$

$D$ is the length of the well screen across the aquifer $(\mathrm{m})$

$Q_{0}$ is the pumping rate of the well during extraction $\left(\mathrm{m}^{3} / \mathrm{hr}\right)$

$n$ is the average effective porosity of the aquifer (dimensionless)

As for the available pore volume, the travel time increases quadratically with increasing distance from the well, and is linearly affected by the ratio of screen length over pumping rate $\left(D / Q_{0}\right)$. As illustrated in Figure 3.2.6, a contact time of 1 day for typical $D / Q_{0}$ ratio's generally require travel distances of less than 10 meters away from the well, while a contact time of 1 week generally require travel distances of less than 25 meters. These are contact times that are multiple orders of magnitude higher than the contact times typical for groundwater treatment operations at the surface (minutes to hour). 


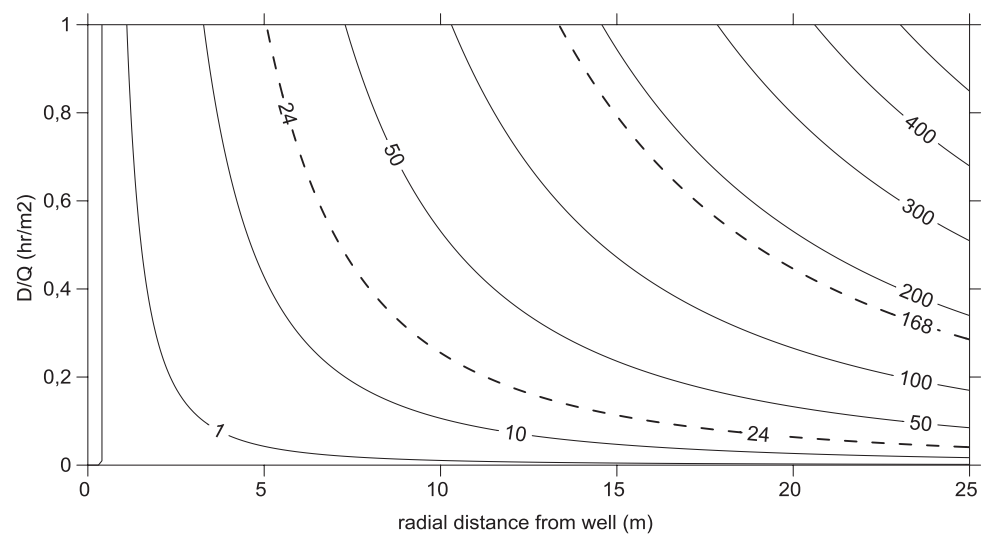

Figure 3.2.6 Travel time (hour, contact time) towards a well as a function of distance from a well and the ratio of screen length over pumping rate $\left(D / Q_{0}\right)$. Assumed well radius: $0.4 \mathrm{~m}$, porosity: 0.3 dashed lines represent travel times of 1 day ( $24 \mathrm{hrs}$ ) and 1 week (168 hrs).

In order for to achieve a desired contact time for a particular groundwater pumping rate during extraction this can be related to the required pore volume (Figure 3.2.7). Although this relationship is influenced by the filter length of a well, this is negligible for relatively small well diameters or negligible distances up to the inner edge of the reactive zone. As a result, the relationship between the contact time $(T)$, extraction flow rate $(Q)$ and required volume $(V)$ for the reactive zone simplifies to:

$$
T=V / Q
$$

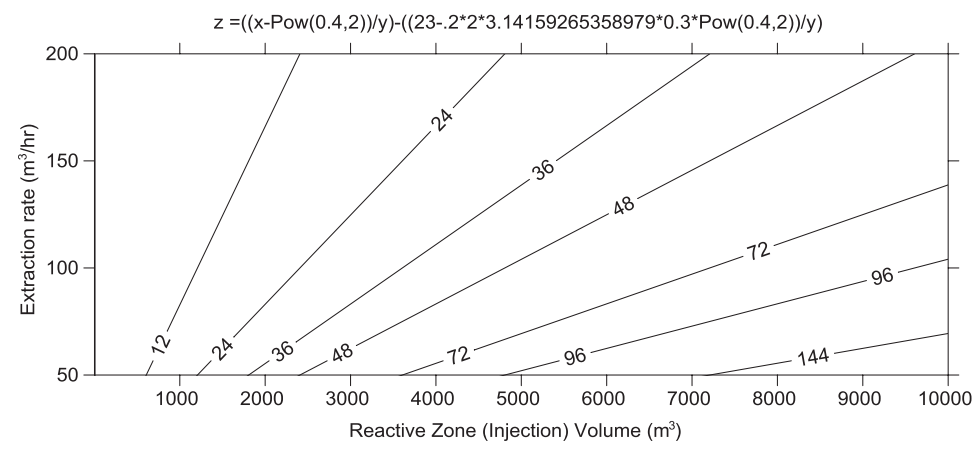

Figure 3.2.7 Contact time (hours) with subsurface water treatment as function of the pore volume of the created reactive zone and the groundwater pumping rate during extraction. 
As shown, for contact times of 24 hours, the values on the basis of this simplified relationship are in good agreement with the relationship in which filter length is taken into account. This indicates that, for the range of injection volumes to $10,000 \mathrm{~m}^{3}$ contact times up to 4 days (96 hours) are feasible.

\subsubsection{Removal during subsurface treatment}

Effective removal is a function of both the extent of exposure to removal mechanism (e.g., intensity of treatment) and the duration of exposure (contact time). The exposure of subsurface water treatment would be increased by increasing the amount of reactive material used to enhance the reactivity of the sediments, for e.g., the amount of precipitates. For a specific filter length and extraction rate, the contact time can be increased by increasing the radius of treated sediments around the well.

As both the available volume and contact times are high compared to above ground treatment facilities, subsurface water treatment around the well may allow for effective contaminant removal, even for removal mechanisms that are intrinsically slow with respect to particular OMPs. To illustrate this, the following function for first-order (asymptotic) removal is used:

$$
C(t)=C_{0} e^{-k t}
$$

where:

$C(t)$ is the concentration at time $t(\mathrm{hr})$

$C_{0}$ is the initial concentration at $t(0)$

$k$ is the first order reaction rate constant $(1 / \mathrm{hr})$

$t$ is the contact time (hr)

Here, using a first-order kinetic model for OMP removal provides a convenient approach for the general assessment of contaminant removal potential for subsurface treatment. However, it is a simplification of the removal processes for individual OMPs as other factors such as the amount of reactive material to which it is exposed (intensity of treatment) and water composition (e.g., redox, $\mathrm{pH}$ ) are likely to affect the actual rate of the removal process.

Replacing the reaction rate constant $k$ by the expression for the time to halve concentrations $\left(t_{1 / 2}\right)$ for a particular first-order reaction:

$$
k=\frac{\ln (2)}{t_{1 / 2}}
$$

And rearranging after substituting $t$ with the expression for travel time in the first-order removal expression yields:

$$
\frac{C(t)}{C_{0}}=1-e^{-\frac{\ln (2)}{t_{1 / 2}} \pi n \frac{D}{Q_{0}}\left(R^{2}-r^{2}\right)}
$$


This equation expresses the fraction of removal as a function of the radius of the subsurface water treatment zone around the well and the half-life for a particular reaction. As illustrated in Figure 3.2.8, a reaction half-life of 5 hours would yield over $95 \%$ removal for treatment radii over $10 \mathrm{~m}$, while a reaction half-life of $20 \mathrm{hrs}$ would yield this removal with radii over $20 \mathrm{~m}$.

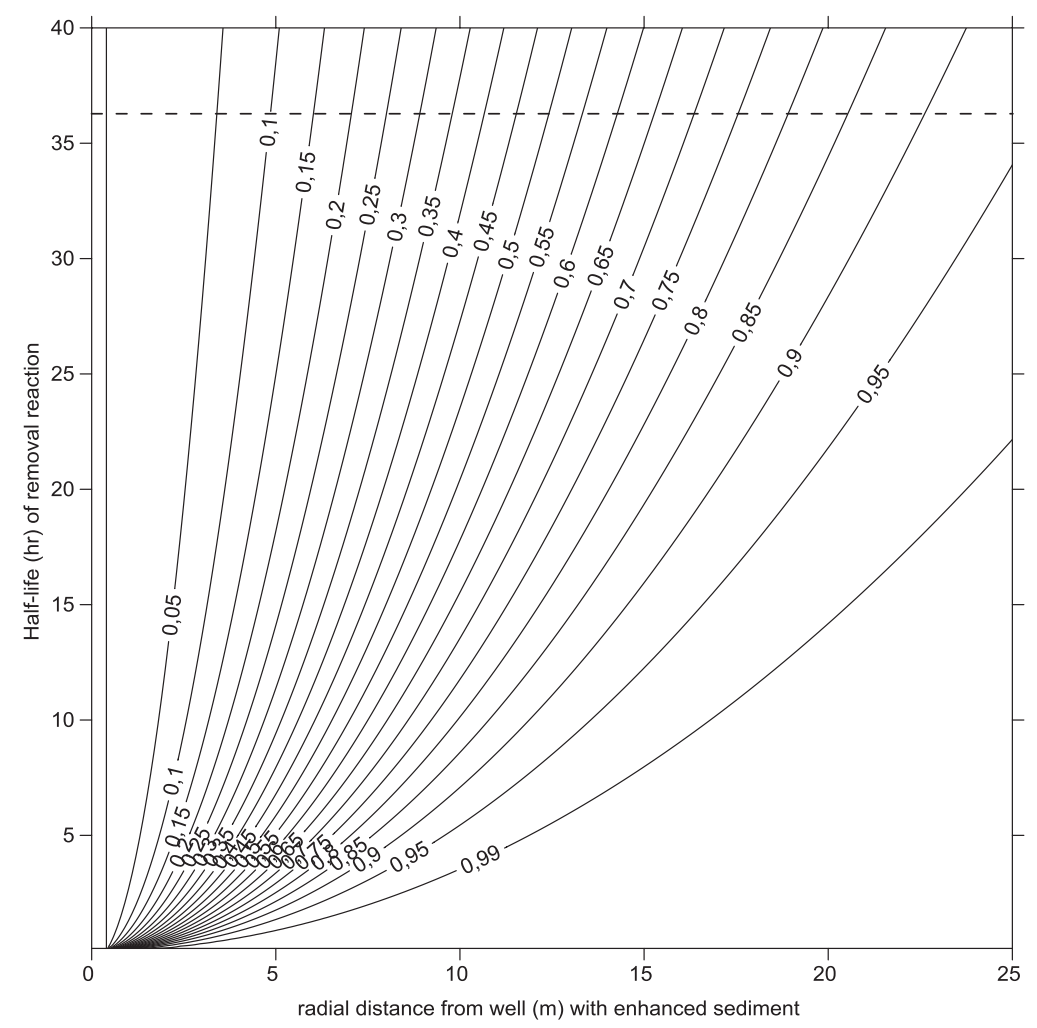

Figure 3.2.8 Fraction removed during subsurface water treatment as a function of the radius of the subsurface water treatment zone and the half-life for a particular removal reaction (for $D / Q_{0}=0.25$ ). Dashed line indicates the dependence of removal efficiency with increasing radius of the subsurface reactor for a reaction with a half-life of 1.5 days ( $36 \mathrm{hrs})$.

However, use of further simplification for the expression for contact time in the reactive zone $(T=V / Q)$, makes it possible to have a direct relationship between the extraction flow rate of the well, half-life for a removal reaction in the reactive zone, and the required pore volume in the reactive zone be deduced (Figure 3.2.9). 


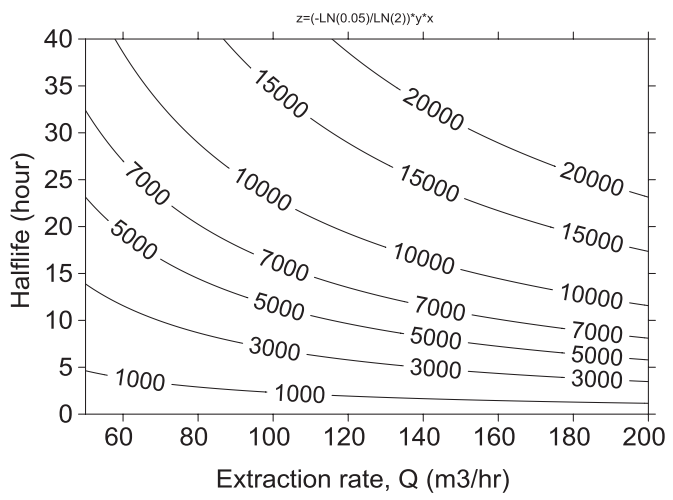

Figure 3.2.9 Pore Volume needed for reactive zone to make up for a removal reaction with a certain half-life, and at a given extraction flow $95 \%$ removal efficiency.

As compared to removal processes in smaller above-ground reactors, relatively very slow removal reactions with half-lives of 5 hours in a reactive zone of up to $3000 \mathrm{~m}^{3}$ of pore volume need to be created. For elimination reactions that have developed more slowly, for example with a half-life of 20 hours (Figure 3.2.9) would be sufficient a pore volume in the reactive zone of 10,000 to $15,000 \mathrm{~m}^{3}$. Although these volumes required are very large with respect to above-ground reactors, they are, in relation to the volumes which are pumped, to oversee. So is there a well with a flow rate of $100 \mathrm{~m}^{3} / \mathrm{hr}$ daily $2400 \mathrm{~m}^{3}$ pumped.

\subsubsection{REACTANTS TO CREATE NEAR-WELL SUBSURFACE REACTORS}

The removal of various organic micropollutants by oxidative adsorption to manganese oxides and iron hydroxides has long been a topic of study, e.g., in the early work on substituted phenols Stone (1987) and Lakind and Stone (1989). These studies have primarily focused on the rates and mechanisms of the degradation from a waste water treatment perspective. The experimental conditions tested were typically: acidic conditions ( $\mathrm{pH} 2-6)$, high OMP concentrations (mg/L) and elevated temperatures $\left(20^{\circ} \mathrm{C}\right.$ and up) and short experimental time scales (minutes to hours). These experimental conditions are thus in contrast with the typical conditions in Dutch groundwater systems, most notably: near neutral pHs 7-8, lower OMP concentrations (ug/L) and lower temperatures $10-15{ }^{\circ} \mathrm{C}$. Also, these studies focused on the isolated interaction between a single OMP and a selected reactant. In contrast, in groundwater systems other reactive phases are always present that could affect (positively or negatively) the removal of OMPs by iron hydroxides or manganese oxides. Finally, OMP-contaminated groundwater likely containing a mixture of OMPs rather than a single OMP. Nevertheless, previous 
studies provide an interesting and useful perspective on the types of OMPs that are affected by iron hydroxides and manganese oxides, and the associated reaction mechanisms. Therefore, below we provide a non-exhaustive summary of relevant literature on this topic.

The early work by Stone (1987) demonstrated that at $\mathrm{pH} 4.4$, substituted phenols degrade by reductive dissolution of synthetic manganese oxide particles. Reduction rates decreased with increasing $\mathrm{pH}$. Anilines were also demonstrated to degrade by $\mathrm{MnO}_{2}$ (Laha \& Luthy, 1990). The reaction rate with aniline was $\mathrm{pH}$-dependent, increasing with decreasing $\mathrm{pH}$ (3.7-6.5), and first order with respect to $\mathrm{MnO}_{2}$ and organic solute. The antibacterial agents triclosan and chlorophene showed similar susceptibility to rapid oxidation by manganese oxides yielding $\mathrm{Mn}$ (II) ions (Zhang \& Huang, 2003). Both the initial reaction rate and adsorption of triclosan to oxide surfaces increased as $\mathrm{pH}$ decreased. Lee and Benson 2004 showed that green sands, a by-product of gray-iron foundries that contains iron particles and organic carbon, have a high sorption capacity for alachlor and metolachlor. (Barrett \& McBride, 2005) proved that glyphosate and AMPA degrade (oxidative degradation) at $20{ }^{\circ} \mathrm{C}$ in dilute aqueous suspensions of birnessite $\left(\mathrm{MnO}_{2}\right)$. Higher temperature $\left(50^{\circ} \mathrm{C}\right)$ resulted in faster degradation of both. Also, the antibiotic oxytetracycline was rapidly degraded by $\mathrm{MnO}_{2}$ (Rubert \& Pedersen, 2006). Initial reaction rates exhibited pronounced $\mathrm{pH}$-dependence, increasing as $\mathrm{pH}$ decreases. Estrogens were found to be effectively removed from water by synthetic $\mathrm{MnO}_{2}$ (Xu et al. 2008). The authors note that estrogen removal was increased at lower $\mathrm{pH}$ due primarily to enhanced oxidizing power of $\mathrm{MnO}_{2}$. (He et al. 2012) demonstrated that also carbamazepine is efficiently removed by $\mathrm{MnO}_{2}$ (adsorption followed by oxidative degradation) and that increased $\mathrm{MnO} 2$ loadings promote carbamazepine degradation. He et al. (2012) further showed that $\mathrm{MnO}_{2}$ in more acidic conditions was more reactive towards carbamazepine while above $\mathrm{pH}$ of 6 the degradation was considered negligible, at least during their short experimental duration of 60 minutes. They also demonstrated that coexisting metal ions, such as $\mathrm{Mn}^{2+}, \mathrm{Ca}^{2+}$, $\mathrm{Mg}^{2+}, \mathrm{Fe}^{3+}$, and natural organic matter (e.g., humic acid) may inhibit carbamazepine reactions with $\mathrm{MnO}_{2}$ to various extents. This aspect is relevant when considering the effect of groundwater chemistry on OMP removal by $\mathrm{MnO}_{2}$-enriched aquifer sediments.

\subsubsection{OUTLOOK FOR THE USE OF NEAR-WELL SUBSURFACE REACTORS}

The evaluation of the potential for applying subsurface water treatment in general, suggests that enhancing the sediments around a well could in general provide an efficient option for OMP removal from groundwater before it is extracted. The subsurface surrounding a well provides sufficient volumes to allow sufficient enrichments to be introduced to the sediment. The relatively long travel times towards a well allow longer contact time for OMP removal than available during 
above-ground treatment. This allows even slow removal processes to be effective in OMP removal. For most common well and extraction conditions analyzed, reaction half-lives of up to 30 hour would yield $95 \%$ removal within a treated zone with a radius of 25 meter around the well.

Towards field application of subsurface treatment, future studies should look into appropriate methods for enhancing the sediments around a well, in terms of both cost-effectiveness, sediment (re)treatment requirements and removal efficiencies. Also, the control of potential negative effects on water quality and well performance should be considered.

Apart from iron hydroxides and manganese oxides tested in this study, the enrichment of sediment with other reactive precipitates or particles (e.g., sorbent, nano-iron) could be considered depending on the properties of the target OMPs and site-specific conditions.

The extent to which sediment pretreatment enhances or decreases the removal of the various OMPs during field application might be affected by specific field conditions (such as $\mathrm{pH}$, ferrous iron, methane and DOC concentrations and characteristics of the sediments surrounding a well). To be able to anticipate more accurately to the effects of subsurface treatment, future studies should investigate the removal of specific OMPs, mimic field conditions in more detail and account for site specific characteristics.

\subsubsection{REFERENCES}

Barrett K. A. and McBride M. B. (2005). Oxidative degradation of glyphosate and aminomethylphosphonate by manganese oxide. Environmental Science \& Technology, 39(23), 9223-9228.

De Vries J. J. (1975). Some calculation methods for determination of the travel time of groundwater. In: Aqua-Vu Serie A. No 5. Vrije Universiteit, Amsterdam, pp. 3-15.

He Y., Xu J., Zhang Y., Guo C., Li L. and Wang Y. (2012). Oxidative transformation of carbamazepine by manganese oxides. Environmental Science and Pollution Research, 19(9), 4206-4213.

Laha S. and Luthy R. G. (1990). Oxidation of aniline and other primary aromatic-amines by manganese-dioxide. Environmental Science \& Technology, 24(3), 363-373.

Lakind J. S. and Stone A. T. (1989). Reductive dissolution of goethite by phenolic reductants. Geochimica et Cosmochimica Acta, 53(5), 961-971.

Lee T. and Benson C. H. (2004). Sorption and degradation of alachor and metolachlor in ground water using green sands. Journal of Environmental Quality, 33(5), 1682-1693.

Rubert K. F. and Pedersen J. A. (2006). Kinetics of oxytetracycline reaction with a hydrous manganese oxide. Environmental Science \& Technology, 40(23), 7216-7221.

Stone A. T. (1987). Reductive dissolution of manganese (III/IV) oxides by substituted phenols. Environmental Science \& Technology, 21(10), 979-988.

Xu L., Xu C., Zhao M. R., Qiu Y. P. and Sheng G. D. (2008). Oxidative removal of aqueous steroid estrogens by manganese oxides. Water Research, 42(20), 5038-5044.

Zhang H. C. and Huang C. H. (2003). Oxidative transformation of triclosan and chlorophene by manganese oxides. Environmental Science \& Technology, 37(11), 2421-2430. 


\section{Chapter 4}

\section{Cost and risk assessment of treatment facilities}

\section{Viktória Mikita}

Researcher, University of Miskolc, Faculty of Earth Sciences, Institute of Environmental Management, Department of Hydrogeology and Engineering Geology; hgmv@uni-miskolc.hu

\section{Tamás Madarász}

Associate professor, University of Miskolc, Faculty of Earth Sciences, Institute of Environmental Management, Department of Hydrogeology and Engineering Geology; hgmt@uni-miskolc.hu

\section{Klára Szita Tóthné}

Professor, University of Miskolc, Faculty of Economics, Institute of World and Regional Economics; regszita@uni-miskolc.hu

\section{Balázs Kovács}

Associate professor, University of Miskolc, Faculty of Earth Sciences, Institute of Environmental Management, Department of Hydrogeology and Engineering Geology; kovacs.balazs@gama-geo.hu

\subsection{HYDROGEOLOGICAL ASPECTS OF CONTAMINATED SITE REMEDIATION}

\subsubsection{Possible goals of groundwater treatment}

Groundwater remediation action in each case is aiming to reduce the risks posed by a given contaminated site. Risk reduction can be achieved by either decreasing the concentration or the toxicity potential of the contaminant. Conventional 
remediation actions are designed lower the environmental concentration of contaminants, while others are designed to change both the concentration and the chemical form of the chemical in concern. Pump and treat technologies belong to the former group, while reactive barriers' decontamination mechanism in each case change the chemical feature of the contaminants through the change of $\mathrm{pH}$ or redox potential, precipitation, sorption or bio-chemical processes.

\subsubsection{Groundwater flow and contaminant transport modeling}

The ability to predict or follow the movement of water and contaminants in the subsurface is the key to the groundwater management. The hydrodinamical and transport modeling is based on numerical approximations of the entire 3D groundwater flow field and the contaminant transport processes related thereto. These models provide information to help decision makers in the groundwater management and remediation process.

Groundwater flow and contaminant transport modeling is an excellent tool during the design, the prediction of efficiency and a life-cycle analysis of treatment facilities. Groundwater flow models are suitable to determine the flow field (velocity and direction of groundwater seepage, hydraulic head distribution in space and time) in the surroundings of an operating PRB or PTS or even in larger environment at a contaminated site where the remediation is planned. Knowing the flow field it is also possible to determine the most relevant groundwater flowlines, the transit-times between different points of the pathlines, moreover the groundwater fluxes at any points of interest. Based on a representative groundwater flow model a contaminant transport model can also be built where the spatial and temporal changes of concentration distribution of different species (contaminants) due to the contaminant transport processes (advection, dispersion, retardation, chemical reactions, decay, etc.) can be calculated. To summarize and simplify the above mentioned things, GW flow models are to determine the relevant hydraulic field, transport models are to calculate the chemical potential fields at a given time or time series.

During the use of both kind of models discretization of the model domain is needed therefore we apply elements of different but predefined shapes that size determines the resolution of the model (Kovács \& Szanyi, 2005). Within each element the material properties are constant therefore the natural changes of the material behaviour can be followed by sets of elements with differing characteristics. As result of the calculation an average value of an element or a distinct value at the node of the element is calculated depending on the applied numerical method (finite differences or finite elements, respectively). Since the numerical models have always iterative solutions they are inaccurate in mathematical sense but they are accurate in technical sense. The results are dependent on the input parameters that are not always well known. To determine the effects of estimated input parameters on he results an input data sensitivity analysis is performed. To check 
the model a validation is also needed, where known processes are simulated using the numerical model and the input parameters are changed until the results become similar to the measured ones. In case of a well validated model we assume that the model will be also representative not only at the investigated case of validation but also for other cases.

The simulation of best and worst-case scenarios shows the vulnerability of the system against design errors, heterogeneity of geological environment and other unknown factors. Using stochastic calculations also the uncertainty of the system performance can be calculated by means of hundreds of simulations with stochastically but reasonably changing input parameters (Szanyi, 2004). As result of the stochastic calculations the results are determined as a frequency factor, that makes possible to determine the most possible case at a given uncertainty level. The design of the treatment technique is an iterative procedure due to the high number of calculated variables.

During the PRB and PTS design procedure a groundwater flow model linked with a particle-tracking module may support the following tasks (Mikita, 2015):

Permeable barrier

- Helps to decide the type of the barrier.

- Determination of size, number and position of permeable parts on the barrier in order to optimize its hydraulic performance using a numerical groundwater flow model.

- Using the model the required position, permeability and ratio of length of funnel and gate sections of the barrier can be calculated to minimize the hydraulic resistance and hence also the groundwater level rise in upgradient direction to the wall.

- Making water budget calculations the fluxes and seepage velocities through the permeable section can be determined which is useful to calculate the frequency of changes of the reactive filling material.

- Calculation of flowlines to estimate the hydraulic capture zone by each or all permeable parts that can be compared to the area of contamination.

- Transit/residence time calculations are to determine and visualize the time until the contaminated particle may reach the permeable wall by advection, which can also be a parameter to be optimized to reach the best PRB performance.

Pump \& Treat system

- Determine the location of the pumping and injection wells with respect to groundwater flow, plume movement and flow velocity, to avoid the well interference and stagnation zones, enhance the containment

- Calculation of flowlines delineates the region affected by the wells (capture zone analysis). 
- Determine the optimal pumping/injected rate of the wells.

- Determine the optimal location of monitoring wells.

- The sensitivity analysis helps to identify those parameters, which could be the greatest effect on the modelling results.

- With uncertainty analysis, running parameter simulations of changing reactive part size, permeability, and number a comparative evaluation of the different possible designs can be performed at very low costs. Also estimate the hydraulic effects of some potential changes, like the decrease of porosity.

- Determination of PRB and PTS performance using contaminant transport model.

After a successful and straightforward hydraulic optimization of the treatment technique design, contaminant transport calculations can be performed

- to determine the pollutant concentration of groundwater reaching the permeable window or pumping well and its variation in time,

- to estimate the transport processes in the contaminated porous medium and the behaviour of chemicals in case of PTS,

- to investigate the transport processes in reactive material and its chemical saturation at calculated influent concentration characteristics. The determination of effluent concentrations downgradient to the PRB,

- to calculate the concentration change in time of different contaminants behind the wall during the lifetime of the PRB. Optimization of PRB design to reach the highest decrease of contamination in the hot spots behind the wall, to realize the most homogenous concentration field at the site, to control the optimal frequency of reactive filling, and to optimize the plume management efforts in general.

Additionally to the above listed problems all site specific tasks can be solved using the groundwater flow or contaminant transport model that has any effect on groundwater flow, groundwater level and concentration distribution. The numerical model is a reasonably low cost tool to investigate parallel competitive scenarios, designs for evaluation of possible consequences of the realization of the treatment technique (Kovács et al. 2013).

\subsection{THE RISK AND PERFORMANCE ASSESSMENT OF TREATMENT FACILITIES}

\subsubsection{Determination of acceptable risk}

An important design parameter of any remediation action is the remediation target value or risk based clean up level. The terminology may change by country, the key concept however is consistent. The clean up effort must decrease the concentration of the contaminant in concern to a residual level, which represents a safe post 
remediation condition. Remediation target value setting for decades was based on a generic approach, which could consider to a certain extent vulnerability or land use aspects. Since the 1990s a remarkable conceptual change has been introduced to the clean up paradigm, when the risk based and site specific approach was implemented first in the USA and than in most of the European countries too. The new concept using the SPR (source-pathway-receptor) concept evaluates relevant exposure scenarios and establishes the clean up targets on a tolerable health risk basis in a site specific context.

Risk based remediation target value setting must compile with the following three design concepts (Madarász, 2005):

- human health risk must be under acceptable level

- ecological risk level must be acceptable

- the protection of environmental media must be assured

The focus of human health risk assessment is to thoroughly evaluate all possible contaminant sources, exposure pathways and human receptors, that in any way can contribute to the realization of exposure scenarios. Human health risk assessment methodology in every case must cover all possible present and future land uses and using a set of conservative assumptions must guarantee that the exposures through the assessed scenarios shall not pose any health risk to receptors. The health risk assessment protocols although vary in details, and nomenclature, they all follow the same line of thought and have a rather standardized 4 step paradigm: Problem formulation (Hazard identification), exposure assessment, toxicity assessment and risk characterization. The risk assessment approach alters for threshold and nonthreshold chemicals and thus the risk quantification method is different.

Ecological risk assessment is much less standardized and the term refers to a risk assessment procedure where the receptors or non human organisms, populations or an ecosystem as a whole (Barnhouse \& Suter, 1986). Having the receptors ranging in such a broad spectrum (not to mention the huge variety of theoretical concepts) no wonder that the ecological risk assessment protocol varies significantly.

The protection of environmental media is not involved as a particular factor in risk based decision-making in most national policies. Some countries put special emphasis to the protection of environmental media, for being vulnerable through the contamination of soil and/or groundwater resources. Relevant legislation incorporates the protection of environmental media, as a separate task to consider. The rationale is for this is rooted in the baseline concept of the risk based approach. The SPR concept of risk assessment aims to protect the selected end points (e.g., receptors) of the exposure scenarios, and neglects the pathways. Human health or ecological risk assessment is not designed to protect environmental media (soil, air, groundwater) and they are not sufficient tool for the protection of environment.

When considering environmental media protection, two principles must be secured during the remediation process: (1) No horizontal or vertical spreading of 
the contaminant plume is tolerated, (2) No cross contamination is tolerated from one medium to an other.

The three aspects mentioned above each appoint a tolerable target concentration respectively. The ultimate remediation clean up level of the assessed scenarios shall be the strictest (lowest) value of the three, thus insure that the remediation target concentration provides appropriate level of protection for each design aspects.

\subsubsection{Performance assessment}

The performance assessment refers to evaluate the hydraulic and geochemical conditions to assess the current performance and predict the future performance of the remediation systems.

The performance evaluation includes hydraulic assessment and longevity analysis (mostly chemical assessment), but in most cases, the performance assessment simply refers to analysis of data obtained from monitoring wells during remediation (Keely, 1989).

\subsubsection{Hydraulic assessment}

The key to the adequate hydraulic performance evaluation, is the investigation of hydraulic gradient in three dimensions at the contaminated area; needs to continually monitor any potential changes in the groundwater flow direction and velocity that may affect to the capture zone and to the performance of remediation system. Therefore the number and position of monitoring wells effects to the performance analysis. The following tools, methods are available for evaluation (Table 4.1).

Table 4.1 The available tools for performance evaluation (based Keely 1989).

\begin{tabular}{ll}
\hline Measurements & Data Analysis Methods \\
\hline Waterlevel measurements & Groundwater flow modeling \\
Slug tests & Graphical methods of data presentation \\
In situ flow sensors and colloidal & Statistical methods \\
borescope & - Analysis of variance \\
& - Correlation coefficients \\
& - Regression equations \\
Single well tracer test (P\&T) &
\end{tabular}

The groundwater modeling coupled with waterlevel measurements provide the best results at the investigated sites (ESTCP, 2003). Monitoring the groundwater flow direction and velocity also provides data to the longevity analysis. 


\subsubsection{Life cycle and longevity analysis}

The life cycle assessment (LCA) as from cradle to grave analysis is a systematic analysis of environmental impact from resource extraction (cradle) to use phase and disposal phase (grave). According the ISO 14040 and 14044 standards a Life Cycle Assessment is carried out in four steps as illustrated in the Figure 4.1. These are the goal and scope of study, life cycle inventory, life cycle impact assessment and interpretation of the study.

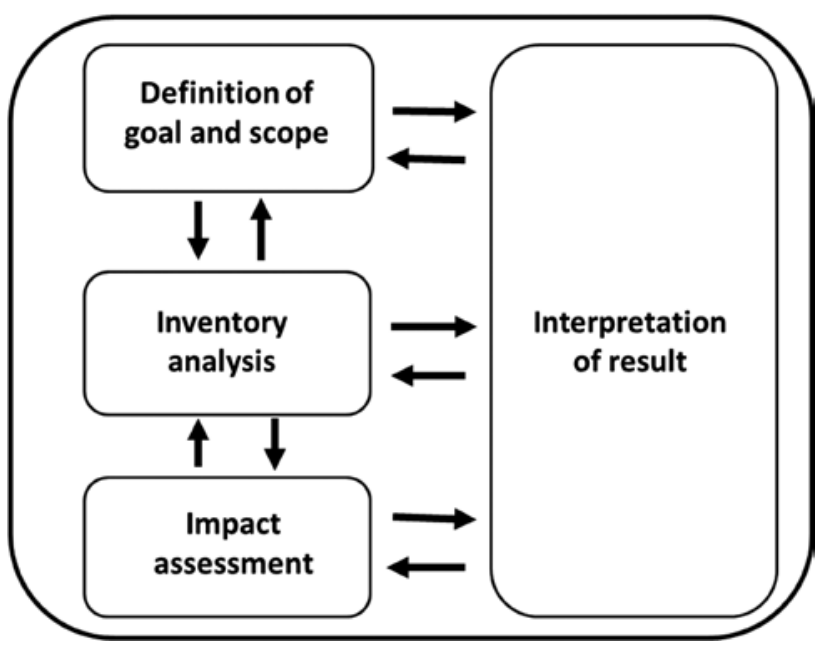

Figure 4.1 The phases of the LCA.

It is wide applied method to determine the environmental impact on the world since early nineties year, and it well useable tool to evaluate the remediation technologies or process and to choose the best of alternative from an environmental point of view.

To this time more authors studied the environmental impact of remediation technologies by LCA, but only several focused for the comparison of PRB and PTS (Higgins \& Olson, 2009; Higgins, 2011; Bonoli et al. 2013). These chapter give a general picture about environmental impacts and those origin and help to the decision-makers. The authors investigated different contaminated sites, different technologies, methods, often applied other and other function unit or analytical tools or software. So these results are not really comparable. The Table 4.2 summarises some LCA studies of remediation technologies.

As the above table shows several studies investigated the environmental impact of the PRB and PTS technology by LCA, but before Higgins and Olson did not analysed the Zero Valent Iron type PRB system. Higgins and Olson 2009, Higgins 2011 studied firstly the environmental impact of ZVI-type PRB with comparison to PTS technology from life cycle approaches. The analysis was applied for a site 


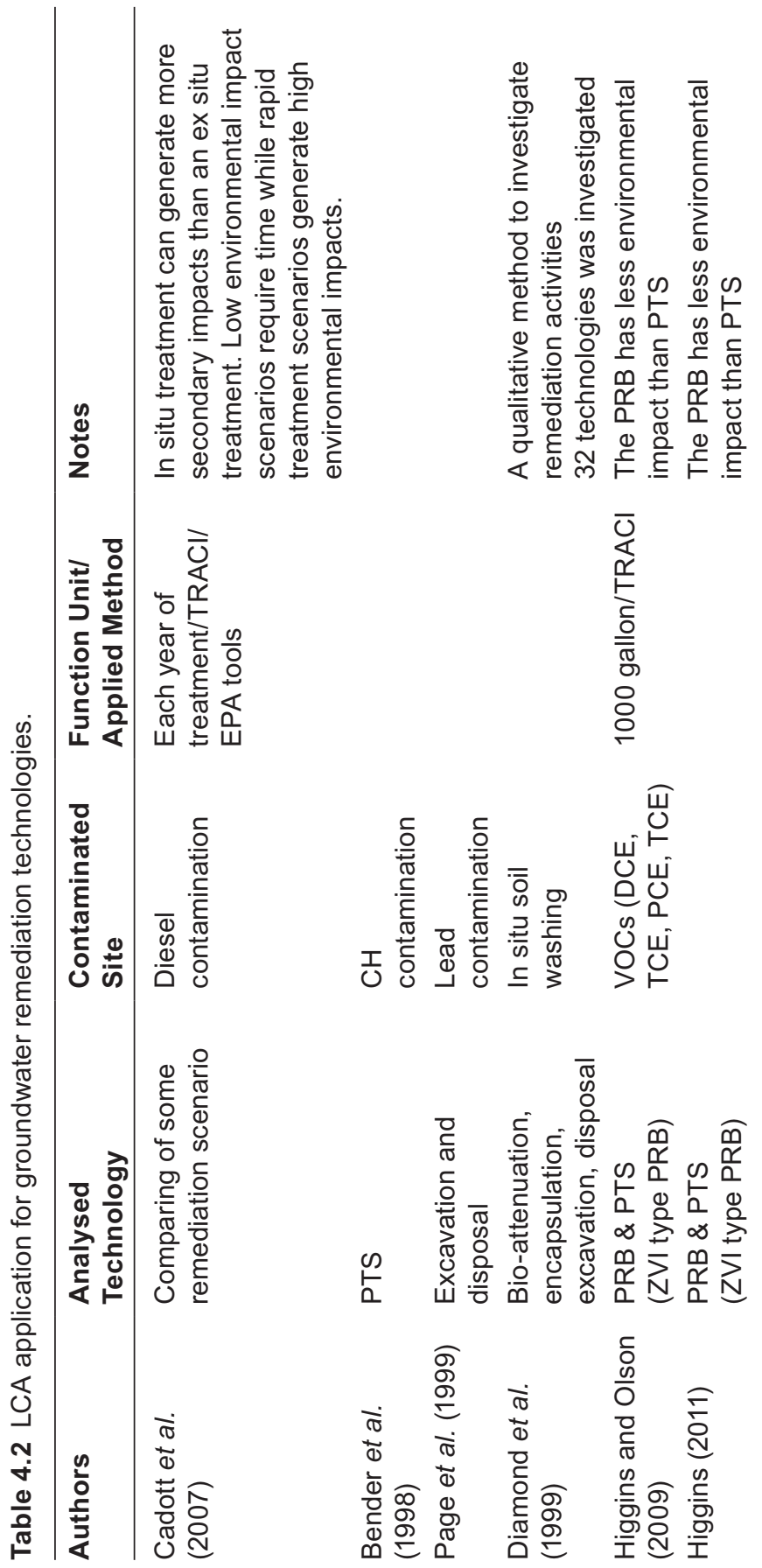



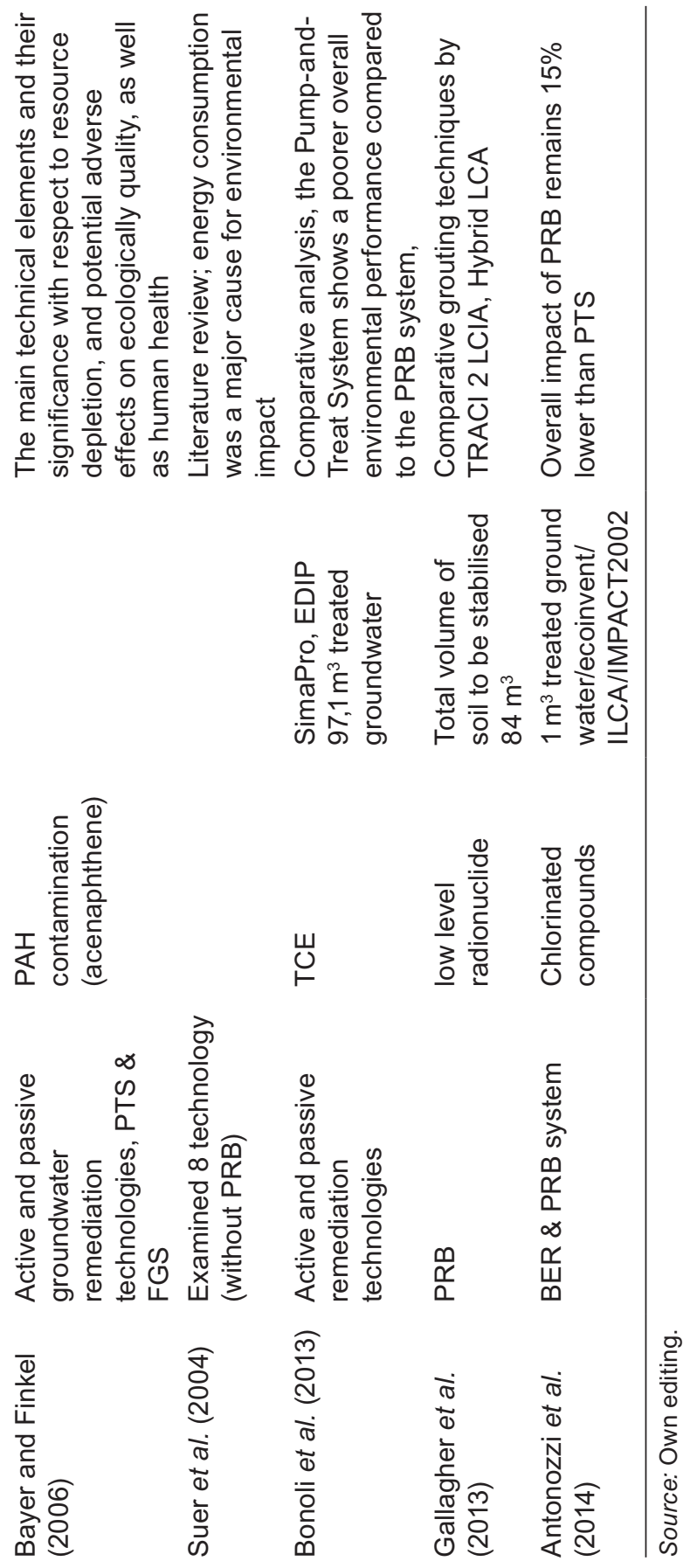
contaminated with chlorinated solvents (as Trichlorethylene, Tetrachlorethylene, Carbon Tetrachloride, Benzene, Toluene, Ethylbenzene, Xylene. The total waste was $650 \mathrm{~m}^{3}$ ) in Dover.

The authors detailed described the technical parameters of the installation and operation for both technologies. Their analysis based on LCA standard ISO 14040 and Franklin database and IDEMAT 2001 methods and used industrial data too and applied TRACI method.

The system boundaries of PRB included the material production, transportation, construction and maintenance. The system contents: pre-site processing (cast iron production, steel production, cement production, sand production), transportation, on-site processing (funnel construction, gate construction) and maintenance gate/ ZVI removal and gate/ZVI re-construction). The PRB scenarios were modelled to investigate the effects of media longevity and repair activities on potential impacts.

The PTS system included material production (primary aluminium production, and aluminium fabrication; PVC resin production and PVC pipe extrusion; steel production, GAC production, concrete production, HDPE resin production), US Grid Electricity Production and Transportation. The on-site Processing contents facilities construction, extraction well construction, pump replacement, GAC replacement; maintenance: (extraction well operation, air stripping unit operation, catalytic oxidation operation) and on-site operation.

The function unit was defined as an equivalent treatment unit, the implicit assumption is that the systems provide adequate treatment that meets remediation goals with respect to volume of water treated and target concentrations.

Life-cycle impacts of the PRB were also evaluated in terms of the relative contributions of the reactive media, gate, and funnel subsystems. Together the gate and reactive medium accounted for more than $80 \%$ of impacts, and the reactive medium contributed nearly $50 \%$ of the potential impacts for the PRB in all categories. Relative PRB benefits depend on longevity (Figure 4.2).

Sharing of environmental impact of subsystem of PRB model (30 years)

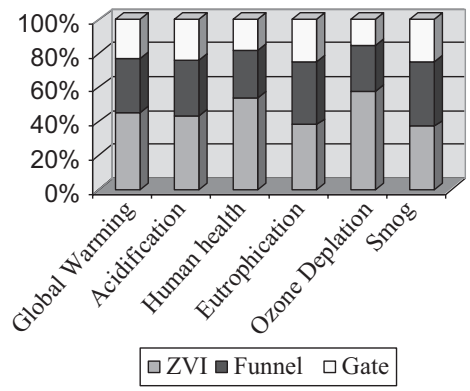

Sharing of environmental impact of subsystem of PRB model (10 years)

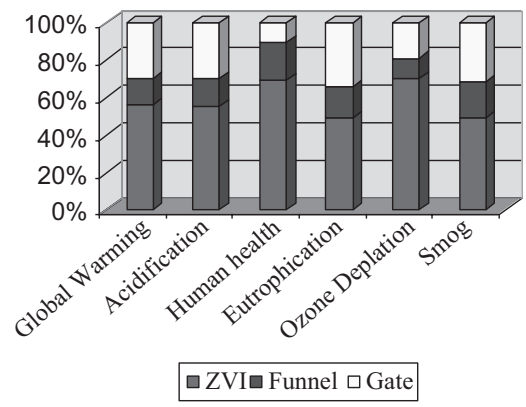

Figure 4.2 Sharing of environmental impact of subsystem (30 years and 10 years longevity), based Higgins and Olson 2009. 
The model PRB has lower environmental impacts when compared with the model PTS. The relative benefit of PRB depends on longevity. The model PRB with assumed ten year longevity offered significant reductions in acidification, human health, ozone depletion and eutrophication compared to the PTS (Figure 4.3).

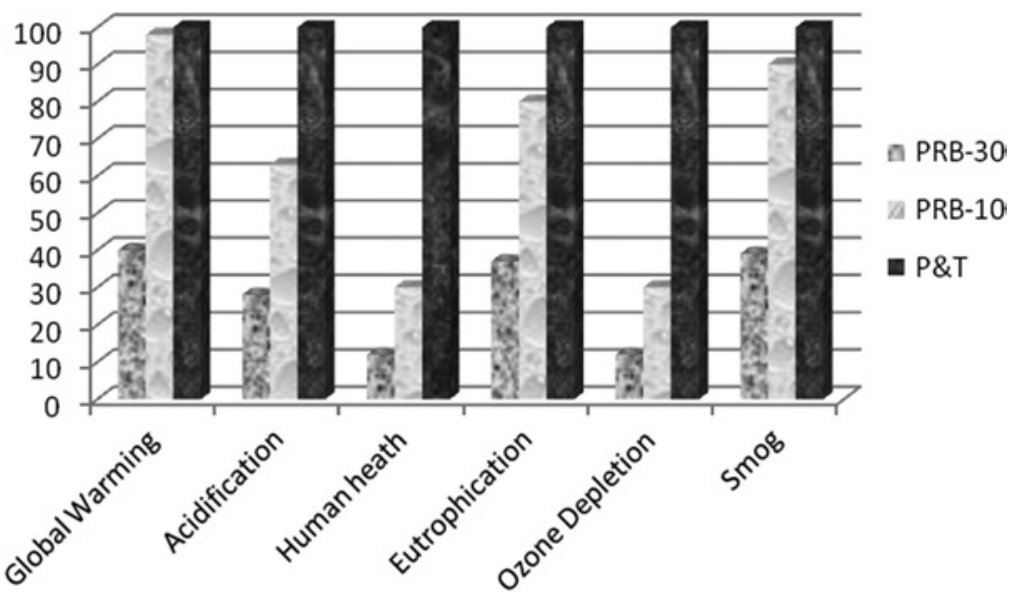

Figure 4.3 Relative environmental impact of PRB and PTS technologies, based Higgins and Olson 2009.

Bonoli et al. (2013) also studied both of PRB and PTS technology by LCA, and compared the environmental performance. The system boundaries include the used material production, installation, operating phase and disposal. The function unit was $1 \mathrm{~m}^{3}$ treated groundwater and the expected lifespan of the technology has been set to 10 years. The applied model was developed by SimaPro EDIP 97. The Pump-and-Treat System has been modelled assuming the same treatment efficiency and volume of treated groundwater as the PRB.

The result of LCA showed that the ZVI and funnel subsystems contribute significantly to the overall impacts of model PRB if longevity is 30 years (Figure 4.4).

The Figure 4.5 shows the result of life cycle assessment for PTS technology and PRB model. The main environmental impact is considering to ecotoxicity water (both chronic and acute) and human toxicity soil. The biggest environmental loads connected mainly to GAC production and disposal and their water chronic and acute ecotoxicity and human toxicity impacts (Bonoli et al. 2013). The biggest impact is the water acute ecotoxicity (0.0135). The forth environmental impact is as bulk waste origins from surface water-slightly organic and inorganic contaminated $(0.007 \mathrm{Pt})$ and the fifth biggest impact $(0.0048 \mathrm{Pt})$ connects to the (GWP 100) and origins also from surface water-slightly organic and inorganic contaminated. 
82 Filtration Materials for Groundwater: A Guide to Good Practice

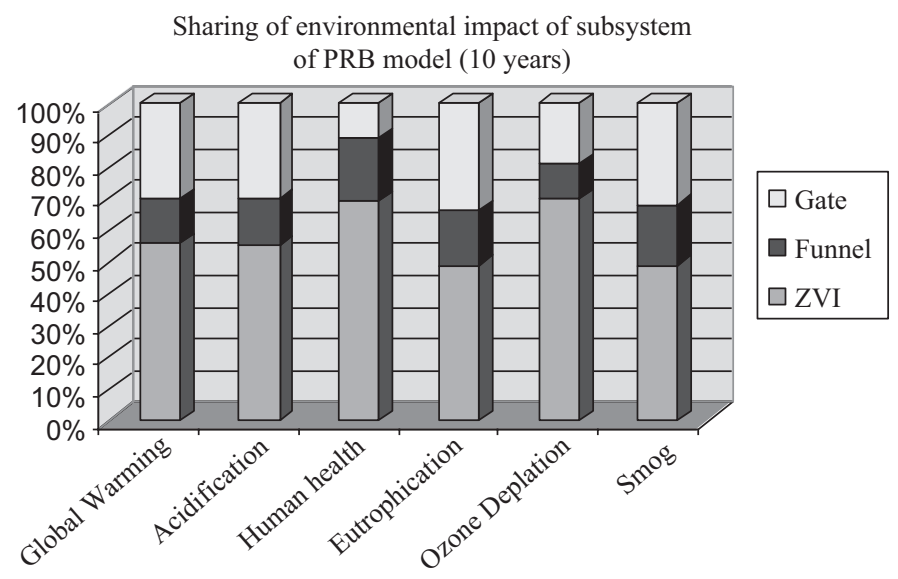

Figure 4.4 Environmental impact of model PRB.

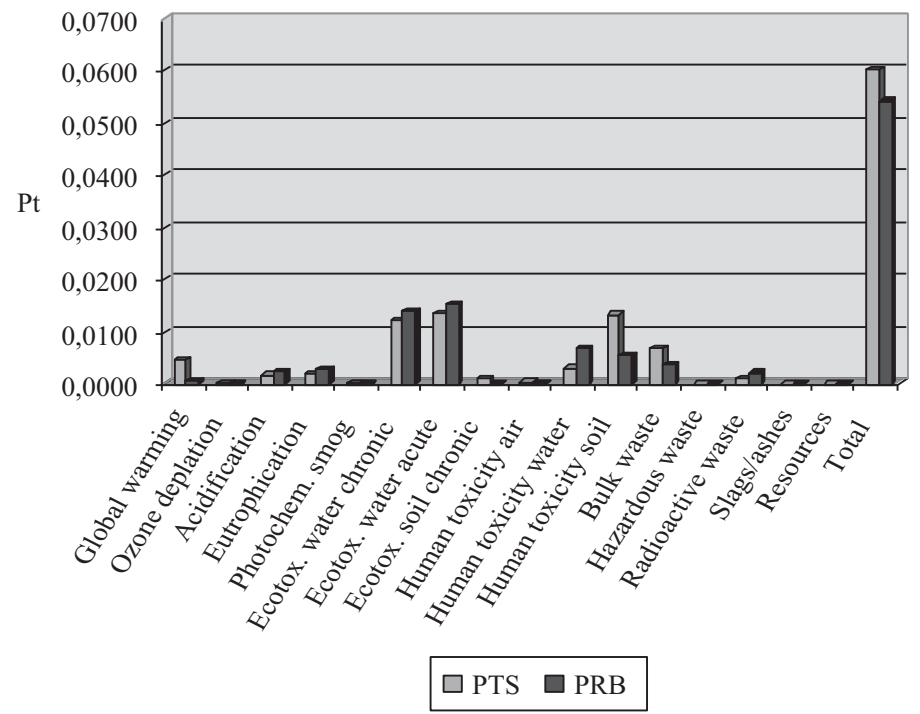

Figure 4.5 Impact of PTS and PRB system in the different impact categories (Bonolli et al. 2013).

The biggest environmental impact of PTS associated with GAC production, construction boreholes and pipes as ecotoxicity water and human toxicity soil, the global warming and bulk waste comes from surface water - slightly organic and anorganic contaminated. The biggest environmental impact of PRB model causes 
also the ecotoxicity water and human toxicity soil and it is origin from recycled iron production and recycled cast iron.

Bonoli et al. (2013) and Antonozzi et al. (2015) concluded that the Permeable Reactive Barrier shows worst environmental performance on ecotoxicity on water (chronic: $0.0138 \mathrm{Pt}$ and acute: $0.0155 \mathrm{Pt}$ ) and toxicity to human health on water. But the environmental load in comparing with PTS technology on the same premises (i.e., same pollution conditions and same water volume to be treated), the overall impact remains $15 \%$ lower.

The two different remediation technologies underlined the different environmental performance they provide, both in absolute value and relative distribution among the impact categories, but, most of all, it has given the opportunity to experiment a possible solution for a gap of the LCA model.

The model PRB has lower environmental impacts when compared with the model PTS though relative benefit depends on longevity. The time at which a PRB continues to treat contaminants at designed levels is finite and is defined as longevity of the barrier. When we choose a remediation technology beside the environmental impact there are numerous factors to consider, from the basic categories of size, weight, and treatment time, to more complicated categories such as filter medium, longevity of the system, and what types of organisms each system is effective at eliminating.

"To date, no PRB has failed due to loss of permeability and reactivity as a result of mineral precipitations. However, it is recognized that all PRBs show a gradual decrease in performance from the time they are installed. Despite all the efforts in the field and in modelling studies to evaluate the geochemistry of iron-groundwater interactions, it is difficult to obtain more than just a qualitative estimate of the type and degree of precipitation and its effect on the reactivity and hydraulic performance of the iron medium. Even when the amount of precipitate formation can be deduced from detailed investigations at sites such as Denver Federal Center and Elizabeth City, by estimating the losses of inorganic constituents from groundwater flowing through the PRB at these sites, it is unclear how much precipitation would have to occur for the performance of the iron to be noticeably affected. Therefore, as part of ESTCP funded study, and accelerated laboratory simulation of the long-term operation of iron PRBs at Moffett Field and Lowry AFB was conducted in a one-year long effort" (Gavaskar et al. 2002).

Skinner (2013) investigated the longevity of remediation technology. "The impacts of remedial measures on the longevity of light non-aqueous phase liquid [LNAPL] releases are rarely quantified at sites where active remediation of LNAPL bodies has been carried out. Without an understanding of LNAPL longevity, decisions regarding the appropriateness of remediation strategies and their scheduling in the life cycle of an LNAPL release could be regarded as arbitrary in some respects. Because LNAPL bodies are continually evolving with respect to composition, internal and external transport, distribution, and lateral and longitudinal mobility, it appears that a necessary part of any site conceptual 


\section{Filtration Materials for Groundwater: A Guide to Good Practice}

model guiding remediation decisions should include an understanding of LNAPL evolution over time in terms of mass remaining".

Accelerated long-term column tests were run to simulate several years of operation of the PRBs at former NAS Moffett Field and former Lowry AFB. The columns were filled with the same iron used in the field PRBs, and groundwater was obtained on a monthly basis from local site representatives. The objective was to observe the kind of aging of the iron that would not be visible in the field PRBs for many years in the future and get some idea about the change in performance of the iron over time (represented by pore volumes of flow).

Several other researchers have studied the potential effects of precipitates on iron PRB performance. For example, Wilkin, Sewell, and Puls (2001) state that "upgradient groundwater chemistry and flow rate appear to be the main factors that control the rates (and type) of mineral precipitation." In Korte (2001), sites with high levels of carbonate and sulphate are identified as being potentially more susceptible to clogging than groundwater with low TDS. Similar concerns with respect to high TDS sites are expressed by Benner, Blowes, and Molson (2001). Specifically, these concerns involve the potential for these precipitates to reduce the activity of the iron and/or to reduce the permeability through pore clogging. Zhang and Gillham (2005) showed in a long-term column study that calcium carbonate precipitation occurs as a moving front through the iron. The maximum loss in porosity was about $7 \%$ of the initial porosity, followed by no further accumulation. These general concerns should be viewed in the context of documented field performance.

The geochemical constituents of the groundwater appear to affect the reactivity of the iron on long-term exposure to groundwater. The rate of decline in iron reactivity over time is dependent on the native level of certain dissolved solids (e.g., alkalinity, sulphate, calcium, magnesium, and silica) in the groundwater. The rate of decline in iron reactivity over time also is dependent on the number of pore volumes of groundwater flowing through the PRB. Therefore, sites with a higher groundwater flow rates are likely to encounter higher rates of decline compared to similar sites (with similar levels of TDS) with lower groundwater flow rates. Over the long term, the PRB is likely to be passivated before the entire mass of $\mathrm{ZVI}$ is used up unless some way of regenerating or replacing the reactive media is developed and implemented.

The porosity and permeability of the iron (and hence the residence time) was not considerably affected over the duration of the test, as indicated by a bromide tracer test conducted in the column after 1300 pore volumes of flow. Therefore, the reactive performance of the iron is likely to decline much faster than any potential decline in long-term hydraulic performance. The progressive decline in iron reactivity over time indicates that the residence time required to meet groundwater cleanup targets also will be progressively higher in the long term. One way of ensuring that sufficient residence time is available in the future is to incorporate a higher safety factor in the designed flow-through thickness of the 
reactive media in the $\mathrm{PRB}$. Therefore, there is a trade-off between current capital investment (construction of a thicker PRB) and future costs (earlier regeneration or replacement of the $\mathrm{PRB})$.

\subsection{DETERMINATION OF POSSIBLE TECHNOLOGIES BASED ON RISK ANALYSIS AND MODELING}

Risk assessment and transport modelling are both routinely used tools in remediation planning as of today. Few decades ago risk assessors often expressed their need for earlier involvement of risk assessment specialist in remediation action planning, as soon as the site investigation is launched. Today risk assessment became the overall framework site investigation, remediation target value setting by conceptual site model setting being the first underlying step of the protocol. Conceptual site model is constructed after careful screening of all possible contaminant sources, exposure pathways and receptors. A sample conceptual site model is shown on Figure 4.6.

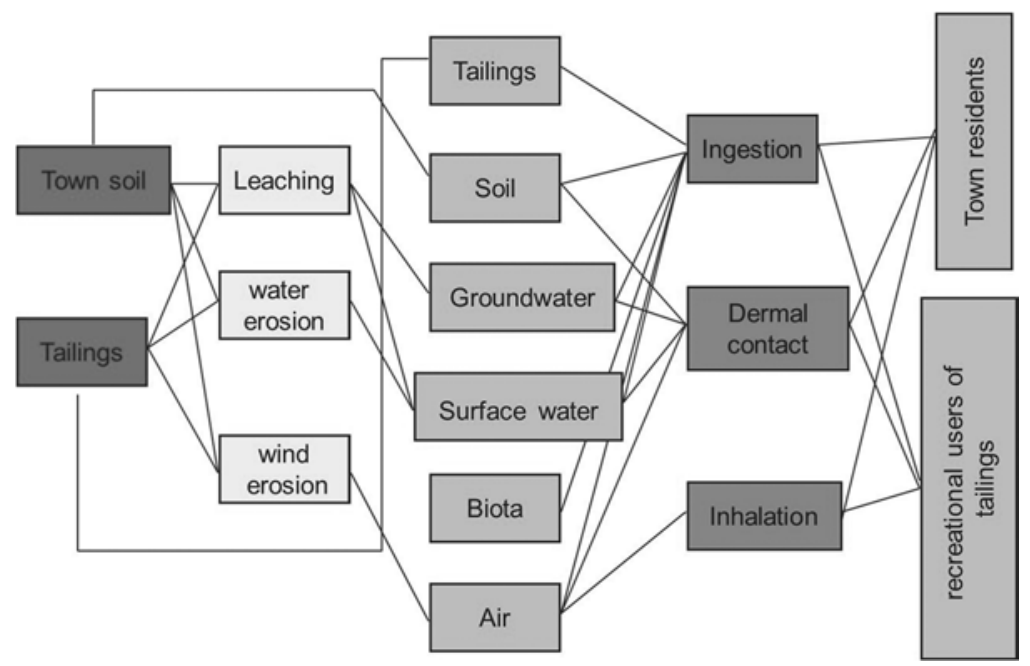

Figure 4.6 Sample conceptual site model for contaminated site management.

Source-pathway-receptor alternatives appoint relevant exposure scenarios highlighting all possible transport media and endpoints through which contaminants may reach receptors. Understanding contaminated site through a well established conceptual site model is crucial for proper remediation design.

Applying the source-pathway-receptor approach to clean up action classification, one can sort clean up actions into three categories (Table 4.3). 
Table 4.3 Clean up action classification.

\begin{tabular}{|c|c|c|}
\hline $\begin{array}{l}\text { Place/Logic of } \\
\text { Intervention }\end{array}$ & $\begin{array}{l}\text { Rationale/Type of } \\
\text { Clean up Action }\end{array}$ & $\begin{array}{l}\text { Technology } \\
\text { Examples }\end{array}$ \\
\hline Source & $\begin{array}{l}\text { Source elimination/ } \\
\text { manipulation }\end{array}$ & $\begin{array}{l}\text { Air sparging, soil vapour extraction } \\
\text { pump and treat technology }\end{array}$ \\
\hline Pathway & $\begin{array}{l}\text { Pathway blocking/ } \\
\text { modification }\end{array}$ & $\begin{array}{l}\text { Slurry wall; PRB; hydraulic barrier, } \\
\text { solidification }\end{array}$ \\
\hline Receptor & $\begin{array}{l}\text { Change/restriction in } \\
\text { receptor habit/life }\end{array}$ & $\begin{array}{l}\text { Restriction in drinking water use, } \\
\text { evacuation }\end{array}$ \\
\hline
\end{tabular}

The rationale of clean up action (Table 4.3) and the complexity of the conceptual site model determines which type of remediation techniques are appropriate. Permeable reactive barrier being a typical pathway blocking/manipulating mechanism, can only be applicable when groundwater is the only exposure pathway. Should there be multiple exposure scenarios (multiple contaminants, or multiple pathways) PRB can not be considered as an option, at least not as a holistic solution for the site (Figure 4.7)

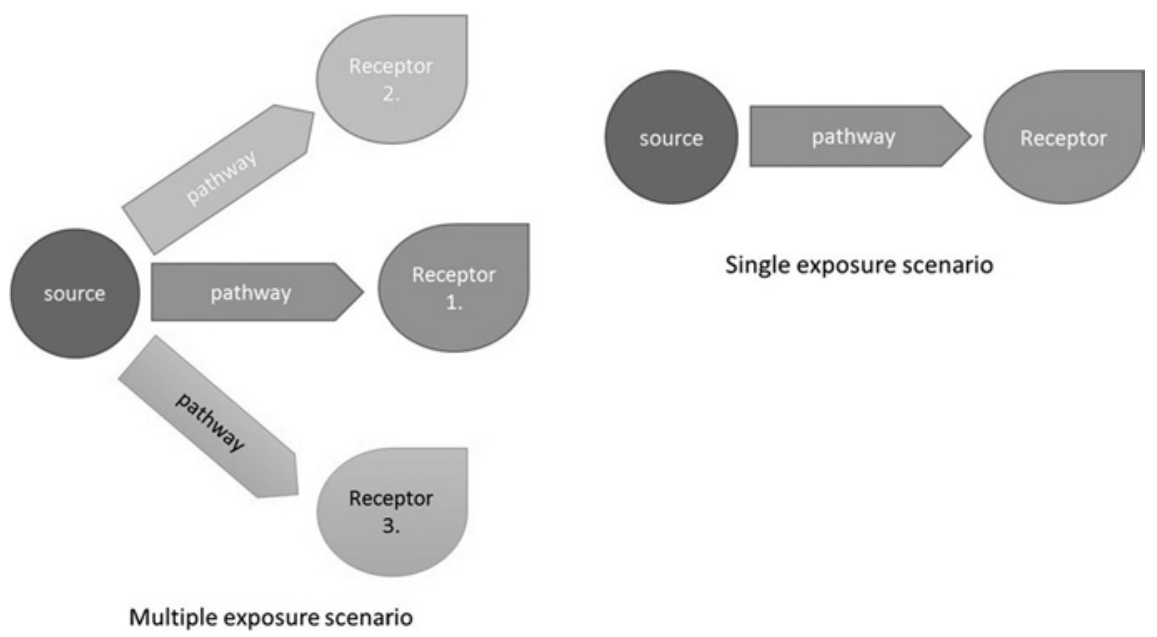

Figure 4.7 The multiple and simple exposure scenario's pathways.

Conventional remediation actions (e.g., pump and treat technology) is a typical source elimination action, targeting either decreasing contaminant concentration below a given threshold, or modifying the form/mobility or toxicity of the contaminant. Decontamination of the source area eliminates all exposure scenarios, decreasing human risks bellow acceptability limit.

Remediation technology selection is influenced by several factors, some of them are natural features of the environment, others are driven by the pollution type/event, 
or by land use aspects. Some of these factors can be investigated by transport modelling or health risk assessment tools, to support proper decision making.

Contaminant transport modelling must answer to a few specific questions, when considering PRB technology as a remedy option. A fundamental premise of PRB application is an adequate understanding of groundwater movement and parameters. PRB application demands permanent groundwater flow direction, well delineated aquifer geometry and knowledge of hydrogeological parameters, based on site measurements.

Groundwater flow modelling can provide the flow gradient pattern and plume dynamics for pre remediation status. Barrier installation must be positioned accordingly. PRB being built into the flow model must show potential contaminant trajectory deviation, while transport model can delineate PRB effected plume and source areas. Certain code modules can model chemical/biological alteration (decay, reactions, precipitation, etc.) caused by the reactive material. Due to the chemical/biological alteration processes both hydraulic and transport properties shall change. Steady state models are not able to quantify these transient phenomena.

Transient models have the capacity to handle variable features of the PRB and its environment (e.g., hydraulic conductivity, reactivity), which is one crucial element of PRB performance. Should the decontamination potential of the barrier decrease in time, the remediation target concentration will not be met, resulting in a failure of the remediation goals.

Health risk assessment's key role in remediation design and technology selection can be to help screening remediation options. By determining the target concentration that clean up must achieve it ultimately narrows down the scope of available technologies. Certain technologies won't have the capacity to achieve the necessary decrease in concentration, which actually is a limitation of PRB technology, if the contaminant flux feeding the barrier extends it capacity (Table 4.4).

Table 4.4 Clean up action classification.

\begin{tabular}{|c|c|c|}
\hline \multirow{2}{*}{$\begin{array}{l}\text { Factors that Influence } \\
\text { Technology Selection }\end{array}$} & \multicolumn{2}{|c|}{ Tool for Assessment } \\
\hline & $\begin{array}{l}\text { Hydrodynamic and cont. } \\
\text { Transport Modelling }\end{array}$ & $\begin{array}{l}\text { Health Risk } \\
\text { Assessment }\end{array}$ \\
\hline Single/multiple source & ++ & \\
\hline $\begin{array}{l}\text { Single/multiple contaminant } \\
\text { of concern }\end{array}$ & ++ & ++ \\
\hline Type of contaminant & ++ & + \\
\hline $\begin{array}{l}\text { Geological/hydrogeological } \\
\text { conditions of the site }\end{array}$ & ++ & + \\
\hline Land use types & + & ++ \\
\hline $\begin{array}{l}\text { Remediation target value vs. } \\
\text { source concentration }\end{array}$ & & ++ \\
\hline
\end{tabular}




\subsection{THE COST ESTIMATION PROCEDURE}

The choice between a passive PRB (e.g., using ZVI) vs. an active system (e.g., frequent and ongoing injection of soluble substrate) is driven by several factors. If feasible, truly passive systems may offer the biggest long-term cost savings, but the difference in cost of the two types may in large part be driven by the frequency of change-out or replenishment of the reactive media (ITRC, 2011).

Generally, selection involves using design parameters to determine the lifecycle costs associated with each treatment technology, comparing the costs and benefits for each technology, and selecting the most appropriate one, with the understanding that concentrations will likely decrease over time and potentially within a few months of operation. The cost comparison should account for the capital expense for installing the system, annual costs for system O\&M, and replacement or maintenance costs. For system components with an expected life span that is shorter than the expected remedy duration, include replacement costs. For other items, an annual maintenance allowance as some small percentage of the installed capital cost should be included (EPA, 2005).

Because PRB are long-term technology applications, the capital investment and annual O\&M costs cannot simply be added up to obtain a total cost. This is because the capital investment is a cost that is incurred immediately, whereas O\&M costs for a long-term PRB (just as with a pumpand-treat system) are spread over several years or decades. Therefore, a present value (PV) calculation is used to obtain the overall or life-cycle cost of the PRB. A real rate of return of $2.9 \%$, as was recommended by the Office of Management and Budget (OMB) in 2000 for long-term (30-year) projects was used to estimate PV. The PV of the PRB at CAAP is estimated at $\$ 24$ million over 30 years, assuming that iron replacement will be required after 15 years.

\subsubsection{Cost analysis by technology}

Estimating the cost of a PRB deployment can be a difficult task since a number of factors need to be evaluated, many of which are not well understood or documented. A number of different sources provide cost data for completed PRBs; however, these data are typically not broken down into the many tasks or cost categories which make up the project's total cost. The Guide to Documenting and Managing Cost and Performance Information for Remedial Projects (Federal Remediation Technologies Roundtable, 1998) could be a useful source of cost calculation. Its use will help to provide improved cost data at completed projects and aid in the estimation of proposed projects. Another tool for estimating the cost of a PRB installation is the Remedial Action Cost Engineering and Requirements System ("RACER"), developed by DoD, which offers a database of costs for activities such as trenching or drilling.

Capital and operating costs were highly variable from site to site with key cost drivers, including variable monitoring requirements, significant system modifications needed, and size and complexity of the remedial systems (Table 4.5). 
Table 4.5 Average system cost of remediation (ESTCP, 2003).

\begin{tabular}{lcc}
\hline Cost Category & P\&T System Average & PRB Average \\
\hline Total capital cost (USD/year) & $4,900,000$ & 652,375 \\
$\begin{array}{l}\text { Average operating cost per } \\
\text { year (USD/year) }\end{array}$ & 770,000 & 150,000 \\
$\begin{array}{l}\text { Unit capital cost (cap.cost/1000 } \\
\text { gallon treated g.water per year) }\end{array}$ & 280 & \\
$\begin{array}{l}\text { Unit average Annual operating } \\
\text { cost per 1000 Gallons of g.water }\end{array}$ & 32 & \\
treated per year & & \\
\hline
\end{tabular}

The following three types of unit costs were calculated for each site: Average operating cost per year of operation \& Capital cost per 1000 gallons treated per year \& Average annual operating cost per 1000 gallons treated per year. The cost elements are differing in the different technologies.

Cost elements in PRB technology:

- capital cost (covers the design, construction, materials, reactive media, engineering, unspecified cost) what is depend on contaminants, the installation method, number of PRBs/gates, PRB location or function, reactive medium material and it's dimension.

- operating cost

Cost elements in P\&T technology:

- capital cost is depending on contaminants and remedial cleanup goals, the type of ex situ treatment (BIO, GAC, PHYS/CHEM, Oxid or strip),

- operating cost depend on years of operation/status, average gallons treated per year.

\subsubsection{Cost factors of installation}

The cost factors that should be evaluated for a PRB installation include the following elements:

- site characterisation cost

- design cost

- construction cost

- purchase and installation of reactive media

- licensing fees and

- reporting

- monitoring costs

- Operating and Maintance costs

- annual monitoring and reporting costs 
- media replacement/rejuvenation

- institutional controls

- unexpected and miscellaneous cost

The site characterization data needed for placement of a PRB require much more detailed data gathering than that typically generated with an overall site characterization. Data gathering on a smaller scale is necessary for placement of a PRB, including the complete vertical and horizontal delineation of the groundwater plume and characterization of hydrogeologic, geochemical, geotechnical, and microbiological conditions.

Site characterization costs associated with a PRB system can be difficult to separate from the overall site characterization costs. The problem with documenting site characterization costs involves determining what cost is associated with PRB as compared to cost associated with the overall site investigation. For instance, if DNAPL is present on site, would the delineation of the DNAPL plume be part of the overall characterization or part of the costs associated with PRB installation? This type of data may be tracked differently at various sites. Site characterization costs can be substantial but are not the primary cost associated with PRB installation.

Design costs include all engineering and work plan development associated with PRB installation. They can include treatability studies, modelling, additional data collection, licensing fees, cost evaluation, cost comparisons, as well as work plan development and reporting. Designs costs can readily be tracked and reported since the costs are easily defined.

Construction is the largest cost factor for the remedial project, including the following costs: media, mobilization, emplacement, waste disposal, health and safety, and site restoration. Depending on the system design, the reactive media can be the most significant cost associated with construction, followed by the emplacement costs. Because there are numerous emplacement methods, the costs associated with emplacement can vary significantly from one installation to the next.

The PRB construction cost includes 10 cost categories by Powell et al. (2004). These are:

- reactive media cost,

- funnel costs,

- gate costs,

- trenching cost,

- mobilization costs,

- equipment costs,

- health and safety costs,

- materials disposal costs,

- other construction cost.

Several construction methods are to construct the granular iron PRB. Selecting the most suitable method depends on several site-specific factors, including the 
design of the PRB, depth of installation, the nature of the geologic materials present, and surface/subsurface obstructions (e.g., buildings and utilities). The flow-through thickness also has an influence on the selection. The choice between trenched methods of construction (continuous PRBs, funnel-and-gate systems), injected PRBs, in situ reactive vessels, and more innovative configurations such as the Geosiphon ${ }^{\mathrm{TM}}$ often drive PRB capital costs. The construction costs increase with depth of application. In general, in addition to some of the technical advantages of injection methods over trenching, costs for reactive media injection are normally less than that for trenching, especially when the cost of excavated soils removal is taken into account. This differential normally increases with increasing depth (ITRC, 2011).

The authors investigated these cost at some implemented remediation case in the USA in year 2000 and 2005. One of these studies analysed 32 sites where five types of ex situ treatment were applied, in the P\&T system. 11 sites operated by GAC. The total capital cost changed from 600,000 USD to 16,000,000 USD while the average 1000 gallon treated moved between 3000-1,400,000 per year.

Several studies have looked at the cost of PRB installations. Originally, the cost of a PRB was compared to a pump-and-treat system. The cost information for a pump-and-treat system was well documented and readily available, providing a straightforward comparison to a conventional technology. Today, however, pumpand-treat systems are not being used at the same number of sites as in past years. This reduction is partially due to issues involving overall effectiveness and the high cost of O\&M for pump-and-treat systems. The commercial availability of other in situ technologies requires a broader review of groundwater remedial technologies in a comparison to a PRB system (Figure 4.8).

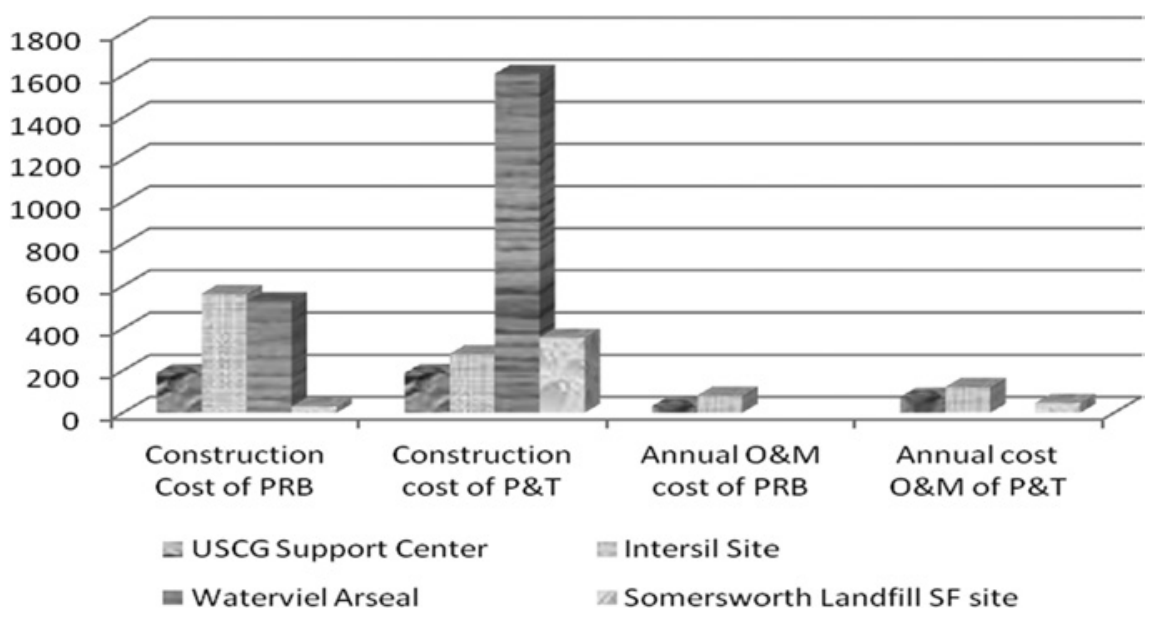

Figure 4.8 Construction and O\&M cost (USD) of PRB and P\&T system per 1000 Gallon treated ground water at different sites (Powel et al. 2004). 


\section{2}

Filtration Materials for Groundwater: A Guide to Good Practice

It seems, that the PRB systems have been generally cheaper and less troublesome to operate and maintain, especially if periodic reactive media maintenance is not needed. The cost effectiveness depend coextensively on the nature of the site and the contaminants. On based of experience of practice the PRB system is less expensive than P\&T technology. It is true for construction and O\&M too (Powell et al. 2004; ITRC, 2005).

\subsubsection{Cost factors of operation}

Operating costs included: labor; materials; utilities and fuel; equipment ownership, rental, or lease; performance testing and analysis (although compliance testing was often not separated out); and other technology operating costs. Source controls, $\mathrm{RI} / \mathrm{FS}$, and system design costs were not included as capital or operating cost.

The operation and maintenance cost covers the following:

- annual monitoring costs,

- annual reporting costs

- other annual costs

In addition to these annual it is anticipated the cost of reactive media periodic replacement or replenishment. During a 30 year lifetime the replacement period needs of five to 10 year intervals. The interval of organic matter-based PRB may be shorter. Because the PRB sites have been in the ground less than 5 years, the media maintenance cost rather hypothetic costs.

" $O \& M$ costs can be difficult to estimate since the life cycle of the reactive media is typically hard to estimate. No ZVI PRB sites have reached the useful life of the media; therefore no data exist on which to base these estimates. Sites have estimated the replacement of the entire reactive media zone on varying schedules such as 5-, 10-, 20- and 30-year cycles. Other estimates are based upon the use of an innovative method to regenerate the iron. Some methods currently being evaluated include ultrasound, use of a pressure pulse technology, jetting, or agitation with a drilling auger to break up any precipitate formation. A reagent flush could also be employed to remove build-up on the iron surface. These techniques have not been employed full-scale, but all have been evaluated to some extent. Development of this type of rejuvenation technology will probably be driven by the need for action at some of the current deployments. It is difficult to determine the best means for estimating operation and monitoring costs associated with reactive media replacement or replenishment. For PRB systems employing iron as the reactive media, a general rule is to expect that some form of media maintenance will be required every 10 years and that the cost could run about $25 \%-30 \%$ of initial construction. However, as the technology matures and sites reach the useful life cycle for the reactive media, a better basis for estimating O\&M costs will certainly emerge.

Some of the cost factors associated with O\&M that can be readily estimated and documented are the annual monitoring costs, any institutional controls, reporting 
costs, and regulatory oversight costs. Another cost somewhat difficult to estimate is any savings associated with being able to return the property to its full economic potential. Because this technology is in situ and passive in nature, the property would have fewer restrictions than a more active remedy with aboveground structures. Cost savings could be associated with a property that has limited restrictions.

A study comparing the cost of several groundwater remedial technologies was published by staff at DuPont (Quinton et al. 1997). The method to compare the technologies posited a generic, non-site-specific template site with a groundwater plume of dissolved PCE 400 feet wide, 1000 feet long, and 60 feet deep. Concentration of PCE averaged $1 \mathrm{mg} / \mathrm{L}$. The study compared enhanced anaerobic bioremediation using both a bio-barrier and a recirculating groundwater system, intrinsic bioremediation, a PRB using ZVI, and a pump-and-treat system using an air stripper and liquid-phase/vapour-phase recovery. The PRB system consisted of emplacement using high-pressure jetting. The scenario assumed that the PRB would be replaced on a 10-year cycle. Costs of each of the four technologies were evaluated on a present-cost basis with a 30 -year estimate for containment remedies. Costs evaluated include design, construction, operation, and monitoring. The comparison addressed the costs on a total system cost as well as per unit costs for both 1000 gallons treated and 1000 pounds of PCE treated. For total cost and unit costs, PRBs were more expensive than intrinsic bioremediation and anaerobic bioremediation but significantly less expensive than pump-and-treat systems.

Battelle (2002) prepared a report in which evaluated PRB systems in comparison to pump-and-treat systems using present-value information. The report evaluated two sites, the Moffett Field site in California and Dover AFB in Delaware, both of which have demonstration pilot-scale PRB systems installed. From this information, an estimate was made for the installation of a full-scale PRB system. Replacement of the reactive media, iron, was included in the estimate on a 10-year cycle. This estimate was then compared to an equivalent full-scale pump-and-treat system. The equivalent pump-and-treat system was designed to capture the same amount of water that was flowing through the PRB system. The cost of the PRB system was less expensive for both sites. The Moffett site cost estimate for the full-scale pump-and-treat system was $\$ 17,081,000$, and the PRB system was $\$ 14,382,000$, a cost saving of $\$ 2,699,000$ (16\%) over the 30-year analysis. The estimates for the two systems at the Dover Site were much closer. The pump-and-treat system was estimated at $\$ 4,857,000$, and the PRB system at $\$ 4,618,000$, a difference of only $\$ 239,000(5 \%)$ in favour of the PRB system.

The economics of PRB systems are tied to the longevity of the media and longterm hydraulic capture in the system. Using the above estimates, if the reactive media functions for only five years before replacement or rejuvenation is necessary, then the cost of the PRB system may be greater than that of the pump-and-treat system. However, if the reactive media functions for greater than 10 years, the PRB system becomes much more cost-effective. The longevity of the media will dictate whether the PRB system will be cost-effective. 


\section{Filtration Materials for Groundwater: A Guide to Good Practice}

Overall, while the costs of PRB systems vary depending on the site-specific circumstances, the length and especially the depth tend to be the biggest factor that drives the cost of the installation. PRB systems typically require a higher cost for installation compared to the conventional pump-and-treat technology; however, O\&M costs are lower and - depending on the useful life of the reactive media - offer costs savings over the project life. PRB systems offer several other advantages that are difficult to assign a monetary figure, such as passive treatment with no aboveground structures that could limit the reuse of the property.

A detailed study of PRB economics entitled Economic Analysis of the Implementation of Permeable Reactive Barriers for Remediation of Contaminated Groundwater (Powell et al. 2004). Cost data for 22 sites were gathered from a number of sources; however, the data were not always available for each site or broken down into the various identified cost categories. Comparisons were made to pump-and-treat systems, for which cost data were also gathered. This report took a different approach in comparing PRBs to pump-and-treat systems. Rather than compare the traditional unit of cost per volume per time, such as cost per 1000 gallons treated per year, the report compared cost per 1000 gallons of treated water. Using the cost per volume per time method skews the treatment toward the technology that treats the greatest amount of water rather than the amount of contaminated water. The cost per volume per time method results in the O\&M costs being cheaper for the groundwater pump-and-treat system, a system that must pump much more water than the actual contaminated water volume to achieve hydraulic control. The cost per 1000 gallons of water treated method looks at the volume of contaminated water treated, making the PRB system much more costeffective for O\&M.

The report draws no absolute conclusions on the cost-effectiveness of PRB systems when compared to pump-and-treat systems. Concise conclusions on the comparison were complicated by the lack of accurately documented costs both for the overall PRB system and its many individual cost components. In addition, questions about the longevity of reactive media and the frequency, cost, and extent of media maintenance all complicate any cost comparisons. The results indicate PRB systems may be more cost-effective over the long term when O\&M are included in the evaluation, especially if periodic reactive media maintenance is not necessary. The document also points out a number of advantages that PRB systems have over pump-and- treat systems that are not typically included in a financial comparison.

In conclusion, PRB systems appear to be cost-effective when compared to groundwater pump-and-treat systems if the useful life of the reactive media approaches 10 years. In many cases, it appears that this longevity may be obtainable. However, until there is a history on the useful life of reactive media and until techniques are developed for media rejuvenation. it will be difficult to accurately gauge the overall costs of PRB systems (Table 4.6) against a technology like groundwater pump and treat, where there is extensive knowledge and experience. 
Table 4.6 Summary of costs of the permeable reactive barrier (Beck, Harris \& Sweeny 2001).

\begin{tabular}{lr}
\hline Activity & Final Cost (\$) \\
\hline Site investigation & \\
Main site investigation & 281,470 \\
Additional site investigation & 54,117 \\
Subtotal & 335,587 \\
Remediation & \\
Soil removal and disposal costs & 109,650 \\
Pilot-scale evaluation & 26,316 \\
Design preparation of contracts and working plan & 23,392 \\
Installation of cutoff wall and PRB & 368,804 \\
Supervision & 55,615 \\
Completion report & 15,366 \\
Subtotal & 599,143 \\
Groundwater monitoring & \\
Monitoring (10 years) & 128,938 \\
Tracer test & 11,696 \\
Consumables & 292 \\
Subtotal & 140,926 \\
Total & $1,075,656$ \\
\hline
\end{tabular}

\subsubsection{Cost factors of regeneration/reuse}

Probably one of the most difficult aspects of predicting the long-term costs of a $\mathrm{PRB}$ is the estimation of the frequency and cost of replacement or rejuvenation of reactive media. Cost to Replenish or Rejuvenate Reactive Media ZVI PRBs is a most significant. The objective of rejuvenation of granular iron would be to restore the permeability loss due to precipitate formation and possibly to remove the precipitate from the iron to restore its reactivity. Using sophisticated flow and transport models a theoretical estimate of the operational time before implementing rejuvenation methods can be calculated.

Conceptual rejuvenation methods may include the following:

- using ultrasound to break up the precipitate

- using PPT to break up the precipitate

- using solid-stem augers to agitate the PRB

- periodic flushing with nitrate free water to remove nitrates.

No full-scale test to rejuvenate mineralized ZVI has been performed to date. One developing method, ultrasound, has been subjected to limited field-scale tests 
to determine its effectiveness, with mixed results. At this point, one can state only that these methods may prove to be successful in rejuvenating a ZVI PRB. For ZVI PRBs - in particular with injected PRBs - the cost-effectiveness of injecting new ZVI rather than attempting to rejuvenate mineralized ZVI is likely greater even though material cost of ZVI may vary greatly year to year (ITRC, 2011).

It is critical that all costs be fully tracked and documented during the planning, installation and operation of PRB systems. The longevity of the PRB system and the need, frequency and extent of media maintenance are critical factors.

Bortone et al. (2013) made a preliminary cost analysis both of remediation technology the PRB and PTS from the design to end of life period for a PCE contaminated aquifer. The investigated many variants and the design requires the use of an iterative procedure by the application of a trial and error approach, verifying that contaminant concentrations downstream the treatment achieve the water quality standards. The best design for both remediation technologies was identified through various numerical simulations considering different working conditions.

The best results of PRB technology origin from the following dimensions: thickness equal to $3 \mathrm{~m}$, length of $900 \mathrm{~m}$ and height of $12 \mathrm{~m}$, and consequently a volume of adsorbing material equal to $27,000 \mathrm{~m}^{3}$ and the total cost $4,150,000$ EUR. During the working period of about $60 \mathrm{y}$ the effluent PCE concentration is always lower than the Italian regulatory limit, also taking into account the possible occurrence of desorbing phenomena from GAC to groundwater.

The best results of P\&T system were obtained with a configuration of 27 pumping wells and 12 recharge wells. The longevity period of about $35 \mathrm{y}$, the PCE concentration is everywhere lower than the Italian regulatory limit so that the whole groundwater volume results to be decontaminated. In the adopted well configuration, when the PCE concentration reaches a value lower than the regulatory limit, a progressive turning off of pumping wells can be adopted in the pertinent zone. The total cost of optimal case was 6,128,000 EUR, and the cost of workers takes about $60 \%$.

Bortone et al. (2013) concluded that the PRB technology might be cheaper than PTS technology, but the cost of technology depend on longevity period and cost of adsorbing material. In the PRB technology it exceeds the $70 \%$ of the total cost, but if there use of low cost adsorbing material this technique is cheaper than the PTS.

But Bortone et al. (2013) also said it is not possible clearly to establish, which remediation method is the most cost-effective because the wide margin uncertainty in the unit cost of the main variable examined (Figure 4.9).

The PRBs are a more robust technology than one might anticipate based on laboratory column experiments. Thus, more detailed and comprehensive field monitoring is crucial to determining modes of failure and, in turn, PRBs' cost effectiveness as a longterm treatment technology (Skinner, 2013).

"One significant unknown is the cost evaluation and the longevity of the reactive medium, a term that refers to the time during which the PRB retains the desired reactive and hydraulic performance. Because existing PRBs have been operational 
only for about five years, and because most geochemical assessment tools have been primarily qualitative rather than quantitative, it is unclear how long a PRB may be expected to retain its performance." (Gaveskar et al. 2000).

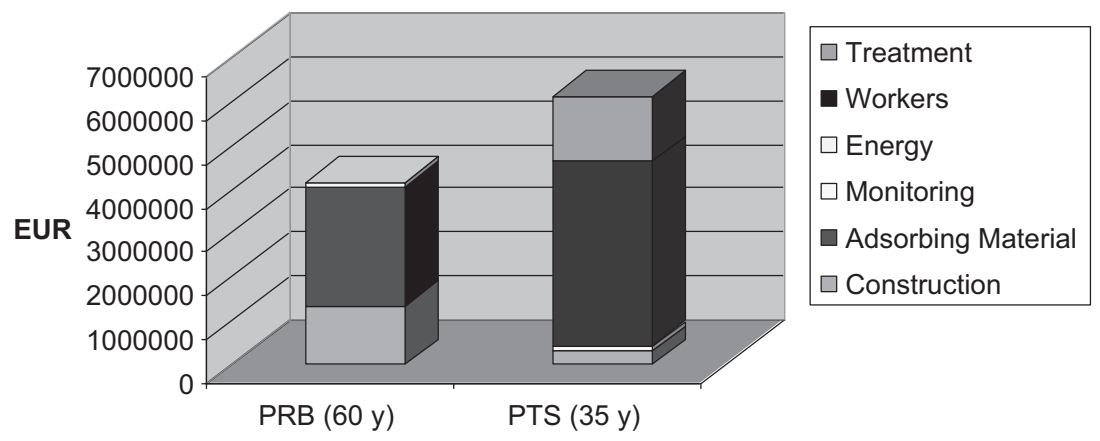

Figure 4.9 The best cases of cost of remediation technology (Borton et al. 2013).

\subsection{THE ADVANTAGES AND LIMITATIONS OF PUMP. AND-TREAT METHODS AND PASSIVE TECHNOLOGIES}

In this chapter we collected the advantages and limitations of the PRB and P\&T systems (Table 4.7).

The selection of remediation technology is always a site specific decision. The efficient performance of the remediation system influenced by several factors, most of them related to the hydraulics of the contaminated site and properties of the contaminants. If both of the PRB and P\&T system are suitable technology at a given contaminated site, the cost estimation and modeling could provide additional information to the decision makers. But it's a hard question to forecast the technical risk of the remediation system, the time of operation when the failure (and the type of failure) occurs, so the real maintenance cost couldn't calculated for the remediation techniques. Among the available techniques, it must be preferred the safer, or which one easiest to repair and modify. Unfortunately in lot of cases there are several professionally marginal factors (like the available professional, technical and mainly financial resources) that deeply influence the decision. The risk of inappropriate operation can be reasonably reduced with numerical simulations of possible scenarios and of the ongoing processes with permanent validation using monitoring data. Computer simulations are not only suitable to support the PRB or P\&T design but they are also useful to control the efficiency of the operation of remediation activities. All remedial activities must be supplemented by an additional and straightforward and continuous monitoring that supports the evaluation of performance but also makes professional interactions, fine tuning of operation, and finally even the redesign of the system possible. 
Table 4.7 The strength and weaknesses of PRB and P\&T systems (EPA, 1990, EPA, 1994, ESTCP, 2003).

Advantages
Permeable Barrier
Passive technology, lower maintenance
cost in long term

Large variety of dissolved contaminants can be treated with commonly available reactive part

The reactive media can regenerate/ reuse

Long period of operation

Lower environmental impact than P\&T

Often cost and time saving

\section{Pump and Treat Systems}

It could reach the remediation goals in shorter time, but traditional P\&T systems designed to remove $0,3-2$ pore volume contaminated water of aquifer per year

Lower capital investment

Easy to control and maintain

Post-construction modification and changes easier

Injection of chemicals could enhance the efficiency of the system

Pulsed pumping could enhance the performance of the system

\section{Weaknesses}

Greater capital investment than for an equivalent P\&T system.

Post-construction modification and changes are more difficult and expensive than for P\&T systems The contaminant plume may outlive the useful life of PRB

The reactive media can be clogged and damaged

Continuous hydraulic and geochemical monitoring needed

Sensitive to the hydraulics of the aquifer

Dissolved contaminants can be treated tht have $\log _{\text {koc }}$ or $\log _{\text {kow }}$ value $<3.0$ and 3.5. For higher values the P\&T can use only for hydraulic containment

High risk of rediffusion from over or underlying formations

Higher maintenance cost in long term

Shorter term of operation than PRB

Sensitive to the hydraulics of the aquifer, continuous hydraulic and geochemical monitoring needed Tailing and rebound phenomena

\subsection{REFERENCES}

Antonozzi L., Bonoli A. and Zanni S. (2015). Life Cycle Assessment Applied to Remediation Technologies: Methodological and Practical Issues Athens, Greece May 21-23, 2015 http://iwwatv.uest.gr/proceedings/presentations/22_May/SESSION_ X/10_Antonozzi_et_al.pdf

Alessandra B., Antonozzi L. and Zanni S. (2013). Life cycle assessment (LCA) as a means of comparison between active and passive remediation technologies for wastewater 
and contaminated soils. Environmental Engineering and Management Journal, 12(S11) Supplement, 141-144, http://omicron.ch.tuiasi.ro/EEMJ/

Barnhouse L. W. and Suter G. W. (1986). User's Manual for Ecological Risk Assessment. ORNL-6251 Oak Ridge National Laboratory, Oak Ridge TN.

Battelle (2002). Cost and Performance Report - Evaluating the longevity and Hydraulic of Permeable Reactive Barriers at Department of Defense Sites Technical Report TR-2213-ENV.

Bayer P. and Finkel M. (2006). Life cycle assessment of active and passive groundwater remediation technologies. J Contam Hydrol., Feb 10; 83(3-4), 171-99. Epub 2005 Dec 27.

Beck P., Harris N. and Sweeney N. (2001). Design, Installation and Performance Assessment of a Zero Valent Iron Permeable Reactive Barrier in Monkstown, Northern Ireland. CL:AIRE Publisher, Technology Demonstration Report TDP 03.

Bender A., Volkwein S., Battermann G., Hurtig H-W., Klöpffer W. and Kohler W. (1998). Life cycle assessment for remedial action techniques: Methodology and application. Contaminated Soil, Thomas Telford, London, 367-376.

Benner S. G., Blowes D. W. and Molson J. W. H. (2001). Modeling preferential flow in reactive barriers: implication for performance and design. Groundwater, 39(3), 371-379.

Bortone I., Chianesea S., Di Nardoa A., Di Natalea M., Ertob A. and Musmarraa D. (2013). A comparison between pump \& treat technique and permeable reactive barriers for the remediation of groundwater contaminated by chlorinated organic compounds. Immacolata Chemical Engineering Transactions, 32, 31-36.

Cadotte M., Deschênes L. and Samson R. (2007). Selection of a remediation scenario for a diesel-contaminated site using LCA. Journal of Life Cycle Assessment, 12(4), 239-251.

Diamond M. L., Page C. A., Campbell M., McKenna S. and Lall R. (1999). Life-cycle framework for assessment of site remediation options: Method and generic survey. Environmental Toxicology and Chemistry, 18, 788-800.

EPA (2005). Cost-Effective Design of Pump and Treat Systems, OSWER 9283.1-20FS and Emergency Response EPA 542-R-05-008 (5102G) April 2005 www.cluin.org www.epa.gov/superfund; http://epa.gov/tio/download/remed/hyopt/factsheets/costeffective_design.pdf

ESTCP (Environmental Security Technology Certification Program U.S. Department of Defense) (2003). Evaluating the Longevity and Hydraulic Performance of Permeable Reactive Barriers at Department of Defense Sites Cost \& Performance Report ESTCP Project: CU-9907 https://clu-in.org/download/techfocus/prb/Evaluating_the_ longevity_2003_CU-199907-CP.pdf

ESTCB (2008). Cost \& Performance Report Project: ER-0223 file:///C:/Users/Szita\%20 K1\%C3\%A1ra/Downloads/ER-0223-C\&P.pdf, downloaded: 15072015.

Gavaskar A., Gupta N., Sass B., Janosy R. and Hicks J. (2000). Design Guidence for Application of Permeable Reactive Barriers for Groundwater Remediation Battele Colombus, Ohio, Strategies Environmental Research and Development Program http:clu-in.org/conf/itrc/prbll_061506/prb-2.pdf, download: 15082015.

Gallagher M. P., Spatari S. and Cucura J. (2013). Hybrid life cycle assessment comparison of colloidal silica and cement grouted soil barrier remediation technologies. Journal of Hazardous Matarials, 250-251, 421-430.

Higgins, M. R. and Olson T. M. (2009). Life-cycle case study comparison of permeable reactive barrier versus pump-and-treat remediation. Environ. Sci. Technol., 43, 9432-9438. 
Higgins M. R. (2011). Environmental Assessment Of In Situ Groundwater Remediation With Reduced Iron Reactive Media PhD dissertation (Environmental Engineering) in The University of Michigan 2011 http://deepblue.lib.umich.edu/bitstream/ handle/2027.42/89676/mrhig_1.pdf?sequence=1

ITRC (2005). Technical/Regulatory Guidelines Permeable Reactive Barriers: Lessons Learned/New Directions http://www.itrcweb.org/GuidanceDocuments/PRB-4.pdf

ITRC (2011). Permeable Reactive Barrier: Technology Update June 2011 Prepared by The Interstate Technology \& Regulatory Council PRB: Technology Update Team Copyright 2011 Interstate Technology \& Regulatory Council http://www.itrcweb.org/ GuidanceDocuments/PRB-5-1.pdf

Keely J. F. (1989). Performance Evaluation of Pump-and-Treat Remediations. Superfund Issue Paper. EPA/540/8-89/005. R.S. Kerr Environmental Research Laboratory, Ada, OK.

Korte N. (2001). Zero-valent iron permeable barriers. A review of performance. Oak Ridge National Laboratory Environmental Sciences Division Publication N5056.

Kovács B. and Szanyi J. (2005). Hydrodinamical and Transport Modeling in Processing Modflow for Windows Environment (in Hungarian), Univeristy of Miskolc, Miskolc, Hungary.

Kovács B., Tóth M. and Kántor T. (2013). Investigation of transport modelling and soil structure influencing effect of biodiesel by-product in agricultural soils. Georgicon for Agriculture: A Multidisciplinary Journal in Agricultural Sciences, 18(3), 57-70.

Madarást T. (2005). The application of risk assessment tools and the set of it's criteria during the contaminated site remediation. (in Hungarian) $\mathrm{PhD}$ dissertation, "Kockázatfelmérés alkalmazása és kritériumrendszere szennyezett területek kármentesítése során". University of Miskolc, Miskolc, Hungary.

Martin T., McNab W. and Kempton H. (2002). Cost Benefit Analysis of Sulfide-Based Treatment Technologies for Remediation of Metal-Contaminated Groundwater, http:// info.ngwa.org/gwol/pdf/032678624.pdf

Mikita V., Kozyatnik I., Hedlund P., Lövgren L., Törneman N. and Tysklind M. (2015). Permeable barrier in boreal region: hydrogeological modelling and sorbents evaluation. Proceeding of 1st International Symposium and 4th Sino-Hungarian Workshop on Remediation and Restoration of Polluted Mining Areas. Vuhan, China.

Müller D. (2007). EURODEMO \& Environmental Efficiency In Land Remediation Dietmar MÜLLER, Federal Environment Agency, Austria MOKKA Conference, Budapest, June 15, 2007, http://Www.Mokkka.Hu/Conference/English_Presentations/Mueller_ Ppt.Pdf

Naftz D., Morrison S. J., Fuller C. C. and Davis J. A. (2002). Handbook of Groundwater Remediation using Permeable Reactive Barriers, Elsevier, ISBN: 0-12-513563-7.

Page C. A., Diamond M. L., Campbell M. and McKenna S. (1999). Life-cycle Framework for Assessment of Site Remediation Options: Case Study. Environmental Toxicology and Chemistry, 18, 801-810.

Powell R. M., Powell P. D. and Plus R. W. (2004). Economic analysis of the implementation of Permeable Reactive Barrier for Remediation of Contaminated Ground Water EPA Environmental Protection Agency.

Quinton G. E., Buchanan Jr. R. J., Ellis D. E. and Shoemaker S. H. (1997). A method to compare groundwater cleanup technologies. Remediation Journal, 7(4), 7-16. 
Skinner A. M. (2013). LNAPL longevity as a function of remedial actions: Tools for evaluating LNAPL remedies Thesis, Colorado State University, 2013, 135 pages; 1550794.

Szanyi J. (2004). The influence of lower-boundary condition on the groundwater flow system. Acta Geologica Hungarica, 47(1), 93-104.

Wilkin R. T., Puls R. W. and Sewell G. W. (2002). Long-term performance of permeable reactive barriers using zero-valent iron. Geochemical and Microbiological Effects, Ground Water, 41, 493-503.

Zang Y. and Gilham R. W. (2005). Effects of gas generation and precipitates on performance of Fe0 PRBs. Groumdwater, 43(1), 113-121. 
Downloaded from https://iwaponline.com/ebooks/book-pdf/651183/wio9781780407005.pdf

by IWA Publishing publications@iwap.co.uk 


\section{Chapter 5}

\section{Examples of modern ongoing facilities for ground water treatment and polluted sites remediation}


Downloaded from https://iwaponline.com/ebooks/book-pdf/651183/wio9781780407005.pdf

by IWA Publishing publications@iwap.co.uk 


\title{
5.1 Constructed wetlands for groundwater remediation
}

\section{Oksana Coban}

\author{
Department Catchment Hydrology, Helmholtz Centre for Environmental \\ Research - UFZ; oksana.voloshchenko@ufz.de
}

\subsubsection{INTRODUCTION}

Wetlands are land areas that are wet during a part or all of the year because of their location, as they are often transitional between terrestrial and aquatic systems. Wetlands, both constructed and natural, are promising in-situ water treatment systems, owing to augmented microbial growth within the plants' rhizosphere, which creates an effective contaminant degradation zone (Kadlec \& Wallace, 2008). Constructed wetlands (CWs) are man-made systems that have been constructed to reproduce enhance specific characteristics of wetland ecosystems for improved treatment capacity of contaminated water (Kadlec \& Wallace, 2008). Constructed wetlands are widely used in both wastewater and groundwater treatment due to their low energy requirements and easy operation (Garcia et al. 2010). While microorganisms play the primary role in pollutant elimination, plants enhance the microbial activity to remove pollutants (Stottmeister et al. 2003). Due to the mosaic of aerobic and anaerobic zones within the root zone of the plants, contaminants can be removed by a variety of processes, aerobic as well as anaerobic.

Constructed wetlands can be designed using various flow regimes. The main types are surface flow (SF) and subsurface flow (SSF), which is further subdivided into horizontal subsurface flow (HSSF) and vertical subsurface flow (VSSF). The main characteristics of these systems are described in Table 5.1.1.

According to specific needs, one of these types can be advantageous over others. Also, hybrid systems can be constructed which combine advantages of HSSF and VSSF CWs (Vymazal, 2010). Furthermore, a floating plant root mat (FPRM) is a hybrid of SF and SSF CWs. Because of their specific structure, an FPRM combines low construction cost from SF and high treatment performance from SSF CWs, 
and is therefore used for the low-cost treatment of different types of contaminated water and removal of different pollutants.

\subsubsection{A CASE STUDY}

An example of constructed wetlands used for groundwater remediation is the Leuna Megasite in Eastern Germany. As Leuna has been a location of chemical industry since the beginning of the last century, a range of contaminants has migrated into groundwater as a consequence of accidental spillage, improper handling, and damage resulting from heavy bombing during World War II. Consequently, the contamination is complex, and the main pollutants are petroleum hydrocarbons (BTEX), methyl tert-butyl ether (MTBE), and ammonium $\left(\mathrm{NH}_{4}^{+}\right)$. Organic chemicals pose a somewhat difficult set of problems for remediation because of their possible toxicity to plants and the limitations of aerobic and anaerobic degradation. In Leuna groundwater, benzene and MTBE were present in average concentrations of $20 \mathrm{mg} \mathrm{L}^{-1}$ and $3.7 \mathrm{mg} \mathrm{L}^{-1}$ respectively. In 2006, the contaminated plume had an area of about $900,000 \mathrm{~m}_{2}$. The dissolved pollutants are transported with the groundwater flow, which is directed generally from northwest to southeast. Downstream from the contamination source, there are different receptors (e.g. rivers, wells), which are potentially impacted by groundwater pollutants. The main aquifer thickness was estimated to be 2-4 $\mathrm{m}$ and the groundwater table is located about 3-4 m below ground surface. The groundwater flow velocity varies between $0.3 \mathrm{~m} \mathrm{day}^{-1}$ and $1.0 \mathrm{~m} \mathrm{day}^{-1}$ (Martienssen et al. 2006).

Table 5.1.1 Characteristics of the main types of constructed wetlands.

\begin{tabular}{|c|c|c|c|}
\hline Type of CW & SF & HSSF & VSSF \\
\hline Media & - & sand/gravel & sand/grave \\
\hline Organics removal & High & High & High \\
\hline $\begin{array}{l}\text { Suspended solids } \\
\text { removal }\end{array}$ & High & High & High \\
\hline Ammonium removal & Moderate & Moderate & High \\
\hline Nitrate removal & Low & High & Low \\
\hline Phosphorus removal & Low & Moderate & Moderate \\
\hline Land requirement & High & High & Moderate \\
\hline Climate sensitivity & High & High & Low \\
\hline $\begin{array}{l}\text { Maintenance } \\
\text { requirement }\end{array}$ & Moderate & Moderate & High \\
\hline Construction cost & Low & Moderate & High \\
\hline
\end{tabular}

At this location, a pilot-scale $\mathrm{CW}$ plant for groundwater remediation was constructed in 2007 within the framework of the SAFIRA II Project "Compartment Transfer - CoTra" (Figure 5.1.1). The pilot scale plant was operated from 2007 
through 2013. The main goal of the project was to develop a near-natural groundwater remediation technique for megasites by transferring contaminated groundwater from wholly anaerobic environments to mixed aerobic/anaerobic environments, which enhances biodegradation/transformation processes. The implemented CW types were HSSF and FPRM. The removal efficiencies of BTEX, MTBE, and $\mathrm{NH}_{4}{ }^{+}$were investigated, including seasonal variations.

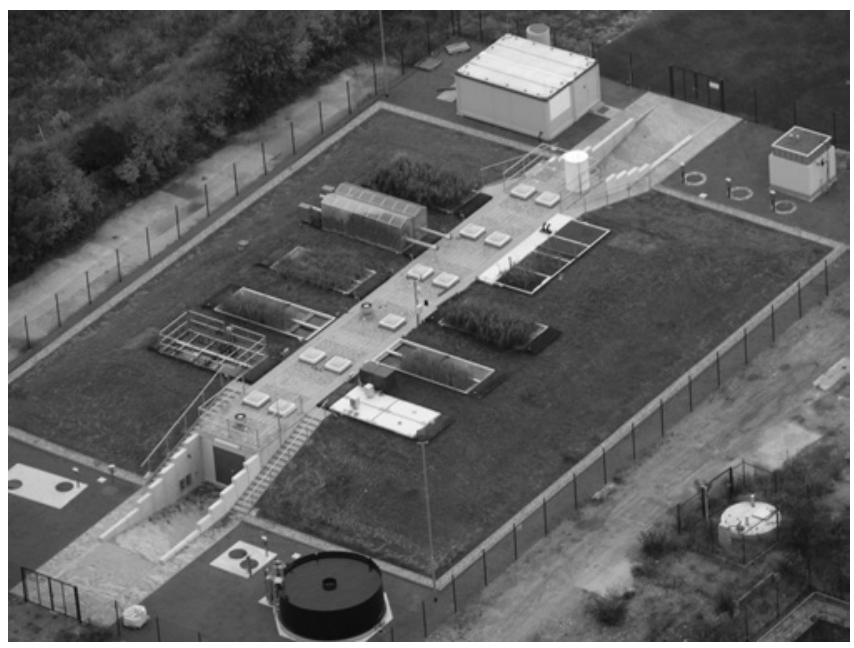

Figure 5.1.1 The pilot scale plant in Leuna (courtesy of M. Kaestner).

Seeger et al. (2011) reported $99 \%$ benzene removal in HSSF CWs, and $82 \%$ MTBE in FPRM. As for $\mathrm{NH}_{4}{ }^{+}$, about $54 \%$ removal for planted $\mathrm{HSSF} \mathrm{CW}$ and $41 \%$ for FPRM were reported. More recently, up to $100 \% \mathrm{NH}_{4}{ }^{+}$removal in HSSF CW was achieved (Coban et al. 2014). This increase in efficiency is attributed to the fact that the average $\mathrm{NH}_{4}{ }^{+}-\mathrm{N}$ concentration decreased from 45 to $23 \mathrm{mg} \mathrm{L}^{-1}$ since 2009 when Seeger and co-workers collected samples. Thus, the removal efficiency increased with time, while the rate of removal remained constant at $23 \mathrm{mg} \mathrm{NH}_{4}{ }^{+}-$ $\mathrm{N} \mathrm{L}^{-1}$ over both studies.

\subsubsection{CONCLUSIONS}

The FPRM, due to an open water body, contains higher oxygen concentrations and therefore could be a cost-competitive variant and an alternative for the treatment of the contaminants with aerobic degradation pathways, such as benzene and MTBE. High removal efficiency of $\mathrm{NH}_{4}{ }^{+}$by the HSSF CW illustrates that this system can be efficiently used for $\mathrm{NH}_{4}{ }^{+}$treatment, but only under loads up to $250 \mathrm{~g} \mathrm{~m}^{-2} \mathrm{yr}^{-1}$. With an inflow rate of $7 \mathrm{~L} \mathrm{~h}^{-1}$, this system could clean up the $\mathrm{NH}_{4}^{+}$ contamination in the Leuna Megasite in 44,000 years. This is due to a large volume 
of contaminated groundwater $(2.7 \times 109 \mathrm{~L})$. Increasing the $\mathrm{CW}$ area or creating hybrid system with a VSSF CW would reduce the clean up time. However, CWs alone cannot be used as a single remediation strategy for contamination on such a scale. In case of Leuna, significant decrease in $\mathrm{NH}_{4}{ }^{+}$concentration between 2009 and 2012 could be partially assigned to a possible occurrence of natural attenuation and only partially to pilot-scale CW plant.

Climate has a strong effect on groundwater remediation rates of CWs. On the one hand, the removal rate for $\mathrm{NH}_{4}{ }^{+}$at Leuna Megasite through the whole year except for the winter season remained constant as the air temperature was always above $10^{\circ} \mathrm{C}$. On the other hand, $\mathrm{NH}_{4}{ }^{+}$removal efficiency in winter was negligible, which has to be considered in the up-scaling of these systems for full scale contaminated groundwater treatment. Also, an understanding of the degradation processes on a molecular level occurring within the system is necessary for further technological improvement of CWs.

\subsubsection{REFERENCES}

Coban O., Kuschk P., Wells N., Strauch G. and Knoeller K. (2014). Microbial nitrogen transformation in constructed wetlands treating contaminated groundwater. Environ. Sci. Pollut. Res., 22(17), 12829-12839.

Garcia J., Rousseau D. P. L., Morato J., Lesage E. L. S., Matamoros V. and Bayona J. M. (2010). Contaminant removal processes in subsurface-flow constructed wetlands: a review. Critical Reviews in Environmental Science and Technology, 40, 561-661.

Kadlec R. H. and Wallace S. D. (2008). Second Edition, Treatment Wetlands. CRC Press.

Martienssen M., Fabritius H., Kukla S., Balcke G. U., Hasselwander E. and Schirmer M. (2006). Determination of naturally occurring MTBE biodegradation by analysing metabolites and biodegradation by-products. J. Contam. Hydrol., 87, 37-53.

Seeger E. M., Kuschk P., Fazekas H., Grathwohl P. and Kaestner M. (2011). Bioremediation of benzene-, MTBE- and ammonia-contaminated groundwater with pilot-scale constructed wetlands. Environmental Pollution, 159, 3769-3776.

Stottmeister U., Wiessner A., Kuschk P., Kappelmeyer U., Kastner M., Bederski O., Muller R. A. and Moormann H. (2003). Effects of plants and microorganisms in constructed wetlands for wastewater treatment. Biotechnol. Adv., 22, 93-117.

Vymazal J. (2010). Constructed wetlands for wastewater treatment. Water, 2, 530-549. 


\subsection{Constructed wetlands for the treatment of petroleum hydrocarbon contaminated groundwater - a pilot scale study}

\section{Andrea Watzinger*, Paul Kinner and Thomas G. Reichenauer}

AIT Austrian Institute of Technology $\mathrm{GmbH}$, Health \& Environment Department, Environmental Resources \& Technologies, 3430 Tulln, Austria

*Corresponding author: andrea.watzinger@ait.ac.at

\subsubsection{INTRODUCTION AND METHODOLOGY}

A site in Vienna, Austria, with an area of around $17,000 \mathrm{~m}^{2}$ was contaminated with petroleum hydrocarbons as the area was used as reloading point for petroleum products and coal from the end of the 19th century until the mid of the 20th century. The site was enclosed with a subterraneous curtain in 2002. The concentrations of total petroleum hydrocarbons (TPH) in the enclosed groundwater body were between 1.2 and $1.8 \mathrm{mg} / \mathrm{l}$ in 2011. Additionally, the groundwater was anoxic i.e. it did not contain dissolved oxygen but had higher concentrations of dissolved iron, manganese and ammonium in comparison to the surrounding uncontaminated groundwater. A pilot scale research project testing bioventing and constructed wetland for the reclamation of the unsaturated zone and the groundwater was launched by the AIT Austrian Institute of Technology GmbH in 2012 (Reichenauer et al. 2015). For the treatment of the contaminated groundwater, four constructed wetlands (CWs) were built in August 2012. The CWs were approximately $3 \mathrm{~m}$ long, $2 \mathrm{~m}$ broad and $1.5 \mathrm{~m}$ deep and were filled with three different filter materials (Figure 5.2.1; Table 5.2.1) and operated at different modes to compare removal efficiencies.

In October 2012 the constructed wetland was planted with willows (Salix viminalis L.). The CWs were designed as vertical flow filters and operated with intermittent loading ( 6 to 12 times daily). The CWs were impounded between 30 
and $50 \mathrm{~cm}$ from the bottom. From July 2013 onwards, concentration of TPH in the groundwater was increased artificially by dosing diesel to the groundwater to test the treatment efficiencies of the constructed wetlands at higher contaminant loads. The concentration and loads of TPHs were measured weekly during the operation in the inflow and effluent water. Additionally, an extensive chemical characterisation of the influent and effluent water including nutrients and various cations was conducted monthly. Total petroleum hydrocarbons were measured by GC after extraction of the water using heptane (EN ISO 9377-2:2000).
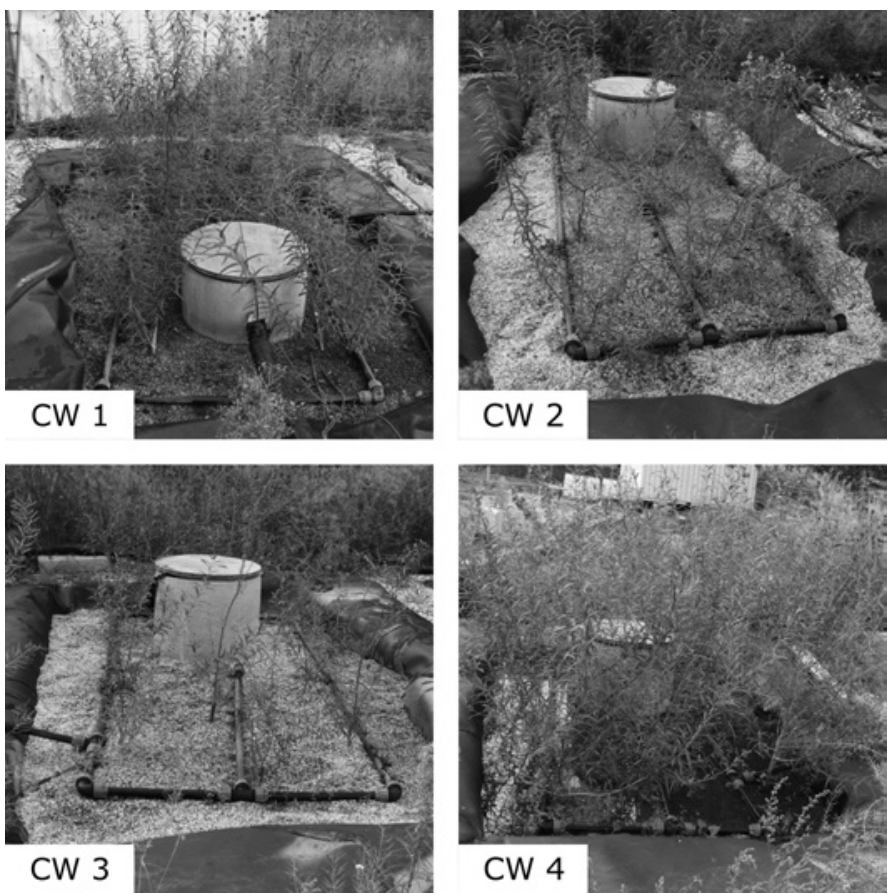

Figure 5.2.1 Pictures of the constructed wetlands (CWs) filled with sand (CW 1 \& CW 2), expanded clay (CW 3) and sand \& biochar (CW 4).

\subsubsection{RESULTS}

The TPH concentrations in the groundwater during CW operation had decreased to $0.15-0.50 \mathrm{mg} / \mathrm{l}$. Consequently, diesel was dosed up to $20 \mathrm{mg} / \mathrm{l}$, average TPH concentrations were $0.37 \mathrm{mg} / \mathrm{l}$ in CW 1 and $1.52 \mathrm{mg} / \mathrm{l}$ in CW 2, CW 3 and CW 4. TPH concentrations of CW 2, CW 3 and CW 4 were increased from $0.15 \mathrm{mg} / 1$ (2012) to $0.43 \mathrm{mg} / \mathrm{l}$ (2013), $1.43 \mathrm{mg} / \mathrm{l}$ (2014) and $8.33 \mathrm{mg} / \mathrm{l}$ (2015). The average hydraulic load was approximately $400 \mathrm{~mm} /$ day (min: $60 \mathrm{~mm} /$ day; max: $800 \mathrm{~mm} /$ day). 
Increased TPH concentrations and hydraulic loads in the inflow did not increase effluent concentrations (Figure 5.2.2). The TPH loads in the inflow and effluent of the CWs was used to calculate the treatment efficiencies. Treatment efficiencies were not affected by the filter materials, but improved over time (Table 5.2.2; Figure 5.2.3). The treatment efficiencies were generally very high with efficiencies of $99 \%$ in the third operational year 2015 and they were positively correlated with TPH concentrations of the inflow water. The treatment efficiencies were not influenced by the temperature of the effluent and the amount of groundwater treated. In our CWs, treatment efficiencies did not deteriorate during winter.

Table 5.2.1 Design of the pilot scale constructed wetlands (CWs).

\begin{tabular}{|c|c|c|c|c|}
\hline Layers & Depth & CW $1 \&$ CW 2 & CW 3 & CW 4 \\
\hline Cover layer & $0-10 \mathrm{~cm}$ & Gravel 4/8* & Gravel 4/8 & Gravel 4/8 \\
\hline $\begin{array}{l}\text { Main filter } \\
\text { body }\end{array}$ & $10-110 \mathrm{~cm}$ & $\begin{array}{l}\text { Washed quartz } \\
\text { sand } 0 / 4\end{array}$ & $\begin{array}{l}\text { Expanded clay } \\
\text { (Liapor HD 1/4) }\end{array}$ & $\begin{array}{l}\text { Washed quartz } \\
\text { sand } 0 / 4 \text { \& } \\
3 \mathrm{w} / \mathrm{w} \% \text { biochar } \\
(80 \mathrm{~cm}) \text { washed } \\
\text { quartz sand } 0 / 4 \\
(20 \mathrm{~cm})\end{array}$ \\
\hline $\begin{array}{l}\text { Transitional } \\
\text { layer }\end{array}$ & $110-120 \mathrm{~cm}$ & Gravel 4/8 & Gravel 4/8 & Gravel 4/8 \\
\hline Drainage layer & $120-140 \mathrm{~cm}$ & Gravel 16/32 & Gravel 16/32 & Gravel 16/32 \\
\hline
\end{tabular}

${ }^{*}$ Range of diameter in $\mathrm{mm}$ : e.g., $4 / 8=4$ to $8 \mathrm{~mm}$

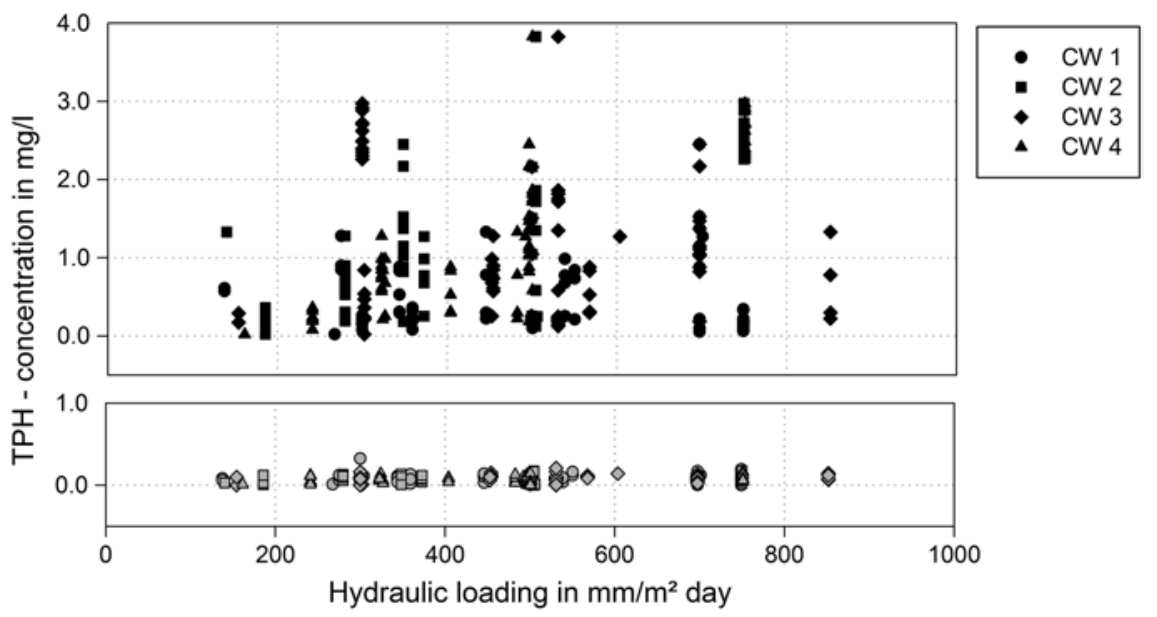

Figure 5.2.2 Total petroleum hydrocarbon (THP) concentrations of the inflow (black) and effluent (gray) were plotted against the hydraulic loading rate. 
112 Filtration Materials for Groundwater: A Guide to Good Practice

Table 5.2.2 Total petroleum hydrocarbon (TPH) loads and treatment efficiencies in the first (2013), second (2014) and third operational year (2015) in the four constructed wetlands (CWs).

\begin{tabular}{llcclll}
\hline & \multicolumn{3}{l}{ TPH Loads $\left(\mathbf{g} / \mathbf{m}^{2}\right)$} & \multicolumn{3}{c}{ Treatment Efficiencies (\%) } \\
\hline Year & $\mathbf{2 0 1 3}$ & $\mathbf{2 0 1 4}$ & $\mathbf{2 0 1 5}$ & $\mathbf{2 0 1 3}$ & $\mathbf{2 0 1 4}$ & $\mathbf{2 0 1 5}$ \\
\hline CW 1 & 52 & 84 & 7.5 & 84 & 81 & 66 \\
CW 2 & 36 & 290 & 230 & 84 & 94 & 99 \\
CW 3 & 72 & 220 & 240 & 84 & 94 & 99 \\
CW 4 & 49 & 310 & 230 & 87 & 96 & 99 \\
\hline
\end{tabular}

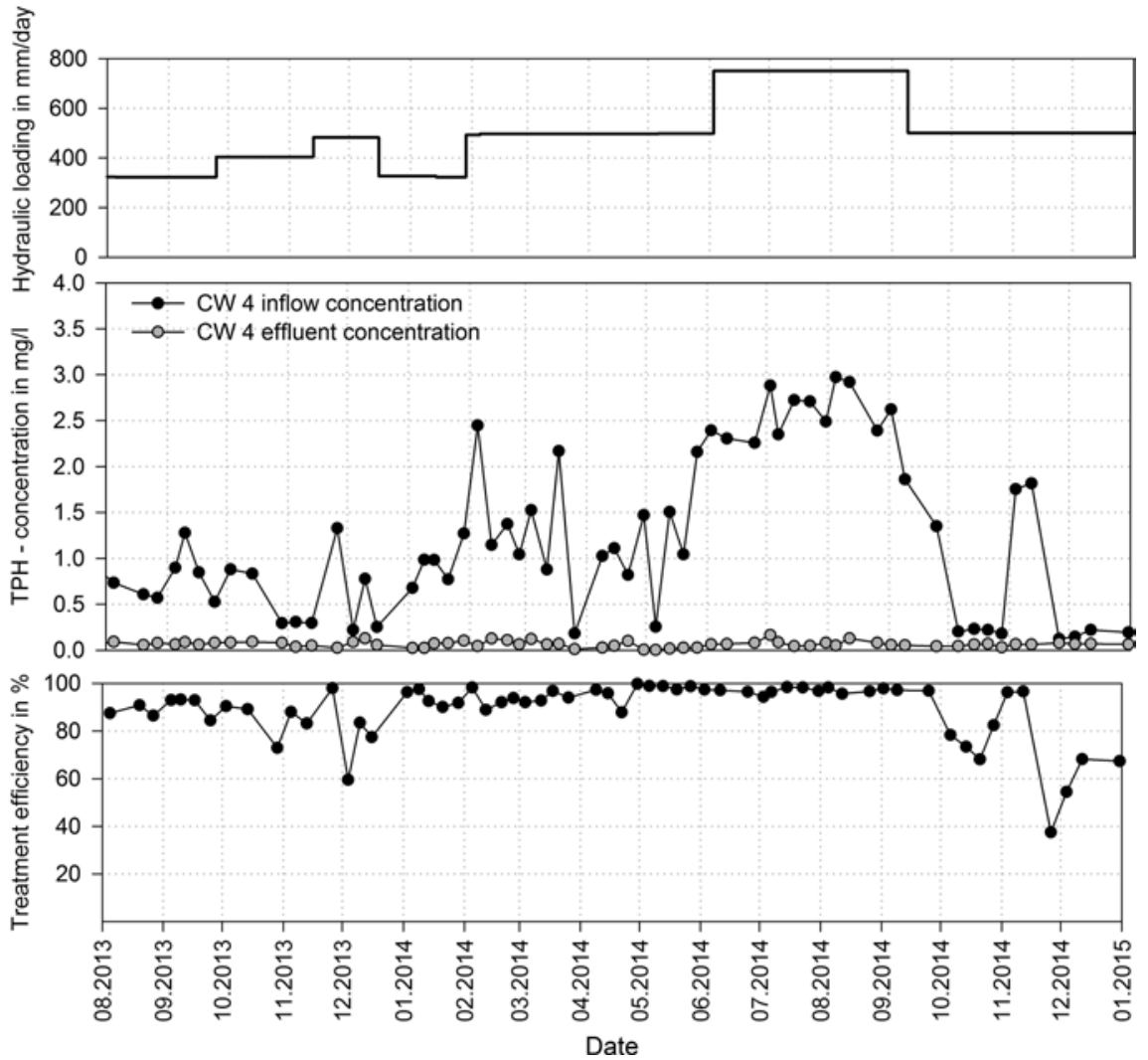

Figure 5.2.3 Hydraulic loading, total petroleum hydrocarbon (TPH) concentrations and treatment efficiency in CW 4 during two years of operation (Aug, 2013-Jan 2015). Low treatment efficiency was monitored if the TPH concentrations of the inflow were low. 
Willows established best in the biochar amended filter sand possibly due to the better provision of nutrients and worst in the expanded clay, where water drained quickly after irrigation. Iron and manganese precipitates were visible on top of the CWs, but a decrease in the water permeability was not recognised. TPH concentrations in the filter substrate were distributed inhomogenously. Hotspots had TPH concentrations of up to $440 \mathrm{mg} / \mathrm{kg}$ and an average concentration of $180 \mathrm{mg} / \mathrm{kg}$ at $10-20 \mathrm{~cm}$ depth in the diesel amended CWs (CW 2, CW 3 and CW 4) in Sept. 2014. TPH concentrations decreased down to $30 \mathrm{mg} / \mathrm{kg}$ within two weeks after TPH loads were reduced. A conservative estimate of the mineralisation rate of hexadecane (major component of diesel) was determined in the lab and revealed $3 \mu \mathrm{gCO}_{2} / \mathrm{g} / \mathrm{day}$ in the sandy filter materials (CW 1, CW 2 and $\mathrm{CW} 4$ ) and $1 \mu \mathrm{gCO}_{2} / \mathrm{g} /$ day in the expanded clay (CW 3 ).

\subsubsection{CONCLUSIONS}

The constructed wetlands treated petroleum hydrocarbon very well with removal efficiencies of up to $99 \%$. The maximum hydraulic load has not been reached during operation (loads $<800 \mathrm{~mm} /$ day). In contrast to the standard filter material sand, expanded clay had a higher infiltration rate and might cope with high loading rates of anoxic groundwater. The higher infiltration of groundwater away from the cold surface enabled a higher temperature in the expanded clay filter in winter. The biochar amended $\mathrm{CW}$ enhanced plant growth, which can have a positive effect on degradation and infiltration.

\subsubsection{REFERENCES}

EN ISO 9377-2:2000 Water quality - Determination of hydrocarbon oil index - part 2: Method using solvent extraction and gas chromatography, German version, July 2001. Reichenauer T. G., Kinner P., Watzinger A. and Wimmer B. (2015). Endbericht: Forschungsprojekt BIOSAN, Biostimulation und bepflanzte Bodenfilter zum Abbau von Mineralölkohlenwasserstoffen in Boden und Grundwasser. (Final report: research project BIOSAN, biostimulation and constructed wetlands to degrade petroleum hydrocabons in the soil and groundwater.) April 2015. 


\subsection{Designs of permeable reactive barriers and examples of full scale treatment}

\section{Sabrina Saponaro*, Elena Sezenna, and Andrea Mastorgio}

Politecnico di Milano, Department of Civil \& Environmental Engineering, Milan, Italy

*Corresponding author: sabrina.saponaro@polimi.it

Permeable reactive barriers (PRBs) are innovative technologies for the in situ remediation of contaminated groundwater. The technology involves the emplacement, into an excavated zone of the aquifer across the flow path of the contaminated groundwater, of a "reactive" filling material permeable to groundwater to intercept and treat the contaminants as the plume flows through under the influence of the natural hydraulic gradient (Careghini et al. 2013).

A wide range of materials are currently available. Some of them remove contaminants through non-destructive mechanisms, such as precipitation, sorption or cation exchange (also promoted by geochemistry modifications in the treatment zone), other through destructive mechanisms, such as abiotic degradation or biological degradation (in biobarriers) (Table 5.3.1). The choice among these is primarily based on the contaminant to remove and the abatement required, but the hydrogeological and biogeochemical conditions of the aquifer may have great influence as well (ITRC, 2011; Obiri-Nyarko et al. 2014). Sometimes, concurrently mechanisms acts in removing the pollutants. Multilayer barrier systems can be developed in order to treat groundwater affected by different kinds of pollutants (Obiri-Nyarko et al. 2014).

The most used abiotic materials include: (i) zero-valent iron $\mathrm{Fe} 0$ (ZVI); (ii) activated carbons (ACs); (iii) zeolites; and (iv) apatites.

ZVI has a high reduction potential $(-440 \mathrm{mV})$ and acts primarily as a reductant material. Therefore it can effectively remove pollutants such as heavy metals and radionuclides, nutrients and aliphatic chlorinated solvents. Typically, ZVI grain 
size ranges from 0.25 to $2 \mathrm{~mm}$ and the surface area from 0.5 to $1.5 \mathrm{~m}^{2} / \mathrm{g}$. ZVI has been conventionally used as the reactive media of PRBs and more than $60 \%$ of the PRBs installed worldwide are iron-based (ITRC, 2011).

Table 5.3.1 Contaminants, main reactive materials and issues at PRB full-scale applications (ITRC, 2011; Obiri-Nyarko et al. 2014).

\begin{tabular}{|c|c|c|}
\hline Contaminants & Reactive Material & Major Issues \\
\hline \multirow[t]{2}{*}{$\begin{array}{l}\text { Aliphatic } \\
\text { chlorinated } \\
\text { solvents }\end{array}$} & $\mathrm{ZVI}$ & $\begin{array}{l}\text { Iron reactions with groundwater } \\
\text { constituents produce } \mathrm{OH}^{-} \text {ions and } \mathrm{pH} \\
\text { increase, which promotes precipitate } \\
\text { formation on the reactive material } \\
\text { (coating) and a reduced surface } \\
\text { contact between } \mathrm{Fe}(0) \text { and pollutants }\end{array}$ \\
\hline & Biobarrier & $\begin{array}{l}\text { Anaerobic conditions are required for } \\
\text { highly chlorinated compounds } \\
\text { Degradation reactions, excessive } \\
\text { variation in } \mathrm{pH} \text { and redox conditions } \\
\text { can lead to the solubilization of } \\
\text { metals (iron, manganese, arsenic) } \\
\text { and potential negative effects (e.g.: } \\
\text { total dissolved solids) on the water } \\
\text { quality }\end{array}$ \\
\hline $\begin{array}{l}\text { Monoaromatic } \\
\text { solvents } \\
\text { Methyl-tert butyl } \\
\text { ether }\end{array}$ & Biobarrier & $\begin{array}{l}\text { Aerobic conditions and an external } \\
\text { source of oxygen are generally } \\
\text { required }\end{array}$ \\
\hline Phenols & GAC & $\begin{array}{l}\text { Removal is strongly influenced the } \mathrm{pH} \\
\text { value (low } \mathrm{pH} \text { values decrease phenol } \\
\text { sorption) }\end{array}$ \\
\hline Cationic metals & Apatite & $\begin{array}{l}\text { Removal is affected by the } \mathrm{pH} \text { (low } \\
\mathrm{pH} \text { is necessary to dissolve the } \\
\text { apatite to release the phosphate) } \\
\text { The contaminant sorption is } \\
\text { reversible and they can be released } \\
\text { again into groundwater when } \\
\text { geochemical conditions favor the } \\
\text { mechanism }\end{array}$ \\
\hline Arsenic & ZVI & $\begin{array}{l}\text { Low } \mathrm{pH} \text { is favorable to remove } \\
\text { arsenic compounds under aerobic } \\
\text { condition, while under anaerobic } \\
\text { condition, acidic and alkaline pHs } \\
\text { seems to be favorable for arsenate } \\
\text { and arsenite removal }\end{array}$ \\
\hline
\end{tabular}


Table 5.3.1 Contaminants, main reactive materials and issues at PRB full-scale applications (ITRC, 2011; Obiri-Nyarko et al. 2014) (Continued).

\begin{tabular}{|c|c|c|}
\hline Contaminants & Reactive Material & Major Issues \\
\hline & & $\begin{array}{l}\text { The presence of other } \\
\text { inorganic species in the aquifer } \\
\text { may compete with contaminants for } \\
\text { ZVI reactive sites }\end{array}$ \\
\hline Chromium (VI) & $\mathrm{ZVI}$ & $\begin{array}{l}\text { Chromium precipitation (as } \mathrm{Cr}(\mathrm{III})) \\
\text { progressively blocks reactions sites } \\
\text { on iron } \\
\text { The formation of mineral } \\
\text { precipitates can cause clogging } \\
\text { Removal may be influenced by } \\
\mathrm{pH} \text {, redox potential and dissolved } \\
\text { organic carbon in the aquifer } \\
\text { The presence of other inorganic } \\
\text { species in the aquifer may compete } \\
\text { with } \mathrm{Cr}(\mathrm{VI}) \text { for } \mathrm{ZVI} \text { reactive sites }\end{array}$ \\
\hline \multirow[t]{2}{*}{ Uranium } & $\mathrm{ZVI}$ & $\begin{array}{l}\text { Possible clogging due to } \\
\text { the formation of mineral } \\
\text { precipitates } \\
\text { Removal may be influenced by } \\
\mathrm{pH} \text {, redox potential and dissolved } \\
\text { organic carbon in the aquifer } \\
\text { The presence of other inorganic } \\
\text { species in the aquifer may compete } \\
\text { with contaminants for ZVI reactive } \\
\text { sites }\end{array}$ \\
\hline & Apatite & $\begin{array}{l}\text { Removal is affected by the } \mathrm{pH} \text { (low } \\
\mathrm{pH} \text { is necessary to dissolve the } \\
\text { apatite to release the phosphate) } \\
\text { The contaminant sorption is } \\
\text { reversible and it can be released } \\
\text { again into groundwater when } \\
\text { geochemical conditions favor the } \\
\text { mechanism }\end{array}$ \\
\hline Strontium-90 & Zeolites & $\begin{array}{l}\text { The use may be influenced by } \\
\text { groundwater } \mathrm{pH} \text {, its constituents } \\
\left(\mathrm{Ca}, \mathrm{Mg}, \mathrm{Na}, \mathrm{SO}_{4}^{2-}, \mathrm{CO}_{3}^{2-}\right) \text { and } \\
\text { dissolved organic carbon }\end{array}$ \\
\hline
\end{tabular}


Table 5.3.1 Contaminants, main reactive materials and issues at PRB full-scale applications (ITRC, 2011; Obiri-Nyarko et al. 2014) (Continued).

\begin{tabular}{|c|c|c|}
\hline Contaminants & Reactive Material & Major Issues \\
\hline & Apatite & $\begin{array}{l}\text { Removal is affected by the } \mathrm{pH} \text { (low } \\
\mathrm{pH} \text { is necessary to dissolve the } \\
\text { apatite to release the phosphate) } \\
\text { The contaminant sorption is } \\
\text { reversible and it can be released } \\
\text { again into groundwater when } \\
\text { geochemical conditions favor the } \\
\text { mechanism }\end{array}$ \\
\hline Nitrates & Biobarrier & $\begin{array}{l}\text { Anaerobic (denitrifying) conditions } \\
\text { are required to transform nitrates } \\
\text { into } \mathrm{N}_{2} \\
\text { Nitrous oxide, } \mathrm{NH}_{4}^{+}, \mathrm{CH}_{4}, \mathrm{CO}_{2} \text { can } \\
\text { be produced } \\
\text { Gases can reduce the hydraulic } \\
\text { conductivity in the barrier }\end{array}$ \\
\hline Sulphates & Biobarrier & $\begin{array}{l}\text { Anaerobic conditions are required } \\
\text { to transform sulphates into } \\
\text { sulphides }\end{array}$ \\
\hline Perchlorate & Biobarrier & $\begin{array}{l}\text { Anaerobic conditions are required } \\
\text { to transform perchlorate to chlorate } \\
\text { and chloride }\end{array}$ \\
\hline
\end{tabular}

ACs are carbonaceous materials with high sorption capacity; therefore, pollutant removal occurs mainly through sorption. They have been widely used for phenols, monoaromatic and chlorinated hydrocarbons, although heavy metals have been treated as well. Granular AC (GAC) was one of the materials commonly used in the early stages of the PRB technology (Bone, 2012).

Zeolites are aluminosilicate minerals that have high cation-exchange capacity (200-400 meq/100 g) and large surface area (up to $145 \mathrm{~m}^{2} / \mathrm{g}$ ) (ITRC, 2011). Natural zeolites generally have low organic carbon content, which makes them unsuitable for sorption of organic compounds; however, surface modified zeolites have been developed exhibiting strong affinity with organics. Contaminants that can be removed include heavy metals, radionuclides, $\mathrm{NO}_{3}{ }^{-}$, monoaromatic and chlorinated hydrocarbons (Obiri-Nyarko et al. 2014; USEPA, 2015a).

Apatites are phosphate minerals, containing mainly calcium and phosphorus, with net negative charge at neutral and alkaline $\mathrm{pH}$. Apatites may remove inorganic contaminants (perchlorate, cationic metals, radionuclides, nitrate) via sorption to their negative charge surface or via ion-exchange, precipitation as phosphates, carbonates, oxides, and hydroxides, or incorporation into their mineral structure (USEPA, 2015b). 


\subsubsection{DESIGN}

A key aspect of the PRB design is a good understanding of the site and aquifer characteristics, which includes the site geology, aquifer hydrogeology, geochemistry, microbial activity and the contaminated plume 3D-geometry. Directions and rates of groundwater flow, including variations over time and depth, and preferential flow paths are important (Smith et al. 2003).

Once the site has been fully characterized, the design of a PRB include selection of the reactive medium, treatability studies at lab scale (batch and column tests) and pilot scale, and engineering design (Obiri-Nyarko et al. 2014). Laboratorybased trials are a prerequisite, while field-based pilot trials are recommended, but not obligatory. Nevertheless, is likely that both laboratory and field-scale trials would be conducted prior to full-scale installation, as these are considered the best ways of optimizing the design and minimizing risk of failure of the PRB (Smith et al. 2003).

After the reactive material has been selected, the dimension, location and orientation of the barrier have to be defined. The "capture zone" refers to the width of the barrier necessary to capture the entire plume. The "residence time" is defined as the time required for the contaminated groundwater to flow through the reactive material within the PRB to achieve the treatment goals (Smith et al. 2003).

The hydraulic conductivity of the filling material is usually selected at a value one order of magnitude higher than the aquifer hydraulic conductivity. In order to obtain this condition, the reactive material is usually mixed with sand to achieve the suitable permeability (Muegge, 2008). However, PRB interior changes its hydraulic properties during operation, as chemical reactions and/or bacterial growth may cause clogging/fouling (Abadzic \& Ryan, 2001; Furukawa et al. 2002; Kacimov et al. 2011; Lampron et al. 2001; Vikesland et al. 2003).

The performance of the PRB over time needs to be addressed. The oldest PRB is close to two decades, but this is still not enough to provide sufficient information to help in adequately understanding and predicting their long-term performance. This can be predicted by simulation of longevity scenarios with the aid of numerical models. However, most of them do not take into consideration the changes in reactivity of the material over time. More recent models are able to incorporate the declining reactivity and permeability of the material in order to adequately represent long- term performance (Kouznetsova et al. 2007; Jeen et al. 2011).

There may be potential for generation of polluting substances within the barrier as a consequence of secondary reactions not considered as part of the PRB design for its target pollutants (Cheng et al. 1997).

\subsubsection{FULL-SCALE TREATMENTS}

A few sites where a full-scale PRB has been installed are reported in Table 5.3.2. 


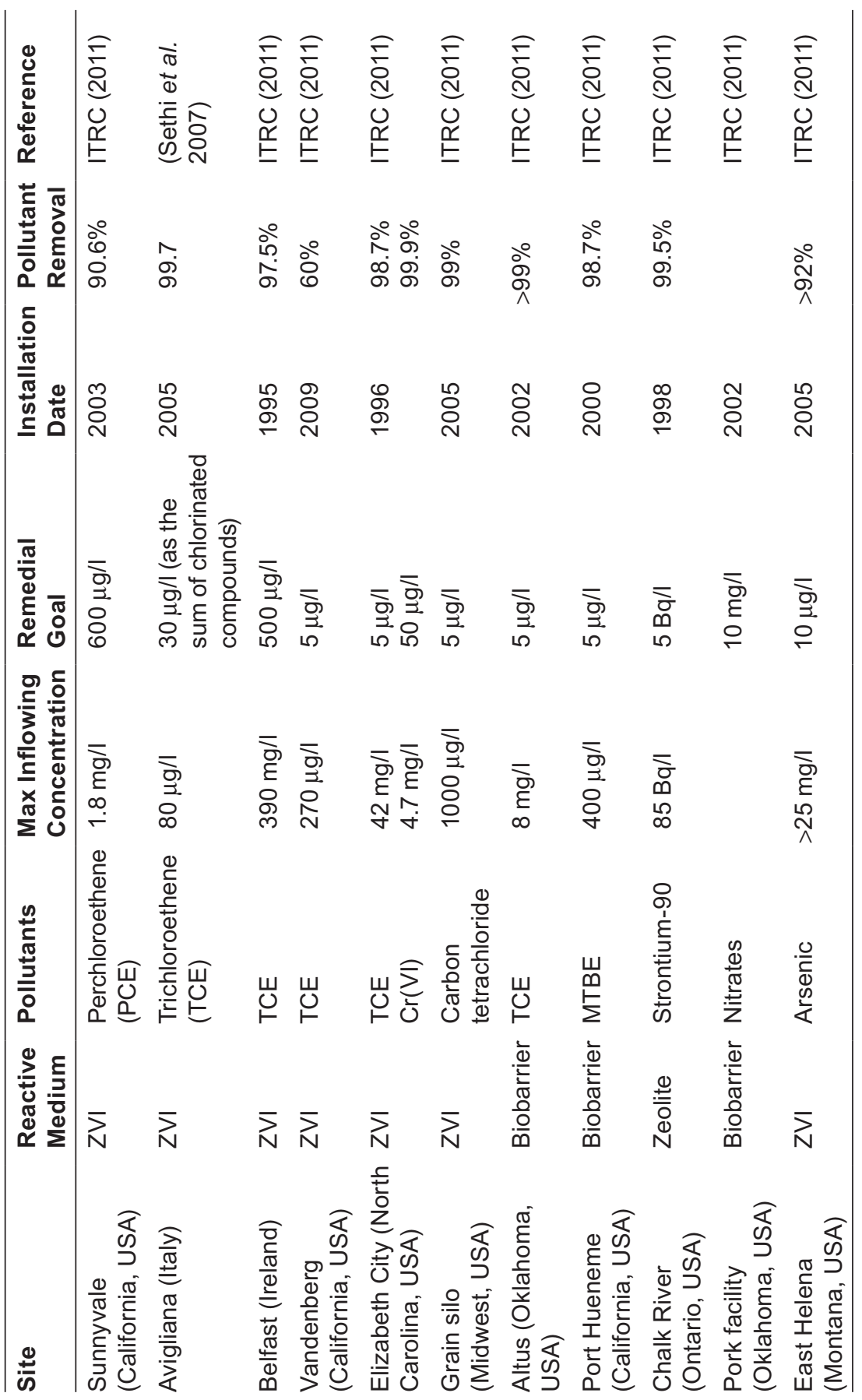




\subsubsection{REFERENCES}

Bone B. (2012). Review of UK Guidance on Permeable Reactive Barriers. Taipei International Conference on Remediation and Management of Soil and Ground Water Contaminated Sites, Taipei, Taiwan. Oct. 30-31, 2012, 626.

Careghini A., Saponaro S. and Sezenna E. (2013). Biobarriers for groundwater treatment: a review. Wat. Sci. Tech., 67(3), 453-468.

ITRC, Interstate Technology \& Regulatory Council (2011). Permeable Reactive Barrier: Technology Update. PRB: Technology Update Team, Washington, D.C., 156 pp.

Jeen, S.-W., Gillham, R. W. and Przepiora, A. (2011). Predictions of long-term performance of granular iron permeable reactive barriers: field-scale evaluation. J. Contam. Hydrol. 123(1-2), 50-64.

Kacimov A. R., Klammler H., Il'yinskii N. and Hatfield K. (2011). Constructal design of permeable reactive barriers: groundwater-hydraulics criteria. J. Eng. Math. 71, 319-338.

Kouznetsova, I., Bayer, P., Ebert, M. and Finkel, M. (2007). Modelling the long-term performance of zero-valent iron using a spatio-temporal approach for iron aging. $J$. Contam. Hydrol. 90(1-2), 58-80.

Muegge J. (2008). An Assessment of Zero Valence Iron Permeable-Reactive Barrier Projects In California. Office of Pollution Prevention and Green Technology, Document No. 1219, California, 147 pp.

Obiri-Nyarko F., Grajales-Mesa S. J. and Malina G. (2014). An overview of permeable reactive barriers for in situ sustainable groundwater remediation. Chemosphere, 111, 243-259.

Sethi R., Zolla V. and Di Molfetta A. (2007). Construction and monitoring of a permeable reactive barrier near the city of Torino in Italy. Italian Journal of Engineering Geology and Environment, Special Issue 1, 1-5.

Smith J. W. N., Boshoff G. and Bone B. D. (2003). Good practice guidance on permeable reactive barriers for remediating polluted groundwater, and a review of their use in the UK. Land Contamination \& Reclamation, 11(4), EPP Publications Ltd.

USEPA (2015a). Permeable Reactive Barriers, Permeable Treatment Zones, and Application of Zero-Valent Iron - Application, CLU-IN, https://clu-in.org/ techfocus/default.focus/sec/Permeable_Reactive_Barriers,_Permeable_Treatment_ Zones,_and_Application_of_Zero-Valent_Iron/cat/Application/

USEPA (2015b). Permeable Reactive Barriers, Permeable Treatment Zones, and Application of Zero-Valent Iron - Overview, CLU-IN, https://clu-in.org/techfocus/ default.focus/sec/Permeable_Reactive_Barriers\%2C_Permeable_Treatment_Zones\% 2C_and_Application_of_Zero-Valent_Iron/cat/Overview/ 


\title{
5.4 State of art of filtration for public water supply in Brazil
}

\section{Giuliano Daronco}

\begin{abstract}
Regional University of Northwestern Rio Grande do Sul; giuliano@daronco.com.br
\end{abstract}

Supply water in adequate sanitary conditions for the population is known to be one of the most worrying problems currently in Brazil, mainly due to its high cost of deployment and low financial return. The systems of water supply have operated in accordance with public health, so that the historical lack of investment results in a deficit in care, culminating in precarious quality of people's lives, in particular, the less fortunate financial (Daronco, 2014).

Brazil, currently, presents urban coverage rate of $92.98 \%$ of water being made available $\mathrm{m}^{3} 23.73$ a month for the economy. The average per capita consumption of water is around 166.29 liters per inhabitant a day so that $82.0 \%$ of the total produced is treated in water treatment plants and only $16.0 \%$ suffers the simple disinfection process (BRAZIL, 2013). These low indices found in Brazil are due not only to lack of financial resources and the lack of assessment of environmental and operating costs, are mainly the lack of a lasting public policy that takes into account the sustainability of the systems. (LEONETI, PRADO \& OLIVEIRA, 2011).

The health dimension of the HDI is a good indicator to assess the social conditions, health and salubrity, considering different age groups of mortality. High child mortality rates are influenced by water conditions served to the locality (PNUD, 2012). According to the latest report that shows the indices HDI, Brazil is in 84th position, they are very far from developed countries.

Silva et al. (2012) understand that several factors combined with urbanization and high population growth rates have caused a big pollution in water sources for water supply for human consumption, becoming imminent adoption of specific measures to improve the quality of these waters to meet the minimum standard of potability. 
Some indicators are used to report the presence of harmful substances in water, such as: color, turbidity, temperature, flavor and odor (BRINCK, 2009).

Filtration is a popular methodology in Brazil for the treatment of water for public supply and it has been quite effective in its goal. This type of water purification was probably created as a result of observation of cleaning groundwater, attributed to the passage of the same natural soils, having news that since the sixteenth century the filtration, as water cleanse method, was already found widespread (Paterniani \& CONCEPTION, 2004).

Historically, until the 1950s, physical processes were believed as the major filtration mechanisms. O'Melia \& Stumm (1967) have changed this view and demonstrated that the filtration process was a combination between physical and chemical processes.

Brinck (2009) understands that the water filtration is a process of particulate material removal already present in the raw water or generated during the treatment process. The water must pass through the filter bed so that the particulate materials are retained in the bed surface or they are collected inside its filter. Filtration is understood, in Brazil, as effective in the removal of particulate material of all sizes including algae, colloidal humic compounds, viruses, asbestos fibers and particulate colloidal clays.

According to Di Bernardo (2005) the filtration process in Brazil is understood as a filtration career, divided into three stages: initial stage, when the filtered water may be unsatisfactory quality; intermediate step, during which there is production of water with desirable quality and the transpassive step, characterized by continuously increasing turbidity of the filtered water.

Filters most widespread in Brazil are classified into various aspects such as filtration rate, direction of flow, treatment type, filter material, hydraulic arrangement and mechanism of action (BRINCK, 2009).

\subsubsection{CLASSIFICATION ACCORDING TO THE FILTRATION RATE (FAST AND SLOW FILTERS)}

Until 1960 the Brazilian filters were built with single layer and filtration constant rate of $120 \mathrm{~m}^{3} / \mathrm{m}^{3} / \mathrm{day}$. After they began to be used with double-layer filters (sand and anthracite) reaching $360 \mathrm{~m}^{3} / \mathrm{m}^{2} /$ day and currently the most widely used filters hit values in the average of $600 \mathrm{~m}^{3} / \mathrm{m}^{2} /$ day.

Slow filters are sand filters with lower infiltration rates resulting in almost total removal of suspended solids. The water produced from the well operated slow filter can be of excellent quality, with $90 \%$ to $99 \%$ bacterial reduction. This type of filtration has been used in the treatment of water for public supply from the beginning of the nineteenth century and has proven to be an effective system (DI BERNARDO, 1999). About $20 \%$ of the drinking water in the United Kingdom is further treated by slow sand filtration system, as well as $80 \%$ of all water of London (ADIN, 2003). 
Fast filters consist of mechanisms that use to passing the pre-washed water through a medium filter to high flow rates. The flow is usually descending and it is many times used pumping system for pressurisation of the water. For its flawless performance continuous pretreatment is essential for a raw water quality considerably.

\subsubsection{CLASSIFICATION ACCORDING TO THE FLOW DIRECTION (UPFLOW AND DOWNFLOW)}

In the case of upflow the water flows upwards, requiring some propulsive force, or the system requires pressurization. But when the flow is downward of the water, after undergoing a pre-treatment, it flows through the filtering medium in a downward movement, thus, the filtration occurs by gravity.

\subsubsection{Rating according to the type of treatment (conventional, direct filtration and filtration line)}

Di Bernardo (1993) considers that whatever the chosen treatment model is, it should use mandatorily a form of filtration.

Water treatment plants (WTP) can be projected from the conventional type of direct filtration or in-line filtration. The use of the conventional type for water treatment is the most widely used in Brazil, mainly by the use of eutrophic water sources. The process consists basically of rapid mixing, coagulation, flocculation, sedimentation and filtration of the water.

In the case of direct filtration, the composition of the system is given by the steps of coagulation, rapid mixing, flocculation and filtration. The absence of sedimentation makes the treated water quality depends on the conditions of the raw water. This type of treatment has low investment cost and low cost decreases the use of chemicals.

In-line filtration works similarly to direct filtration, but the absence of the flocculation tank is checked so that flocculation occurs in its own filter.

The choice of the type of filtration according to the treatment depends on imminently the condition of the raw water to be treated.

\subsubsection{CLASSIFICATION ACCORDING TO THE FILTER MATERIAL (GRANULAR BED FILTERS AND FILTER TYPE PRECOAT)}

Granular bed filters have deep beds and they use as filter material anthracite, sand, coal or composition of them, they may be constructed by single layer, double or triple. In the case of the use of the sand there must be care, as it is necessary the presence of quartz grains from rock decomposition. (DI BERNARDO, 1993).

In the case of the Brazilian anthracite usage it is recommended that its hardness exceeds 2.5 . 
For the support layer of these filters pebbles are used whose sizes vary from 2 to $50 \mathrm{~mm}$ and density must provide equal or higher than $2500 \mathrm{~kg} / \mathrm{m}^{3}$. The solubility in concentrated hydrochloric acid should not exceed $5 \%$ and $10 \%$ for smaller sized pebbles than $9.6 \mathrm{~mm}$ for pebbles larger than $9.6 \mathrm{~mm}$, respectively.

The filters of the type Precoat are designed based on the use of a thin filter bed layer composed of extreme thinness material such as diatomite, and this must be disposed of each filter cycle. As the filtration mechanism is basically physical, they are not required chemical pretreatments, however they require good quality water sources.

\subsubsection{CLASSIFICATION ACCORDING TO THE HYDRAULIC ARRANGEMENT (GRAVITY FILTERS AND PRESSURE FILTERS)}

In the filter by gravity the flow is obtained by gravity so that they are open to the atmosphere on the other hand pressure filters are worked under pressure with the use of a pumping system.

\subsubsection{CLASSIFICATION ACCORDING TO THE MECHANISM OF ACTION (ACTION OF WATER DEPTH AND SURFACE ACTION)}

In filters that use the action of depth, the particles to be removed are far smaller than the size of the interstices formed among the filter grains. It is necessary the use of transport mechanisms and adherence mechanisms for moving the particles, resulting in longer careers.

Surface action filters use the retention only on top of the filter media providing shorter careers as in Precoat models.

\subsubsection{REFERENCES}

Adin A. (2003). Slow granular filtration for water reuse. Water Science and Technology, 3(4), 123-130.

Brasil (2013). Ministério das Cidades. Secretaria Nacional de Saneamento Ambiental. Sistema Nacional de Informações sobre Saneamento: diagnóstico dos serviços de água e esgotos -2012 .

Brinck N. C. P. (2009). Avaliação do tipo de material filtrante no comportamento hidráulico de filtros de camada profunda no tratamento de águas de abastecimento. Escola Politécnica da Universidade de São Paulo (POLI/USP). Tese. (Doutorado em Engenharia).

Daronco G. C. (2014). Proposição e aplicação de metodologia para avaliação e auditoria dos Planos Municipais de Saneamento Básico. Instituto de Pesquisas Hidráulicas (IPH). Universidade Federal do Rio Grande do Sul (UFRGS). Tese. (Doutorado em Recursos Hídricos e Saneamento Ambiental). 
Di Bernardo L. (1993). Métodos e Técnicas de Tratamento de Água, vol 2. ABES, Rio de Janeiro.

Di Bernardo L. (1999). Tratamento de Águas de Abastecimento por Filtração em Múltiplas Etapas, Rio de Janeiro: ABES/PROSAB.

Di Bernardo L. (2005). 2 ${ }^{\text {a }}$ ed, Métodos e técnicas de tratamento de água. RIMA, São Paulo.

Leoneti, A. B., Prado, E. L. and Oliveira, S. V. W. B. (2011). Saneamento básico no Brasil: considerações sobre investimentos e sustentabilidade para o século XXI. Revista de administração pública. Rio de Janeiro. p. 331-348.

O'Melia, C. R. and Stumm, W. (1967). Theory of water filtration. Journal American Water Works Association. [S.l.], 59(11), 1393-1412.

Paterniani, J. E. S. and Conceição, C. H. Z. (2001). Utilização da pré-filtração e filtração lenta no tratamento de água para piscicultura. Ecossistema, 26(1), 8-12.

PNUD - Programa das Nações Unidas para o Desenvolvimento (2012). Atlas de Desenvolvimento Humano no Brasil 2003 (Censo, 2000).

Silva, G. G., Naval, L. P., Di Bernardo, L. and Dantas, A. D. B. (2012). Tratamento de água de reservatórios por dupla filtração, oxidação e adsorção em carvão ativado granular. Engenharia sanitária e ambiental. 17(1), Rio de Janeiro: ABES. pp. 71-80. 


\subsection{Development in groundwater treatment - Indian perspective}

\section{Arun Kumar Thalla and Devatha C. P.}

Department of Civil Engineering, NITK Surathkal, Mangalore-575025, INDIA; thallpce@gmail.com

India is one among the fastest growing country in the world; with its economic progress, demand for water is likely to be increased considerably. The Business-asusual (BAU) scenarios stated that the projections of water demand in India for 2025 and 2050 is to be about $22 \%$ and $32 \%$ respectively, from the present demand of 680 billion cubic meters (bcm) as shown in Figure 5.5.1 (Amarasinghe et al. 2006). In India, water supply, sanitation and drainage systems are designed according to the standards specified by Central Public Health and Environmental engineering Organization (CPHEEO). According to these standards, a minimum of 135 liter/ capita/day is to be supplied for domestic purpose. Further, Industrial requirement is computed based on population equivalents of the Industry. Main source of water to meet the above requirements come from surface and ground water.

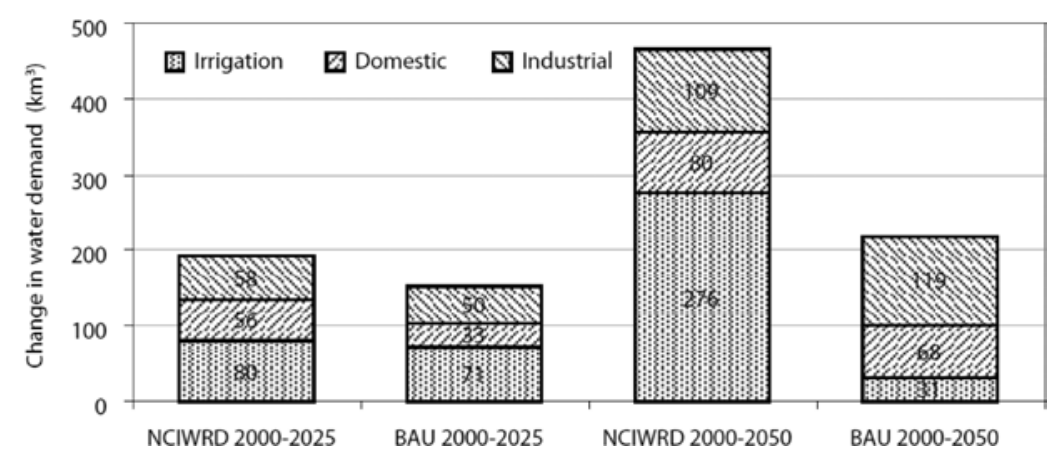

Figure 5.5.1 Difference of water demand. 


\subsubsection{SURFACE AND GROUNDWATER POTENTIAL IN INDIA}

In India, $80 \%$ of annual rainfall occurs only for 3 to 4 months that too highly nonlinear in pattern both temporally and spatially. Brahmaputra, Barak and Ganga rivers are the major surface water resource in India (60\%). About $1869 \mathrm{bcm}$ of run-off use to be generated by rainfall and snow melt in India, among this only $37 \%(690 \mathrm{bcm})$ of water is utilized. International standards mentioned that, if per capita annual availability less than 1700 (Cum/capita/year) is considered as water stressed then most parts of India become water stressed area within a short period (Vijay Kumar et al. 2010).

Precipitation is the main source for groundwater recharge, most part of the India receives rainfall during south-west monsoon. Statistics showed that annual groundwater recharge is about $433 \mathrm{bcm}$, except from natural groundwater discharge. As on 2011, the net annual groundwater availability is about $398 \mathrm{bcm}$ and annual draft of groundwater is $245 \mathrm{bcm}$. 1071 units of different states of India being considered as overexploited units (blocks/mandals/taluks) and 217 units are categorized as critical units, where extraction of water being higher than the availability of groundwater as per Central Ground Water Board, Ministry of Water Resources, India, 2014 reports. Decrease in long term water trend is observed during post monsoon and pre monsoon and these trends may increase in the future due to high intensive growth in groundwater.

\subsubsection{DRAWBACKS WITH SURFACE WATER}

As said earlier, India receives rainfall only for 3 to 4 months. So, peak run-off in the rivers occurs during these months and need to be trapped to fulfil water demand. The system for water storage in surface water reservoir has drawbacks like evaporation, sedimentation of debris present in the run-off water, there is chance of environmental disaster, distribution of water supply to needy area by means of economic aspects which is expensive. Thus groundwater is considered to be a safe water resource for mankind with its natural filtration into the aquifer and most of the sectors depend on groundwater in India to meet the demand as compare to surface water (Pallas, 1993).

\subsubsection{GROUNDWATER CONTAMINATION}

Due to the unscientific waste management, liquid pollutants are added to the groundwater aquifer by means of solute transport with percolating rain water through the pores of soil. Due to this a large population is under risk of being infected by diseases like water borne diseases due to the presence of dissolved organic matter, fluoride, Iron, magnesium, arsenic etc. The permissible limit of fluoride in water is $1 \mathrm{mg}$ per litter, but the states like Rajasthan, Gujarat and Andhra Pradesh of India had been greatly affected by excess of fluoride content 
in available fresh water. More than 37 million people of India suffered from water borne diseases, out of which 6 million children (below 14 years) suffer from dental and skeletal fluorosis. Arsenic (permissible limit is $0.05 \mathrm{mg} / \mathrm{L}$ ) and nitrate (permissible limit is $45 \mathrm{mg} / \mathrm{L}$ ) are other chemical compounds present in the ground water in some of the Indian states. (CPCB, 2007a).

\subsubsection{METHODS ADOPTED FOR WATER TREATMENT IN INDIA}

Chemical quality of the groundwater is being examined once in a year by CGWB with 15,000 observation wells over different parts of India. Apart from this, states have their own water boards that monitor groundwater quality and quantity on regular basis.

Due to the severity of water borne disease, ground or surface water is been treated to remove pollutants from it before it is supplied to public. The conventional treatment methods adopted for surface water treatment are Screening, Grit removal, Plain or Coagulant aided sedimentation/clarification, filtration and disinfection. However, based on the impurities present in the treatments viz. de-fluorination, reverse osmosis, Ion exchange etc. may be included to the treatment process (Vigneswaran et al. 2007; CPCB, 2007b).

\subsubsection{GOVERNMENT INITIATIVES - IN CONSERVATION OF SURFACE \& GROUND WATER RESOURCE}

Indian government has taken initiatives to recharge the groundwater system artificially to maintain equilibrium in input and output of water. Department of Science and Technology (DST) with the help of state governments has initiated programs to train and educate people on the relevance and need of ground water recharge. One major problem encountered during artificial recharge is clogging of soil. It requires prior attention to treat water before it enters to recharge process and such recharge is done by the technique called Soil Aquifer Treatment (SAT). Nowadays, the advance techniques like Remote Sensing and Geographical Information System (GIS) are used to locate pollution source. (Source: Technology Information, Forecasting and Assessment Council (TIFAC), Department of Science and Technology, Govt. of India).

The Natural Resource Data Management System (NRDMS) Division of DST, Govt. of India has developed programs regarding sustainable development of groundwater system and also a sub-program like Ground water modelling was initiated in 1988.

The Jal Abhiyan Program was launched during December 2005 to spread mass awareness among the stakeholders about current issues like scarcity of water, groundwater recharge etc. Public Private Partnership (PPP) service is introduced to serve duty of water supply and sanitary. 
India in partnership with other countries is working extensively on research projects related to groundwater recharge, surface water quality modeling etc. To name a few The Dutch Ministry of Economic Affairs and Indian Department of Science and Technology (DST) have collaborated and initiated 9 projects on water resource in India called DIWALI (Dutch Indian Water Alliance foe Leadership Initiative) (DST, 2015).

\subsubsection{RESEARCH INITIATIVE BY ACADEMIC AND RESEARCH INSTITUTIONS}

Institutions across the country are extensively working on the mitigation of groundwater pollutants. Some of them are presented here for reference.

A research group from IIT Chennai, India has invented nanoparticles which can terminate organochlorine pesticides like endosulfan, DDT, dioxin, hexachlorohexane and aldrin, those have been widely used in India for agriculture and human health from past few decades in India. The study says that, solution state of gold and silver nanoparticle and supported over activated alumina can remove chlorprifos and malathion quantitatively (Nair \& Pradeep, 2007).

Most recent adaptation schemes used in India are, in Hyderabad low cost biological treatment and reuse system is been tested. Bhabha Atomic Research Centre has developed a Domestic Ultra-Filtration (UF) system for iron and arsenic removal in rural Maharashtra. For villages of West Bengal, the Defense Research and Development Organization (DRDO) has developed an environmental friendly filter technology to remove Arsenic from drinking water (Source: Finding Sustainable Solutions to the Global Freshwater Crisis, 2011).

Central Salt and Chemical Research Institute (CSMCRI), India has developed technology to produce polyamide TFC RO membrane for desalination and by the use of this membrane CSMCRI has installed brackish water desalination plants in different places of India. Further, it has developed technologies for effective removal of various micro and macro pollutants in ground water eg. arsenic filters (CSMCRI official website).

\subsubsection{REFERENCES}

Amarasinghe U. A., Shah T., Turral H. and Anand, B. K. (2006). India's Water Futures to 2025-2050: Business as Usual Scenario and Issues. Draft prepared for the IWMICPWF project on 'Strategic Analyses of National River Linking Project of India.

Central Ground Water Board of India (CGWB) (2006). Dynamic groundwater resources of India (as on March, 2004), Cent. Ground Water Board of India, New Delhi. (Available at http://cgwb.gov.in/)

Central Pollution Control Board (CPCB) (2007a). Status of Groundwater Quality in India Part - I, Groundwater Quality Series: GWQS/ 09/2006-2007. Delhi, India.

Central Pollution Control Board (CPCB) (2007b). Status of Water Treatment Plants in India. Retrieved from http://www.cpcb.nic.in/upload/NewItems/NewItem_103_status ofwaterqualitypackage.pdf 


\section{Filtration Materials for Groundwater: A Guide to Good Practice}

Central Salt and Marine Chemical Research Institute. See: http://www.csmcri.org/

Department Of Science and Technology (DST) (2015). Diwali Water Concepts, Retrieved from http://dst.gov.in/whats_new/whats_new13/DIWALI\%20Concepts.pdf

Finding Sustainable Solutions to the Global Freshwater Crisis: Lessons from India. International Workshop on Sustainability and Water Quality (IWSWQ, 2011). Retrieved from https://www.acs.org/content/dam/acsorg/global/international/regional/ eventsglobal/gii-report.pdf

Nair A. S. and Pradeep T. (2007). Extraction of chlorpyrifos and malathion from water by metal nanoparticles. Journal of nanoscience and nanotechnology, 7(6), 1871-1877.

National Institute of Hydrology. See: www.nih.ernet.in

Pallas P. (1993). Conjunctive use of surface and groundwater, Land and water integration and river basin management: Proceedings of a FAO informal workshop, Rome, Italy.

Vigneswaran S., Ngo H., Visvanathan C. and Sundaravadivel M. (2007). Conventional water treatment technologies. In: Vigneswaran, S. V. (ed.), Wastewater Recycle, Reuse, and Reclamation, Eolss Publishers Co., Ltd., UK, 37-56.

Vijay Kumar, Sharad K. Jain and Yatveer Singh (2010). Analysis of long-term rainfall trends in India. Hydrological Sciences Journal, 55(4), 484-496. 


\section{Filtration Materials for Groundwater}

\section{A Guide to Good Practice}

Ivan Kozyatnyk

Groundwater is a source for drinking and industrial water supply and pollution created by active industrial sites which often cause social, health, and environmental problems. This groundwater eventually drains into adjacent water sources.

Filtration Materials for Groundwater: A Guide to Good Practice presents the up-to-date technology of purification of polluted ground water, its treatment for industrial and human needs and the remediation of polluted sites.

The book examines:

- Types of pollutants in ground water including the main inorganic and organic pollutants and their behaviour

- Filtration materials for water treatment and principles of their choice. How to choose suitable filtration materials according to targeted compounds and estimate its efficiency

- Technologies for ground water treatment.

- Cost and risks estimation of treatment facilities. Lifetime, risks and cost estimation of technology

- Examples of modern ongoing facilities for ground water treatment and polluted sites remediation.

This book is of interest to scientists and engineers who deal with the problem of purification of groundwater for different purposes and the remediation of polluted sites. 